482

8.226.294. 


\section{Paterlendsche}

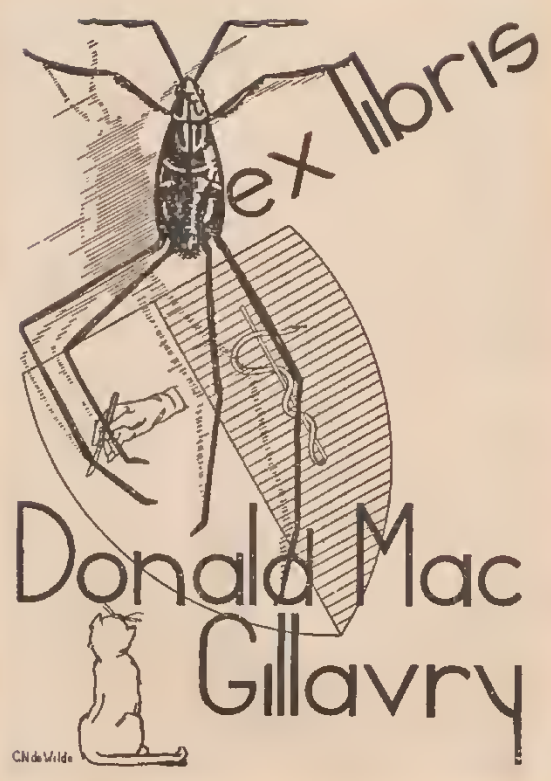



Leber

\title{
cinige Sulftenatert,
}

welche

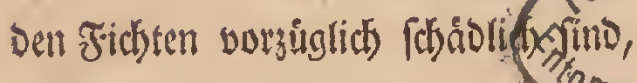

und $\mathfrak{i} \mathfrak{i b c t}$

\%ologische veret

\section{Die 23 urmtrodnis Der Sichtenmailder}

\author{
Des Shatres.
}

\section{Ton}

c. S. von Sierforpff,

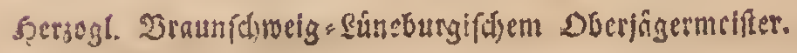

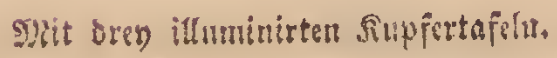

$$
\text { Selmpitest, }
$$

bey Earl Bottfried Flecteifen. I.794. 

iefe fleitre 2 (bbandlutig war nitht beftimmt, einzeln, fondern erft in ber Folge, in eituem

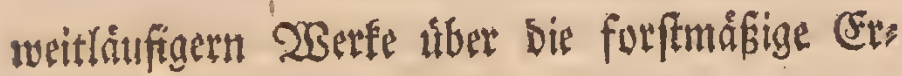

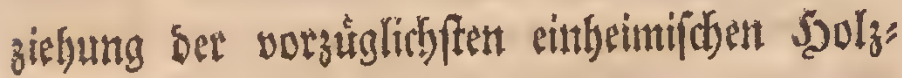

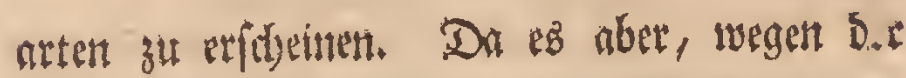

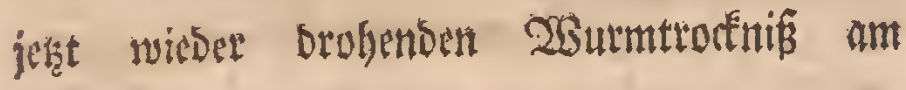
Sarge, manthent meiner sejer angentbmer feyn mothte, fie fiton jest zat whalten; fo babe iif) fie, famt ben bazu geljurigen Ritwfern,

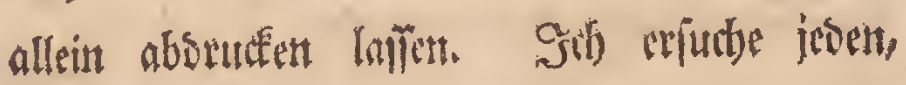
ber burd) netuete Somerfungen Dariu viellesit)t Berfdiebenes beridytigen, ober beffitigen 
4

fơnnte, mir foldge mitz̧utheilen, indem ith jede Belehrung Sartibut nit Danf annehmen und วu benutzen futhen wetbe. Fraunfthweig, ben 15 ten May, 1794.

\section{Der Werfaffer.}




\section{§. $x$}

O) (uf ben Fidten, Siotḩtannen (Pinus picea Linn.) finbet man, fo wie auf bem Nabelfiolze uberţaupt, jwar weit weniget 2trten von Snjeften, als auf bem

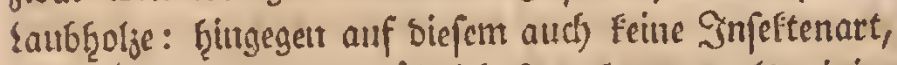
weld)e bemfelben fo gefäherlid) jenn Eann, als einige Zirten bavon bem פabelfidje finto. Denn, wenn

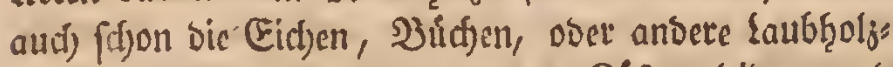

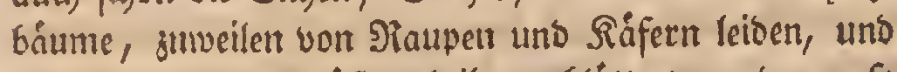
oft fogar bavon gróptenţ̨eils entblättert werben; fo trift bas sod) nur fiód)ften Fleine Gtrecten, uno ges noif̧nlicl) utur cingelne Báume. Es nirs baburch nur

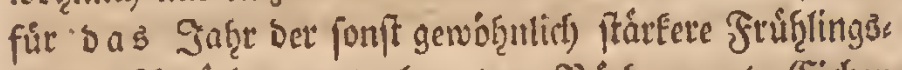

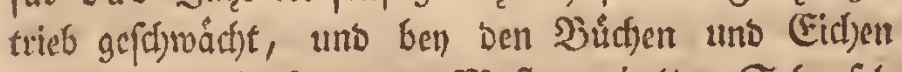
allenfalls bie Scoffnung ocr Maft vereitelt. Gchre fels ten abar tooten bie Infeften bes Saubrolzes ben fonft gejurioen \$aum felbft, unto ber burd) fie eniftanocne Sdhaben, fo gefährelich er aucly oft sul fonn foleint, ift

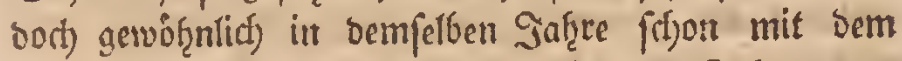
jwenten Triebe, ober in bem folgenden Jafqe aubs gę̧eitt.

MSeit gefáfrticher aber Eonnen cinige Infeften: arten bem Mabelf̧olje retben, befonbers wenn fie in grofer Metsge crfdeinen, unb bas llebel baburch gleithfom episemifoth madten. 


\section{3.'}

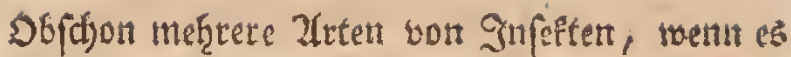

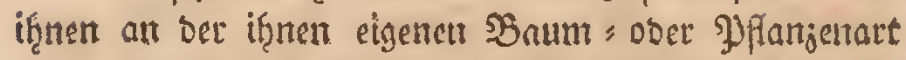

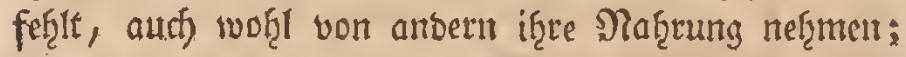
fo wits man bod metrige berfelben auf tenden Syolg: arten jugleids finton, wowwn bie greßze Berfujiebenţeit bes Gofts int Saubs unt Nabelf̧olje bie llepach ift: bie

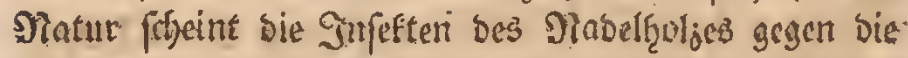

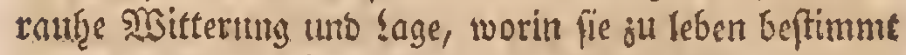

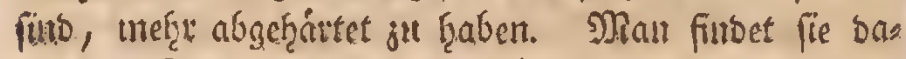
fer zutn Sheil anth) auf ben fältent Biefirgen; bahints

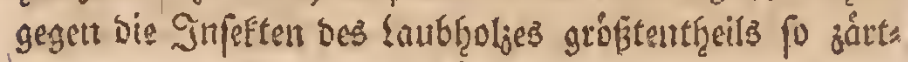

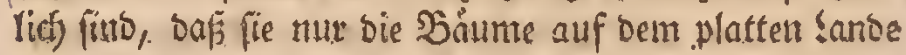

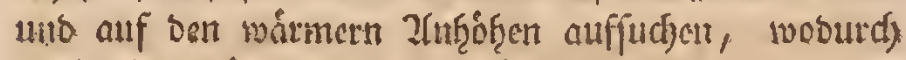

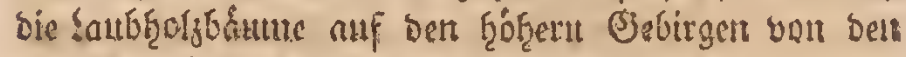

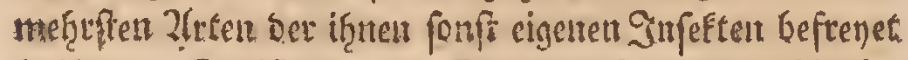
Gleiben. So if audh oft Ein falfet Mebel unb Nadjts

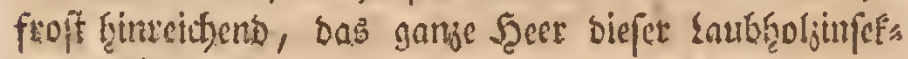

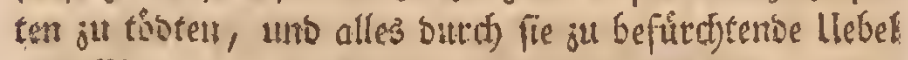
curf Eimmal ju entfernen. Die meţrffen 21nten you Nabelģoizinfeften fingegen fins weit unempfintlicher, unt fonnen bie ftrengfte Siltte aushalten. Fes ift nichts

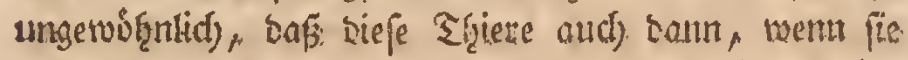

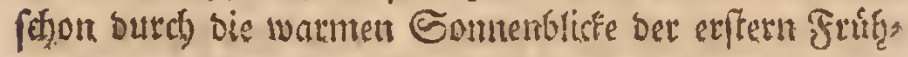

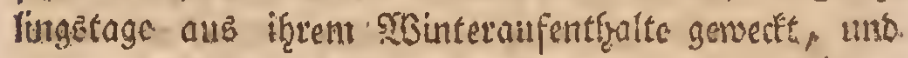

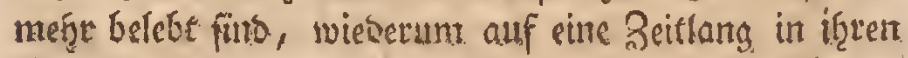

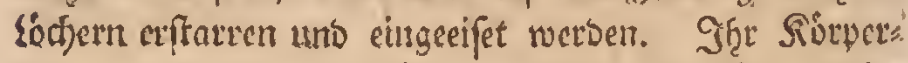

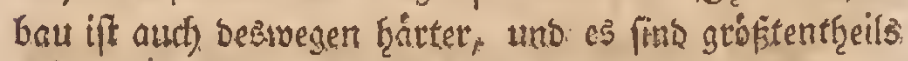

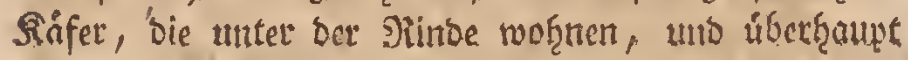

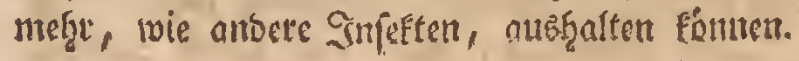




\section{S. 3 .}

Da eine ridjtige Senutuif biefer \$njeften, ih̨es

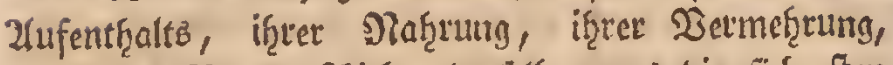

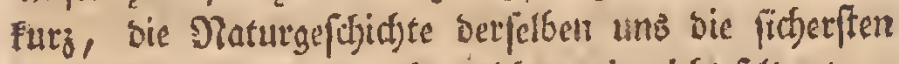
Mitfel anmeifen fant, mit weldjen wir nidjt felten bem burd) fie jal befurdjtellbet Hebel juborfommen, uno ben fonft grofern Gdjaben verminbern fonmen; fo

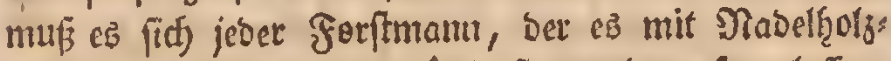

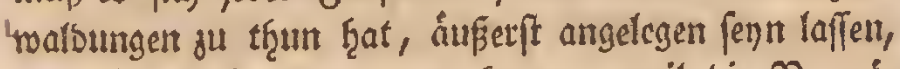
biefe bojen feinbe genau ju Eenuen, weil bic Derwus: ftungen, welche eitrige 2lrten berfelben anticteten, für bie Nabelf̨oljforftet unftreitig bic nadjtheiligften fints.

\section{4.}

3u bet Infeften, weldye fich in ben fiefigen ums in ben benadbarten beutiásen Forften burch bie gropen

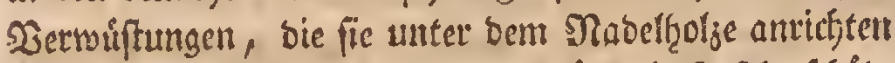

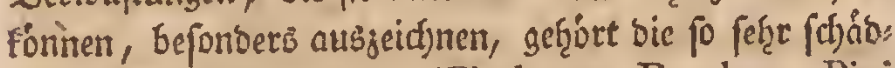
fiche fof̧rencaupe (Phalaena Bombyx Pini Linn.) uto bet: berudatigte BorEenfafer (Boftrichus Typographus Fabricii).

$$
\text { ख } 4
$$

Die

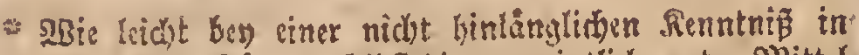
ocrgleid)on fállen, jelbit die vermeintlid) guten Mittel unb Dorfechrungen nadjtheilig werten einnen, bavon hat man in Englano vor cinigen Tahtran bey bem letz:

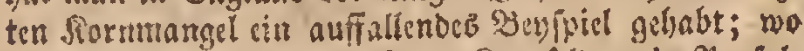
man sus Furat, ein auf ben Sivrnicloern in 引enipl=

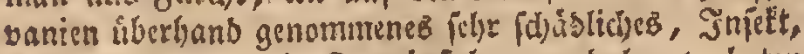

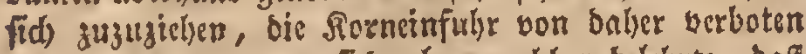
hatte, you bent man fid) aber nadher belchrte, bafis es nur in ben grinen 2lefirent pirne Eyer ablegte, uns ba man jwar nidot baz Strol, abci bód) baş aub:

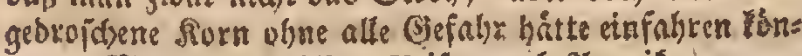

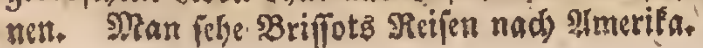


Die erffere, melche auth unter sem bentfoien

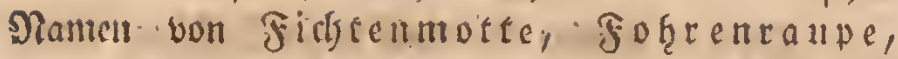
Fid tenfpinner: befant ift, if nut fur bie Fof̨s

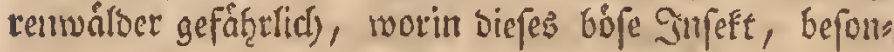

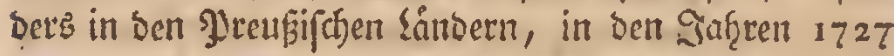
unt 1728 , unt and 1791 uns 1793 fo grefje Sietfees rungen angerichtet ḩat, Daf Davon feit ben- lefeten Jaf̧s.

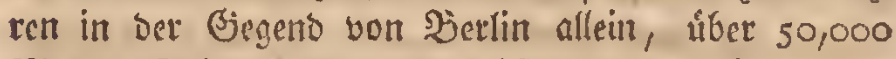
Morgen fohrenmoloung verwuffet uns entblofigt fins.

Man finbet bicfen wưtţenben feino in ben bes

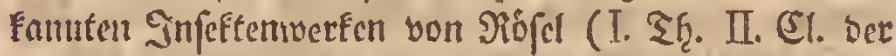

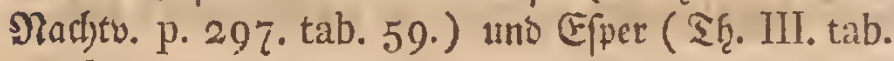
12. f. I -6. und t. I3. f. I.) fowol im Riaupen: als 9lad)tvogeliguftanbe beutlich uno genau abgcbilbet, aud)

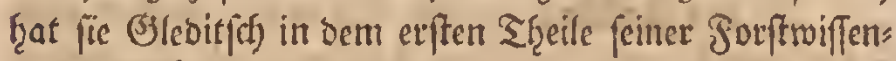
fajaft Gintanglich Gefdrieben.

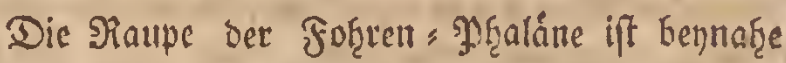
I Soll lang; ifire Surtmbfarbe ift an einigen afdygtall,

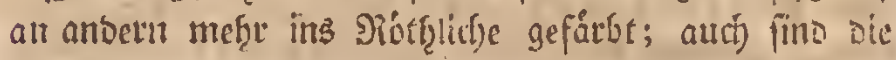
Slecten, womit fie gejeichnet ju fent pticgen, an cinis

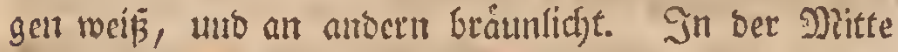

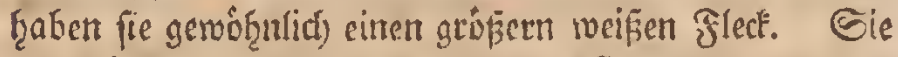

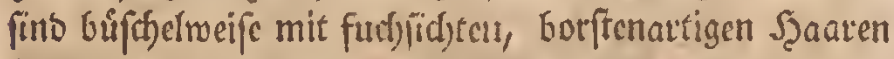
beferst, weld)e fie Ettro vor der Derwoublung jur gluppe abiverfen, unb jum Tzeil in if̨r Bef̧áure mit verwes ben. Diefe fraben eine längliche bieftalt, fino pergas mentartig jufanmengefpomen, und unter ben feinert. Slweigen ber Fohren glcirffant angeḩångt. Der obere

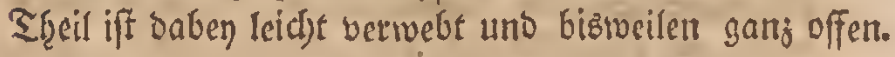

Die Duppe ift linglicft, zu benben: Seiten ges rumbet, unb von fomarj6rauner Sarbe. Gdjon nach 


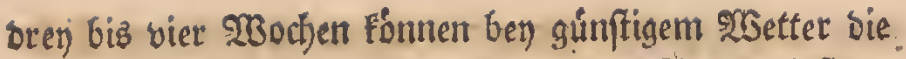
Falter ausfriect)en. Man trifft biefe Raupe faft zu allen Jaḩrezjeiten an, nur bie falteit eigentlidjen 20 sins termonate ausgentommen; wáf̧rento weldjer matr fie aud) zroift)en ben Minten ber Foḩren eingeftodjen ans trifft.

Diefe Roupe finbet man am Gáafigftert auf ben áltern volliwitdfigen Şof̨ren, wovon fie von ben obern

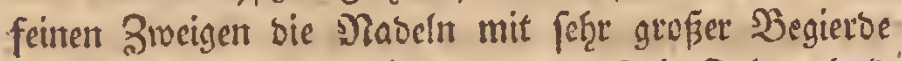
unto in grofier Menge abfrif̧t, worauf bie Fohren bals' FranE merben, uns faft burchgefients abfterben.

Die Gdyntetterlinge biefer Paupe fimo von farbe cbenfalls verfdyiesen; einige fint hefler, antere bunfler graubrifunlid), aud) fint bie (Einfaffunget und Sianber Der Flugel theils breiter, tficils fojmaler. 23efonbers aber jeidjnet fid) bicfer Sdjmettetling butct) cinen weifs fen brenecfigen slutult auf jebem ber obetn :Flugel aus, woourd) man if̧n von anbert bergleidfen Ifrten beutlid) unterfofeiden Fant.

\section{§. 5.}

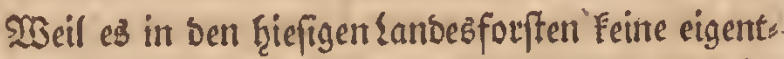
lidjen Foferentwalsungen giebt, uns mur barin fiin untb wieber Fleine Derter mit biefer Scoljart befintlid) fint; fo braud)t ber ficefige Forftmann fid) um bieje bofe Taupe wenig ju befummern; bie aud fier nur vors ơ ưglid) in ber 2(bfidjt genauer befourieben ift, um fie unit antern Injeften ridjt zu verwed)felu, uno bamit siejenigen meiner (ejer, rveld)e fie nicht genau Eennen,

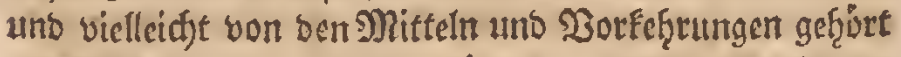
ḩaben, bie man in anbern కänbern gegen biefeb Jnfeft angetoendet f̧at, nidjt auf Den Sicbanfen fummen mos 
gen, baf bieje audj gegen ben untent bejwriebenten Fidjs tenÉfer antroenbbat fenth Émtent.

\section{6.}

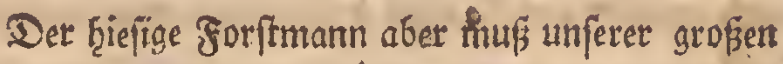
Fidjten = ober Sotfitannentwálbet wegen cine genauere

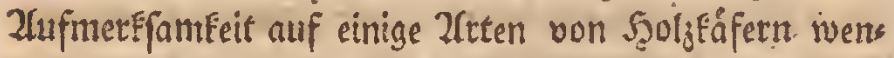
ben, bon weldyen biejentgen f̧ier befdritieben werben fols Ien, welaje entweber megen ber grojen ß̧ef̧äbigun gen, bie fie antidten foumen, fid) vorjughlich ausjoeifys nen, ober beswegent einige Iufmerffamfeit verbienten, um bavon bic bofeften feeltibe genauer ju unteifdjeiben unb fentren ju Yernen. $\$$ d) werde mid) baben befons

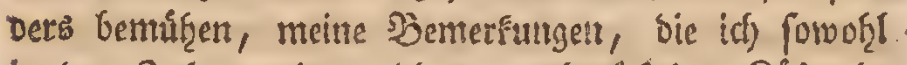
in ben Jahrent, in tveldyen ber berúdjtigte Sáfer in

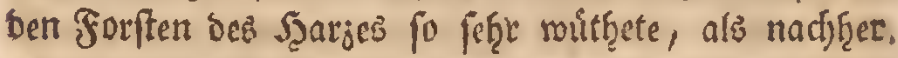
auf Drt unt Etelle mefrmals ju madjen Selegentzeit

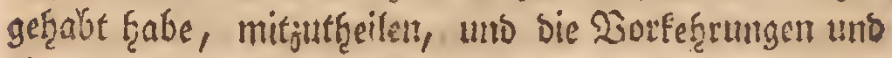
Mittel gegen biefes großse llebel anzufüţret, yon beten gutem Erfolge iơ surd) wieserḩolte Erfahtungen ůbet: zeugt bin. Dabey verbient bes Scertn Drofeffor Simes

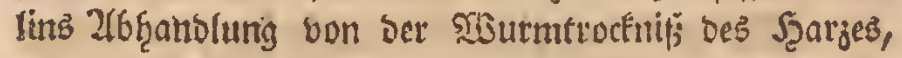

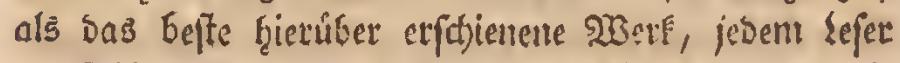
empfob̧ไen zu veerben, weldyer von biefer: Sinfeften meţs

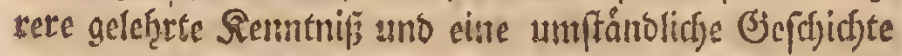
Det van if̧m angeridjteten éltern uno neneen Betwú.

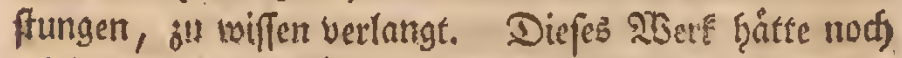
wichtiger soerbent fonnen, went ber Serr \erfaffer

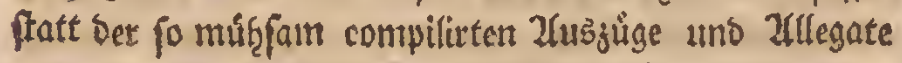
aus sen, if̨m Daju mitgeţ̨eilten, Fouftamtsaften ano antern Gdjriften, es mit mef̧reten eigenent Şemers Fungen bereidjert Şâtte. Die vibrigen in ben Beiten ber 


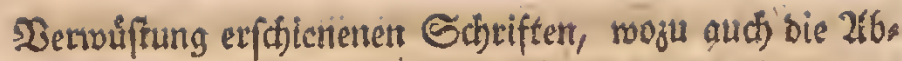

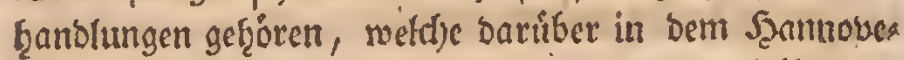

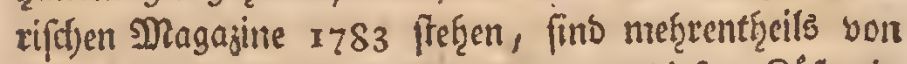
geringerer Erţebfidfect; und șas von biefem Ráfer in Sirunif̧ens of́onomijâter Encytlopábic unter bem $\mathfrak{Z}$, tifel Silefer angefúţrt wirs, if gróstentheils aub

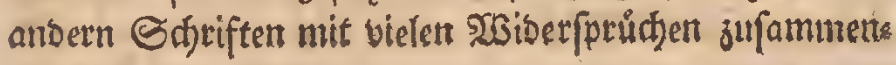
getragen.

\section{7.}

Der bojefte unter allen Sáferm, welkbe man auf Qen hiefigen finften ober Rotf̧tannen finbet, if Der 9. 4. genaunte $\mathfrak{B}$ or én graphus Fabr.), ber in ben Giefigen Jegenden unter Dem Slamen bez 25urms, ober bes Tanuentourms befannt iff.

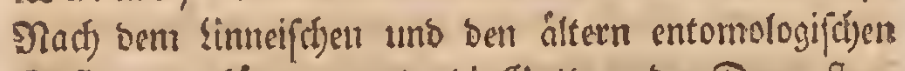
Snftenen gef̧iorte er unter bic Battung ber. Dermeften,

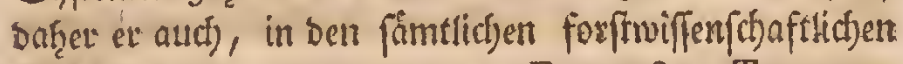
Sibriften, unter bem Dramen Dermeftes Typographus aufgefuthet ift. Siachoem Gber bie neudrn En tomologen, uno befontbers Fabrigius, unter ber Sinnei f(t)en ङ゙attung Dermeftes verffriebene Siffer vercinigt fanben, bie in Zfnjertung ber sebentart, ber Frefwerts zéuge, uno des ganjen SBaues fef̧e bon einander abwi: ben, fo tremten fie verfojicbene bou benfelten, unt bereinigten fie in neuen Gattungen, Apate uno Boftrichus. ลूu ber lef̧tern sourbe bann aud unter meţa reren ber D. Typographus gejogen. Den Betnamen

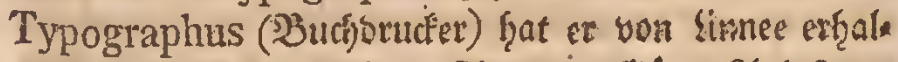
fen, roju vermutf̨lid) bie figut ser (şånge 2Inlaj gea geben f̧at, welche biefer Sơfer, ober eigentlich feins. 


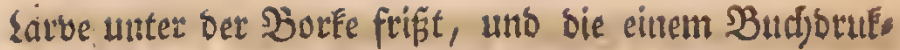
ferfaşe nicht ganj unåf̧ulich ift.

\section{8.}

Diefer Sâfer ift in bet x ften uno zten Jigur in

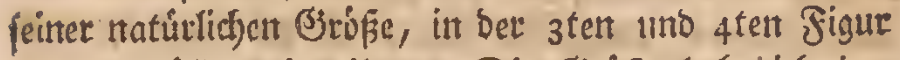
aber vergrósert abgebilbet. Die Brißje ḩabe id) im mer, fo wie es ben Infeften überb̧aupt Det Fall jt fenn pfiegt, bey allen Siffern biefer 2lrt faft gleid) ges, funtoen, einen aus Sactjent herframmenten Si̊fer aus; gentommen, wo ber Borfentaffer in Den Saf̧ren 1780 bis 1784 ebenfalls in groperer ) Menge gewưtţet bat. Dief̧er war um ein Merfliches gróp̈er, übrigents aber

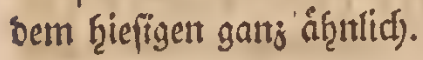

Der hiefige Scarjer Typographus ift beynaḩe

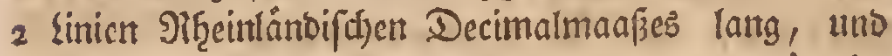
1 Sinie biff. Gcin Siorper ift bennaţe sualjenformig.

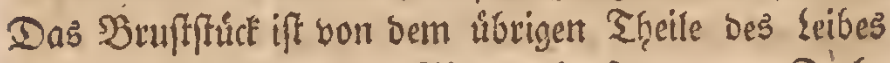
mit einer plattuertieften Sinne abgefeste, bon fárbe etrab bunfler, als biefer, mit feinen, fur jen, jiem: fid) freifen Saaren beferet, uno vorn am Sopfe abges runbet. Die Flúgelbecken finto an bem, ber, Duppe fo eben entfd)lüpten Sáfer Lzellbraun, werbent aber immer bunfler, unt am Ende fatwarjbraus. Sie fino mit cinigen ఇeihen verticfter Punfte geftreift, uno mit wenigen, aber åf̧ntid)en Şaaren, wie bas Brufts

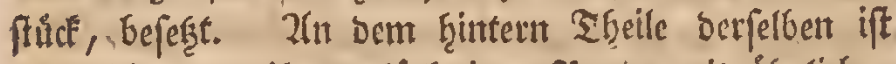

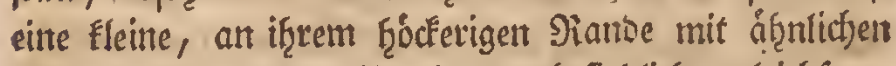
Scaaren eingefafte, כertiefung befindlid), glcidjfam, als went aus ber waljetrformiget figur bes ßáfers eitr

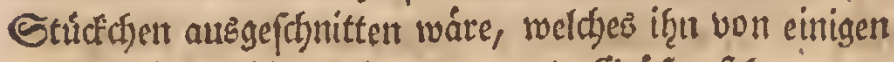
anbert Zrten feiner Sattung uno Brófe Fef̧r unters 


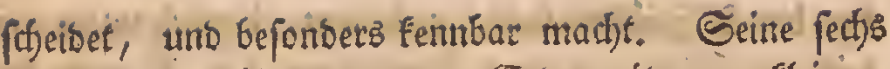
Fúfe fint an ifrem borbern Enve mit jwey Fleinen,

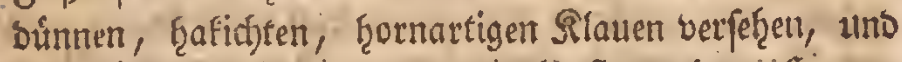
if̧re frárfern Serioen mit cinigen borftenartigen "Searen bejeģt. Der seib ift unten, wie an allen ßåfern, mit Siingen berfę̧et. Der aแb einer, mit Şaaren einges faften, Deffnung bes Brufffrúç Kervortagende Sopf ift mit feţr foften, hornartigen, fpisen uno fdjarfen frefiwerffeugen verję̧ent, bie in ber fig. 5 . vergrófiert abgebilbet fino. Die feinen, nicf)t pefre langen, cht

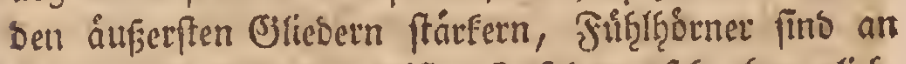
if̨m, fo wie ben ben ureiften Sinfeften, feţr beweglich. Die unter bell Slugetbecfen brenfad eingefalteten; fei nen, fiảutigen Slügel finto, svenn ber Sáfer fie jum Flliegen attechnanberlegt, mę̧r als juenmal fo lang, als, ber Sáfer felbft.

Uleberḩaupt ḩat biefer Siffer, fo Elein er auth ift, ganj bas rautre, fratte, unempfindliche Injefren, wie es feinem 3ufentf̧alte in ben raufen, finftern, boen Tannenmálbern angeneffen iff, wto oft vermetreen nod

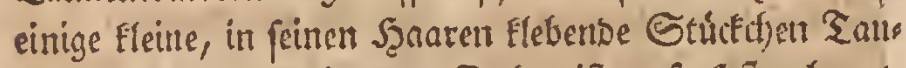
nentrars biefe Siaurfigfeit. Dabey ift er fo feft gebauet, wie wenige anbere Sáfer feiner Brobje; er roiro and nid)t fo reidft, wie anbere, befthobigt, uno ift barit anizugreifen.

(Ev: wohnt in. Den Fidften jwifgen bem Sgolje unb bee \$otre, in weldjer leştern er von ben martith ten Sinden'agen lebt, unb tarit bie Saníle nad) eitur

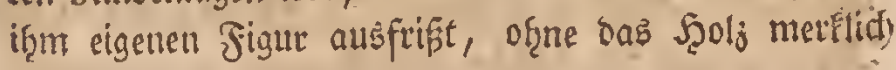
วu berứfৃen.

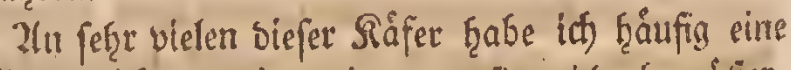
2(rt פMilben (Acarus), wie man jie, jebod) grojerer, ben 


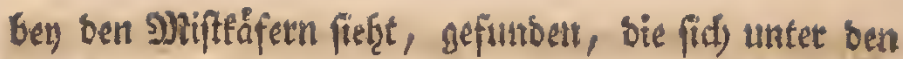
teib uns in bie hintere \$ertiefung bet SFligeloecten fefent, uno rold be fo grofi find, baf man fie mit blofs fen Zlugen beutlich ferten fanm. SBey einigen Ráfern

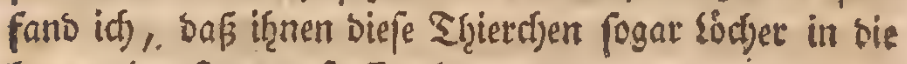
bornartige \̧aut gefieffen ḩatten.

\section{9.}

Menn bet Siffer feine 2 ollfommentieit etreidje

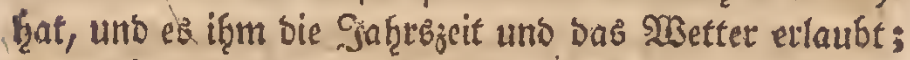
fo veliafjt er feinen bisf̧erigen Ifufentḩalt, wotin es iţm bann aud an guter friffjer Maf̧rant gebricht. Er

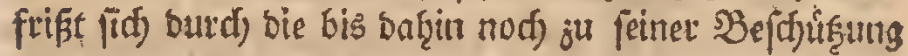
errialtenen obetn trodfneu Finbenlagen hinourd), frieche oft, wenn if̧m bas æetter nicfit gan gefállt, eine

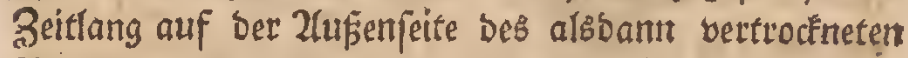
3aums, unb fliegt aus, um beffere פiah̨ung aufous fuchen, fich ju begatten, uno fein Befd)(ed)t fortgus pfianzen.

Diefes gefditht von ben Säfertit, weldje bèn Sinter úber ausgewadjen fitio, in ben warmen Fituf

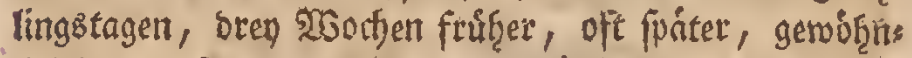

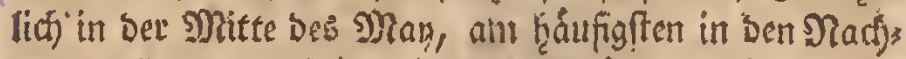

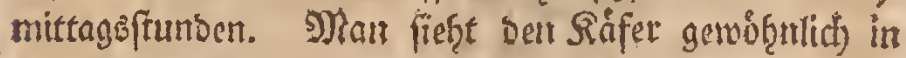
ben lef̧ten Stunden vor Sonnemuntetgang, einjeln, wenn biefes Jufett in bem Jaf̧re in gewibhnlid)er 2(n.

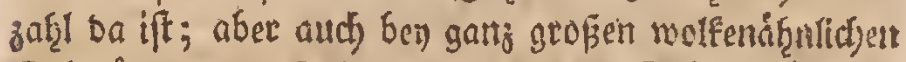
Ectrvårmen, auf bie anjufrefferben Etomme fallen, rent biefer Saffer in $_{0} 0$ ungefieurer Menge, wie in bent

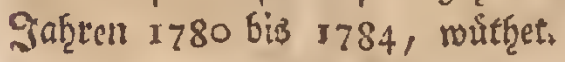

Bermoge feines Rorpertaues fann er nidje feh̨t weit fliegen, woben es fehts Darauf anfommt, 06 cr 


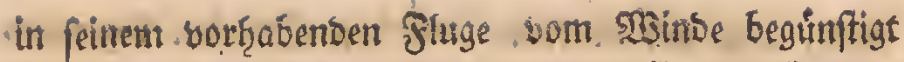

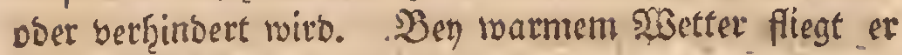
fioferer, uno oft iber bie hiochften Tannen weg. So ḩabe id) bisweilen bey. foldjem Woetter Edywárme von

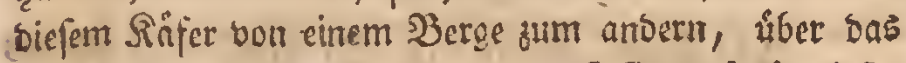
şal weg, fliegen feţen, of̧ne bas fie auf bie tiefer

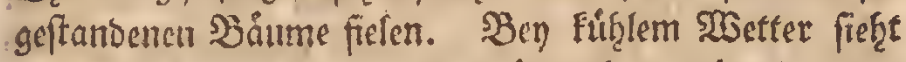

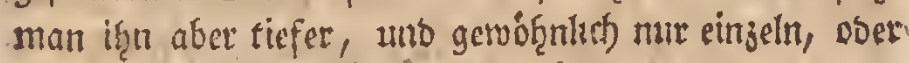
in fef̧r fleinen Echwärmen fliegen.

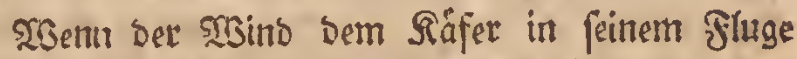
Filft; fo mag er mol ḩalbe, ja ganje Stunten, weit fortfommen fonntr, wie matt foldjes mehirmals an Drten bemerft frat, bie fo reit bon ben bom Safer ans geftodjenen Forftorten entfernt waten.

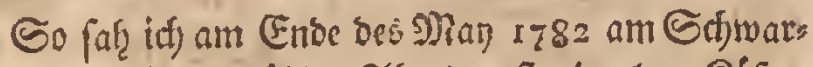
zenberge ben einem fủhten 2tbent erft cingelne Ráfer, unt bernach ganje Gdjwärme nieberfallen, bá meine Sleibung bavon voll faj, uno bie Ráfer in ungeţeurer Nenge auf bem Soben jwifhen ben Tannennabeln hers umfrochen. Diefe Siafer ţattelt alfo an Dem Sage if̨r Ziel nicht erreint, uno vermutţlich fiaben fie am fols

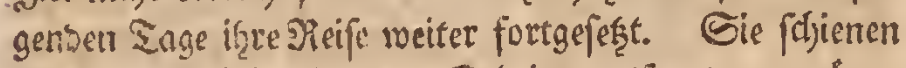
einen, auf einige humbert Ed)ritte entfernten, grúnen alten Sannenvet zu bevrofen, oer audy it bem folgen ben Serbfte troden wurde.

roie viele von biefen Siffern ben if̨rem Şerauss flegen ober Ecifmintmen umfommer mügen, fann man Daf̧er uttheilen, ba man fie in ben Jạtren aud) an

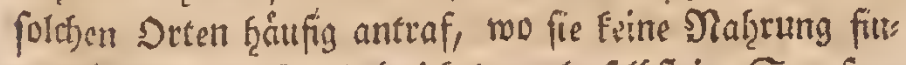
oful ronuten. So babe id bamals feloft in Seefen biefe Säfer auf ben Etrafien uto Dádjern f̧erumfries chen, 
den, utb fid) in bem, auf ben Strafen liegenben, Sannẹnf̧olge verfammien fę̧en.

\section{S. IO.}

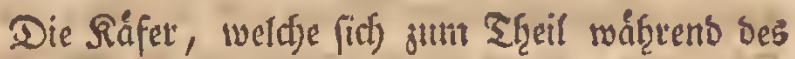

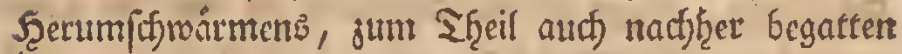

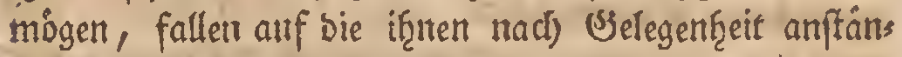
bigen grúnen Ficfsen obet Rotţtannen, auf welchen fie fid) in furser Beit jwifden ben Sofuppen ber feften Sorke empig ein Эylóf(hen fudjen, uno in Gefdjwinbigs Feit einfreffen. Gab fabe mef̧rmals̀ bergleidjen Stjmárs - me anfallen feicher, wildse nach einer halben Stumbe gröpitentheils unter ber Borke ftecten; uno babey fo laut fiaßsen, baf man es beutlid) fióten, unt aud) att

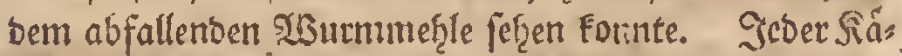

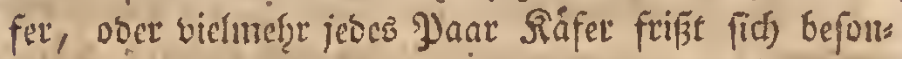

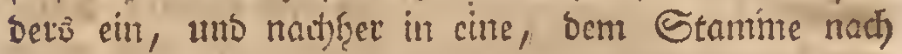
auf = ober unterwåto laufenbe mef̨renţ̧eils gerabe Siins ne, wie man es̃ in ber roten Fignt, bie nad) einem, yor venig Tagen angefreffen getwefenen Stuff §orfe genau abgejeidfutet ift, feben fann. In biefer Rimne,

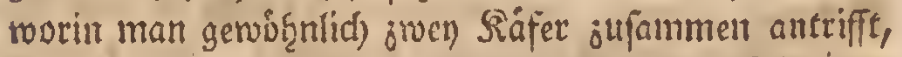
legt bas Meibchen auf benden Eeiten in ocr Mitte ber grunen Borfe ifre Ener, jebes berfelter in eir Flines

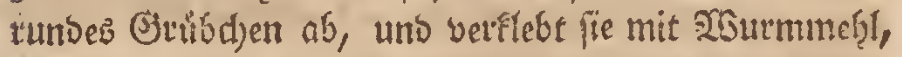
of̨ne baß ber Scauptgang baburd) gefperte wirt. Eols

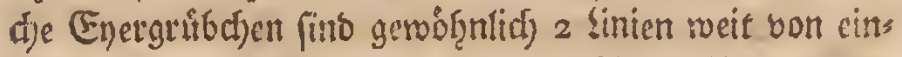
anber entfernt, uno mant finbet wob̨ 60 bis 80 bets gleidyen in einem Shatprgange, bic alfo von einem cins" zigen Paare mit Enern belegt wer'sen. Dod Eommiert bie Ener, wie matr eื auz bell [poiter abgenommenter Rinbenftúffen beutlich fef̧en fann, nidjt alle auz, unb erreis 


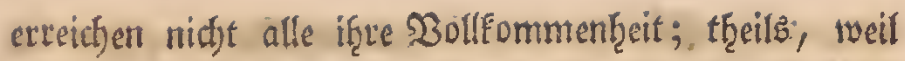
oft Ein Yyan Rafer fict bem anbert fo nafe cinfrift,

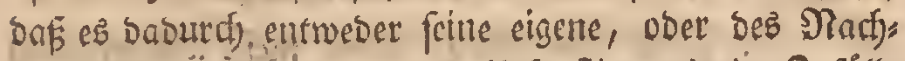
bars Brut jerifbrt, ober meil fonftige svibrige. Sufálle Dem beffern Beorifen Der Strut nad)tbeilig fitio. Die alten Siffer freffen, nad)bem fie ifr Fortpflanjungsges

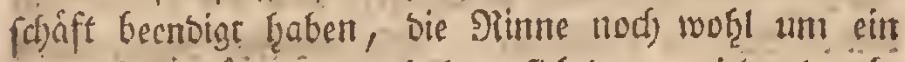

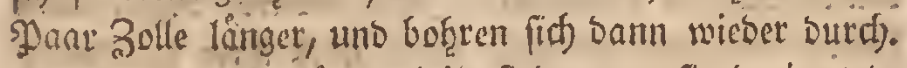
Eefre oft, uno givistentheils findet man fie barin todt unb vertrocfnet, oft aber audl) bic alten Sinfer lebens mit ben jungen Siffern zufammen. Git Der auf bet

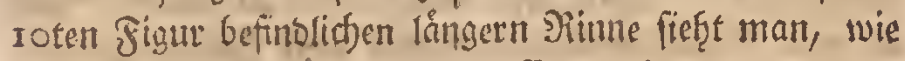

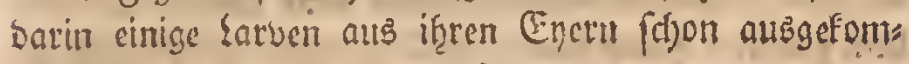
men fint, unt ju freflen anfartgent.

Xllem Dermuthen nach wito biefer B. Typographus rook̨, wie bie ufbrigen Juffeften, init ber Begattung

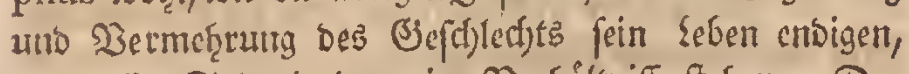
und deffen Biel mit jener im \erf̧áltniffe ftefen. Der

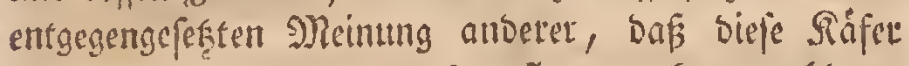
jucynal ficl begatten uno fortpflanjen, fann wohl mur burch bie Znalogic rviberfprod)en werben, ba entfdees

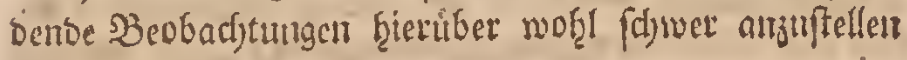
[enu modjten.

\section{II.}

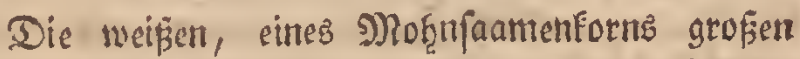

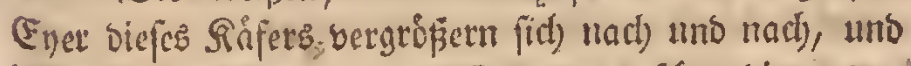
in einer Seit vot ${ }_{4}$ Sagen finot man fdon bie atteges. fommenen Larben als fleine Maben, bie fich von bem

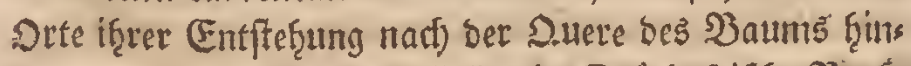
freften. Die 6fte Sigut fitlit ein Stük frijhe Borke 
bor, worin fich bie ausgefommerten Maben figon bis

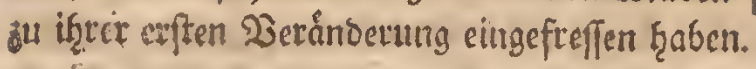

Die junge Brut macjt samit meift wellenfiornig neber cinantser herlanfentoe, unb feltent" fich sinanoer tref: fenoe ober surchfdneidentse flad)e Sange, gwiftyen Dem Solge, bas fie Faum betsfrren, unb Der Rinbe, in

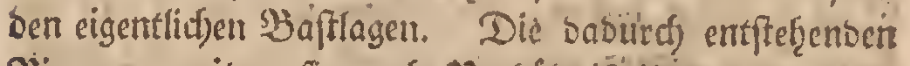

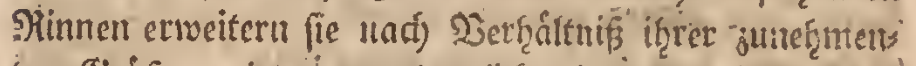
ben Grofse, wie'man es bentlidjer in bet 6. Fig. Fef̧er! viro; moben fid biefe larven forgfältig eitrander

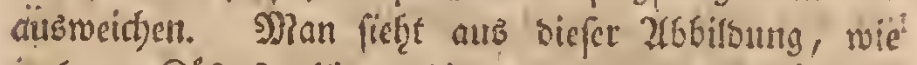

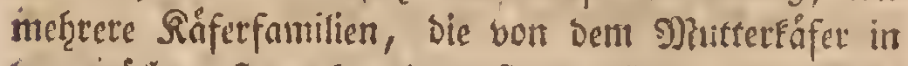

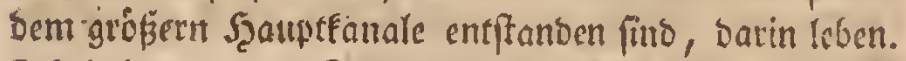

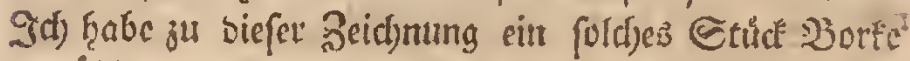

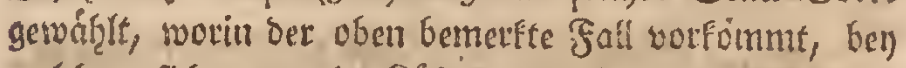
weld)em fich jwen alte saface ju nab̧e gefommen finto, unb. aus \$) langel ber nothigen Ną̧rumg bie benderfeitige Brut fic einander: jerftort hat.

\section{\$. 12.}

Dach vierzeţn Sagen bis bren sisodjen fintot mau bie satben, weldye in ber fig. 7. bergripert zu fes fien fint, fchen in sem jocnten Buffanbe if̧res tebens, mit abgẹtreifter erftern Scaut in shupwen lieggen, wets

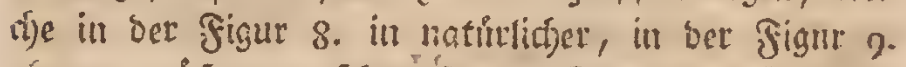

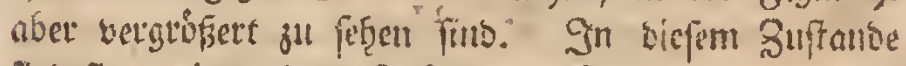

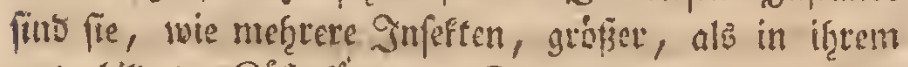

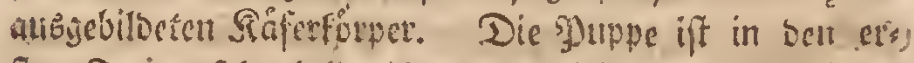
fren. Tagen feţr helltweif uns weid), unb fie forjeint

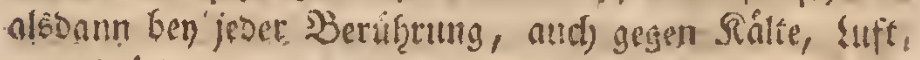
alto Diaffe ferst empfintlic) ju ferti, wentil man sic:

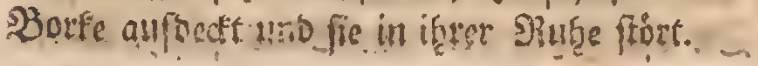


SBen Sem Serpuppen, ober bem Hebergange von bet \{arve jur Yuppe, bey roeldjem alle Jinfeften ju leis

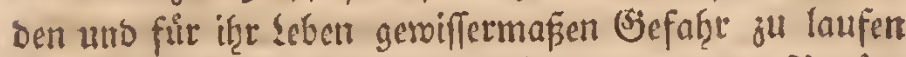

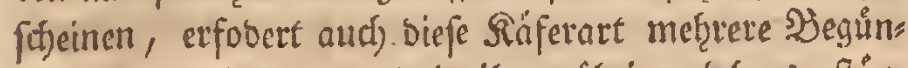

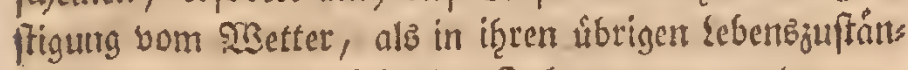

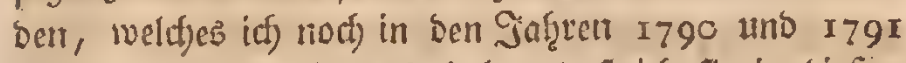
mehremals baraus bemerkt f̧abe, baf idf) fie in biefem

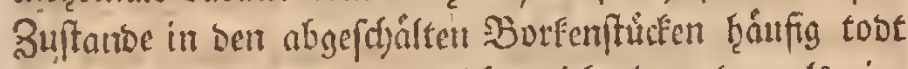
und vertrocktret farb, weldjes id) bem bamals im

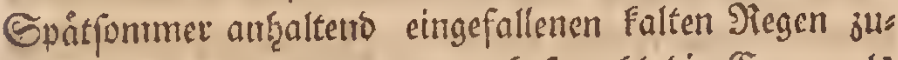
fatreibe, bey welchem bent bod) furoofl bie Eyer, als

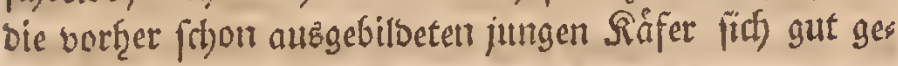
haalten ḩatten.

\section{\$. I3.}

Weit unenwfinticter ift siefe Yuppe, wenn fie fich if̧rer Entıvictelung jum Siafer nábect, fo roie ber junge Rififer jelbft, weldber bie ftrengfte Rålte ausftes fzen fantr.

Die Sluigelhedfen ber lefetern fint erft gand hell braun, unb färbetr fict), wadibem fie ailter werbelt, meşe ins dutufelbraune, biz fie benm 2lusfiegen, wie

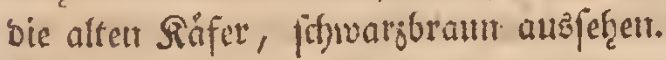

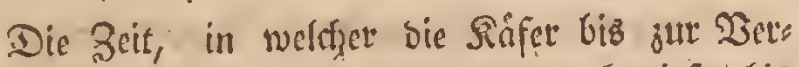
soattolung it ber Jlupe liegen, unt nad) biefer bis

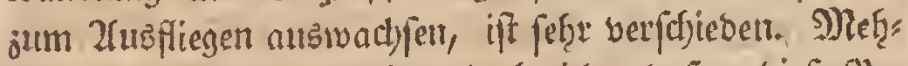
reren Butmerfungen nach, glante id), bof er biefe syes riover in Sommer bey gutem wetter wohl in fieben biz acht MSodjen abmadjen faint. Sim sointer aber,

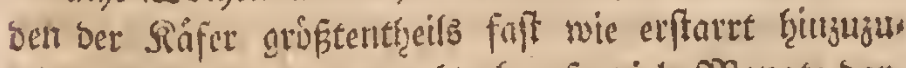

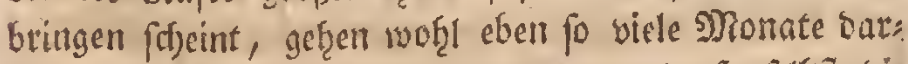
auf hin, inbem bie לarven, Jjuppen utw oft felbjt sie 
fdjon ganj aus̆gewathfenen jungen Ráfer, weldje maı in Eeptember in Den Borfen Der angeftodjenen B̉ôs me finbet, boch) erft in ben folgenven Ipril ober Man aușficgen formen. Man finvet bnf̧er aud bie Borfe, in welcher bie Riffer Den Wointer iber gelebt f̧aben, secit frótzer aușgefreffen.

Scieranb folgt Die ßermutf̧ung, baß̈ biefer Siăfer

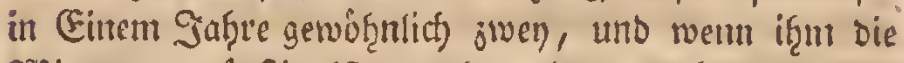

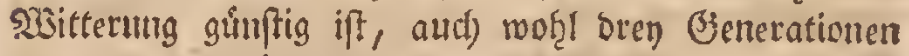

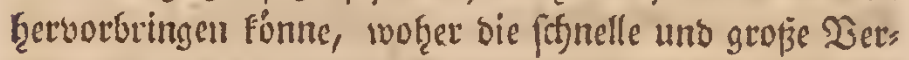
mef̧rung beffuben begreiflid wirb. Denn wenn man yon eitren einjigen Ware fur bie erfte Oeneration nut 25 Iaare, Inno fuir bie jonente anf jebes Want so Strict anmimmt, fo betrágt bas fdjon an 1300 , nto bey) bren Benerationcu liber 30,000 Rífer. Weldje ungef̧eure Dermef̧rung iff alfo bon cinem eingigen

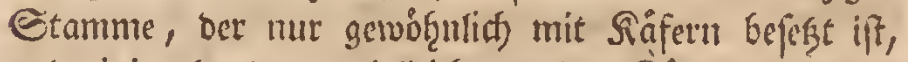

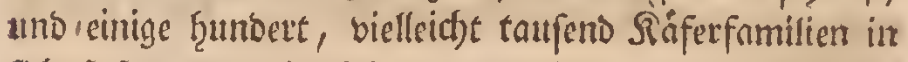
fiit) fafit, unb wie biel gar von einem ganjen angefto: ct)encu Forftorte jul befürd)ten, befonders, wenn baz llebel einige Jab̧re nadjeinanoer bauert!

\section{§. $\mathrm{r}_{4}$.}

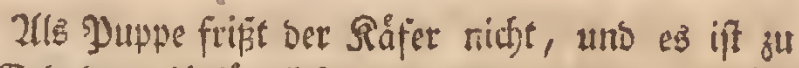
feitret Erf̧altung binlänglid, wenn er als fold)e ungeftort in feiner 230 hृmung liegen bleibt. 2Ils Soffer aber frifit et nach uns nach alles gröjtentf̧eils weg, was er jwi:

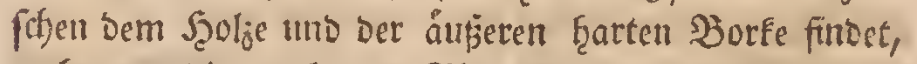
- wobely er bie trudtenere Rinbe an ben ausgefiefienetr Etellen ftegen läit, uns bie frifonere auffud)t. Ev

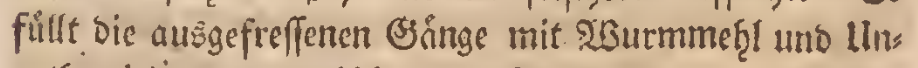
rath wieber an, jmifden welden man oft tobte vets flebte 
Flebte Sífer antrifft, bisz er fid entolich butch ein run tes Sod burd) bie nufere Worfe burd) boţrt, ausfiegt uno Das Beftyaft feiner Wóter forttreibt. Pie I 3 te Figur ftellt cin fold)es Etuck Dootfe bor, ants bem bie junge Brut gróftentheiles fajon ausgeflogen ift.

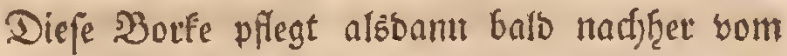
Solje son felbft abjufallen, unb man wirt ans Obis

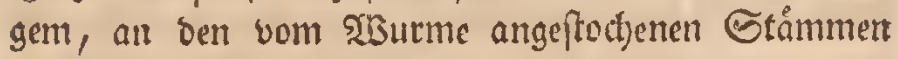
leid)t unteridjeiben Fonnen, ob foldhe nudy von Demfels ben bewohnt ober fdyon verlaffen fint, inbem in bem erftern Falle auf ber aufern Gite ber Gtomme ture roenige sócjer, nemlid) nur biejentigen fint, woourd) bie Mintterf́afer fid eingefreften ḩaben; im andern falle abar erfojeint bie Borfe gleidjam mit (odfern úbers fiet ju fentt. Diefe Bemertung ift für ben Sorfmann rvid)tig, wie unten umftändidjer gejeigt wirb.

\section{§. 15.}

Der Rnfer ift in diefem Suftanoe fef̧e b̧art und

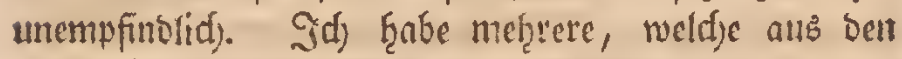

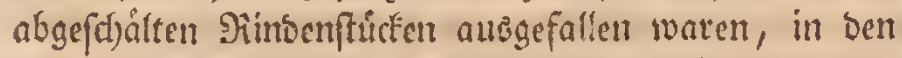
auf bem 23oben liegenden Diabeln lange 3cit nad) get gut etbalten sefunben, utb vermuthlid) wurben! fie

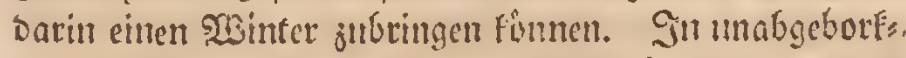
tem gefáltemt Selge, fowoht in Erammen, als it 2) Talterbónfen, Gleiben fie gants gefund uno woht, wenn fie andy mit biefem eine Zeithng im $225 a f f e r$ ober Eife

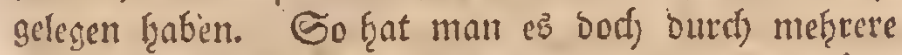

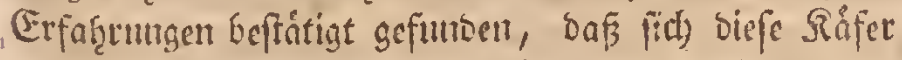
in bem gefofisten uno uber bren SToc)en lang eingefroren

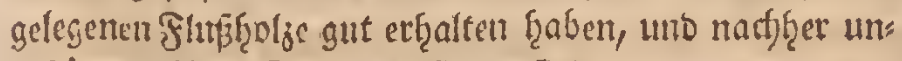
geftort ju if̧rer 3̧cit ausgeflogen fins. 
3ie leidt bie sisámte berglcidyen eingefroren ges wefene Ráfer wieber telebt, fann man an foldjen

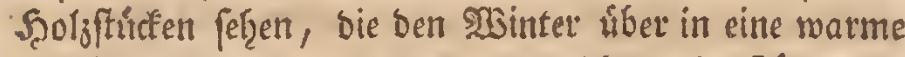
Stube gebrad)t werben, aus meldyen bie Sáfer fith balb burchfreffen, unt in ber Stube umberflegen,

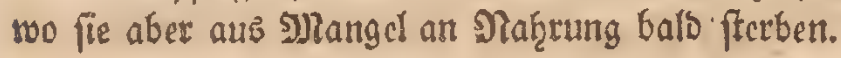

\section{16.}

Det eigentlidie von ber Natur biefen Rafer ant gerviefene Zufenţ̨alt unt feine Siaf̨rung ift bie fidfte

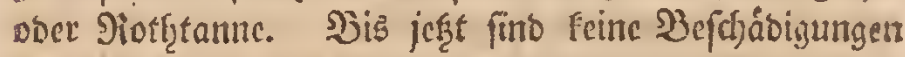
befaunt, bie et in anbern Nabelf̧olzarten angericl)tet

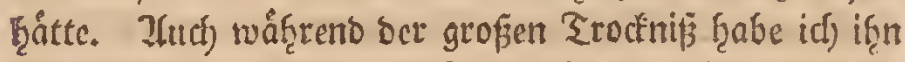

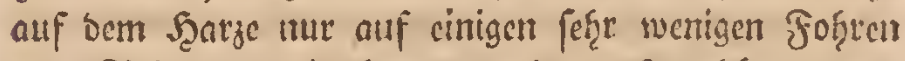
boer Riefern utio lerdien entbects, auf weidfe er bers fd)lagen ju felu, uno bie er nut aus Mlangel befferce Maf̧ung angeftod)en zu hiaben fdjien. Dicfe waren att(b), vermuth̨lid), weil bie barin abgelegte Brut nidjt

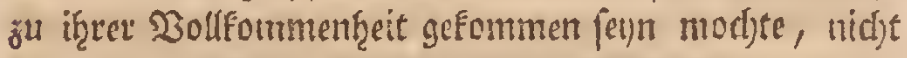
Davon betrodftet. So fano man jum Sicyfpiel bon

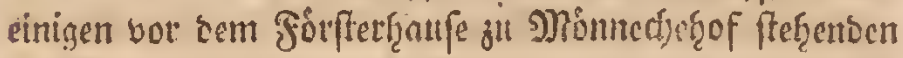
Setchen, bie alle bom soume angeftodycu waren, mux Eitce truden, bie úbrigent hatten diefen Bufall atıs geţalter.

\section{§. 17.}

Seiermit roite alfo ber beriddtigte Siffer, Bofrichus Typographus, bicfer gefáfrerlidyfte. Seino uns

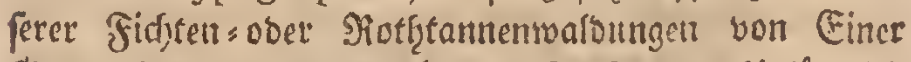
ઉ̉eneration zur andern fứ Den Forftriann Ģinlánglid)

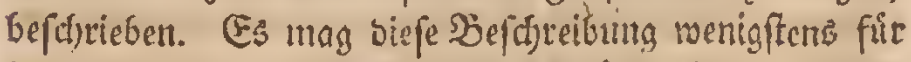
if̧n bitureichen, um fid) mit Sttverlaffigheit úberjengen 
full fornmen, of es bey eilnem sotformmenten falle ber twaţre boje Råfer fen, Doce nidjt. Şierben ḩat er vot: jüglich) auf bie Beichm!ng bet angefreffenen Borfe ju adhten, weld)es citres ber fidjetfent Unterfd)eisungảjeis d)en ift, anto zur vorláufigen SBeftimmung volleommen Finteidts, ba alle übrigen Tamnenborfentéfer, von bes nen in ber Folge noch einige befdrieben werben follen;

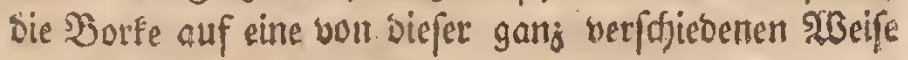
anfrefien.

\section{18.}

Die Båmme, velche von biefem Siafer angefref

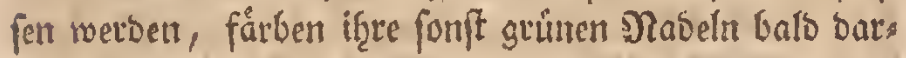
auf gelbfich, uno laffen einige Wodfen nadjher eitrets grofent Theil berfelben fallen. Daut erfeint alfo fo:

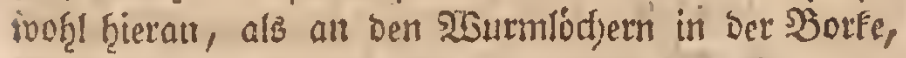
an ben aus biefen zumeilen ḩervorquillenten Şar jtrop: fat, unto an bem vor biefer !óf)ert utt in ben Scfup.

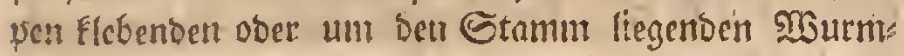
meşle, wonn eine Fid)te vom Siffer angegriffen ift. Dod) Faun man bie 23 urmlodjer folbft nidft immer in ben feferentoen angeffod)enter Bäumen fogleid) maf̧rnef̧=

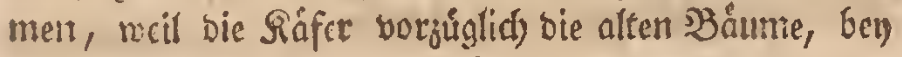

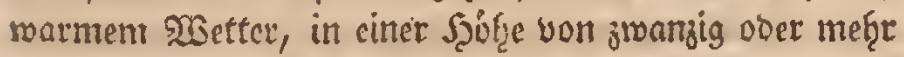
Fuß ant Ģáufigiten atzuffiegen pllegen. Inoefen fief̨t alld) bief:s, wie in altoern Fâllen bns baranf geubte Zluge leidjt, befonbers welln es surd) anbere Nicbenber merfungat Darauf aufmetffam gemadjt mirb.

\section{I9. .}

Die bon dieferm Sífer in ben fichtentwailbern

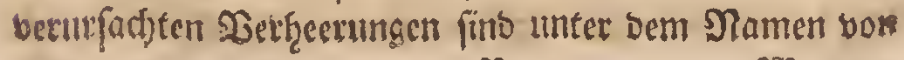
$23+$, 23 urm 


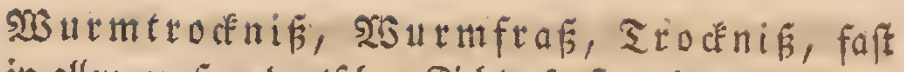
it allen grofen beutfhen fidjtenforften befannt, uno

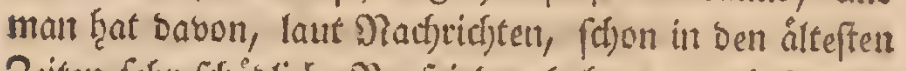

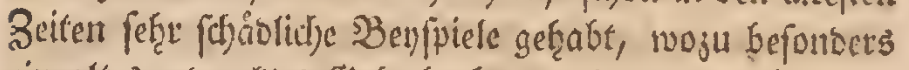
cin altes gebrudtes Đebetbuch, worim biejer Sâfer uns ter ben nach bamaliger Eitte abjubetensen llebeln nas

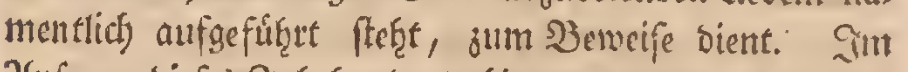

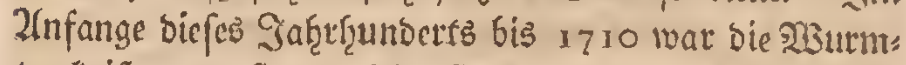

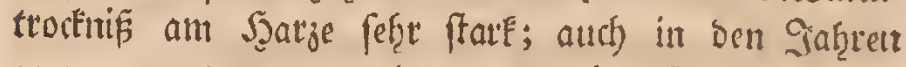
1745 " 1748 " I 750 und 1752 , jeigte fie fich hiur unt wieber, jebods nicht fo frate. Es ift baher imglants: lid), bafi man beym 2fnfange bet leşten guenen 20 urms trodénif in Den Sahten 176911110 1 1770 biefes llebel nidjt genauter fannte, unt bamals nicht gleidf im 2sin. fange, bevor es liberḩand naḩm, mit meţrerem Eifer bagegen arbeitcte, 1nto fogar bie in Den ältern Seiten einigemale mit gutem Exfolge Sagegen angewendeten

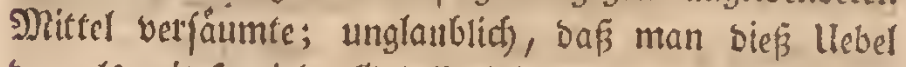
bamale mit fo vieler bielaffentreit anfah, bis bie ₹rocks

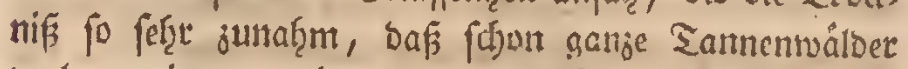
verloren gittgen, wie es I 77 I am Kiegen Margarethen Betge unt 1772 auf ber fflache nim Soudjberge it bent Monnecbefroferforfte ber fall war.

Dem ungeachtet glaubte man mit bent gemeffus fichen forftbetriebe bem llebel juvorfommen ou finner,

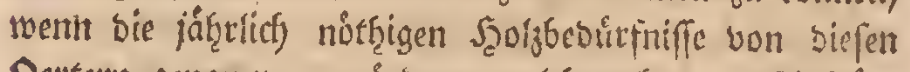
Dertern genoumen wúrben, meldye aber zur Zfufrêt: mung berfelben bey weitem nidft fimteidjten.

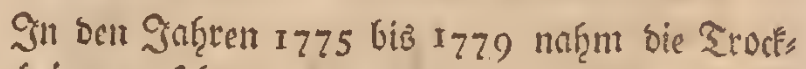

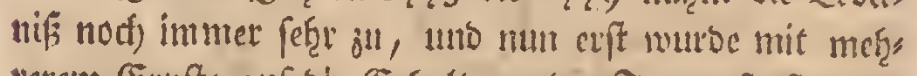
reten Entte auf ble Erf̧altung ber Saunenforften ges bact)t, vieles batuber gefdrteben uno úberlegt, eigents 
fiif) aber wenig bagegen vergenommen, unb nidfts atts

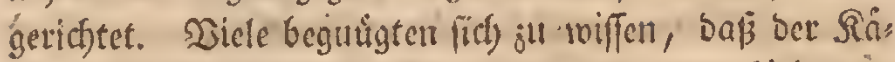
fer Dermeftes Typographus hich. Thtore bielten è fưr cinc befonbere Gtrafe bes Soimmela, bie man mit d)riftlicher' (j)elaffenţcit für feine Sủnben crtragen mifitc.

Der Sâfer war Damalz in ben Sarzgegenten ber gemóhrnliche ङegenftanto Der Conferbationen, worin

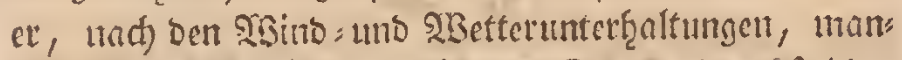

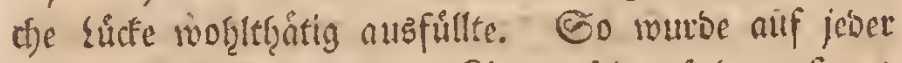
23ergrechmun, auf jeber Simbtaufe auf bem Sanje

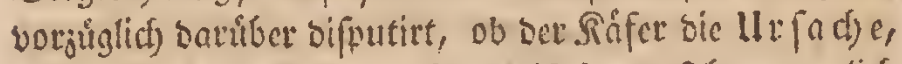
ober nur bie folge ber Srodtnif (er). $26 \mathrm{cr}$ uemlid auch gefunbe Stamme, ober mu foldye augriffé, mels d)e surd) ftarfe Sointofurme; Scife, ober butch bet: gleidjen Sufälle Erante wịren, und of̧nebem tructen ges

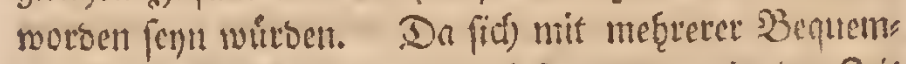

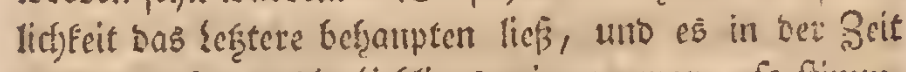
auf bem scarje bie bieblingsincinumg war, fo frimms

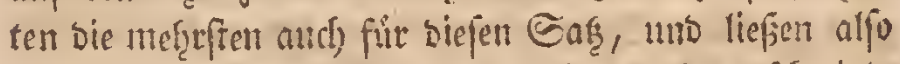

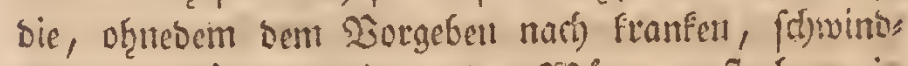

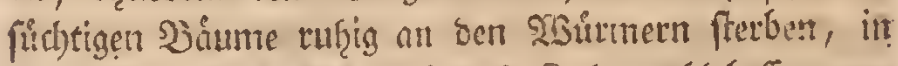

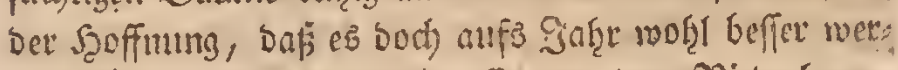
ben módyte! Es wutbe inseffen all bem Nics:uthauten ber troctuen Derter fos fratf gearbeitet. Es geffiah

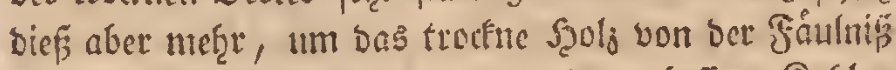
unto bem Serberben ju retten, und jul beffern Sofflen ju benufen, als um ben 20 sum ju verminbern, inben

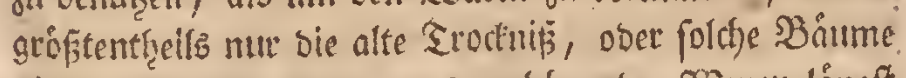

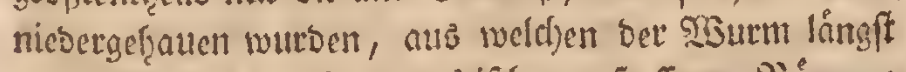
autsgeflogen wat. Sin ben frif(i) antefreffenen ḃåument lief man if̨n inseffen feu Tortpfianjuntgsgefthift rubig forttreiben. 
So murbe autd in sem gemeinfichaftlidyen Com munionforftamte ju Eellerfolo 1776 feftgejçst: Dá in sen fimtlichen forften bie alte Troctinig suerft, uns bie friftie erft nadhere aufgearbeitet werben foltte, mels d)er ganj jwectwibrigen 2jerorbnung man bie nadjheris gen traurigen folgen ber Trodfnif vorjuglid ju verbalts. Eetr ḩat.

\section{§. 20 .}

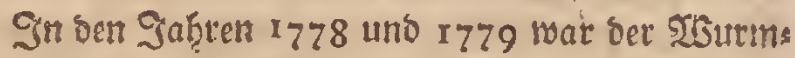
frofif ticht gand allgemein, unt in ben mefreften Drten nur nod) Gice uno ba, gewobnnlich atl jefn bis jwanzig zufammenftetenten Båumen ju finton, uno aller

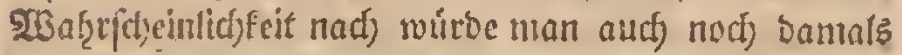
bas lleóel butrch ernfţafte J̦úlfe ju verminbern uno ju Geben im Gtanbe gewefen fenn. In Dem warmen trocks nen Eommer voul 1780 aber, in weldy

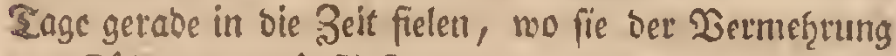
ber Siafer am gưmftigften fint, naḩm bie Srodfnifß noch an folchen Drten allgemein ju, two man fie bis bas Fin uur f̧ód)ftens an cinjeltuen Stámmen bomerft fratte. In bem Jahre 1781 murbe bie \erwúftung enditf fereetflich, unoem, wie man aus ben, bamals barúber sefůţrten, 2lften erfief̧t, allein im Eommunionţarge uno in ber Begent von Slausthal t́ber 300,000 Etán: tme troden fanben, bie mit ber in fir faffenten Siffers

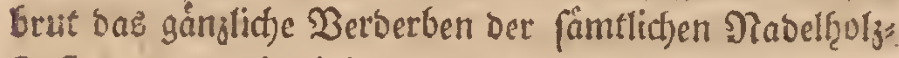
forfter, uno mit biefem ben bavon abhangenten Gtills ftano ocs Bergbaucs, utto den Siuin ber Scarjbewof̨,

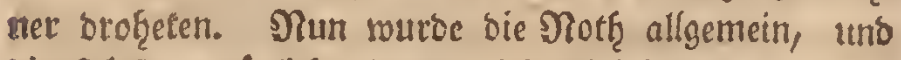
bie Şûlfe unmóglid, inbem nid)t Zróeiter genug anjus ficjaffen waten, um bie ungeḩeure Menge Srudfnis am 


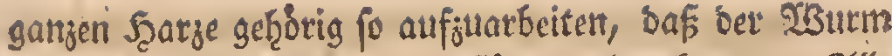

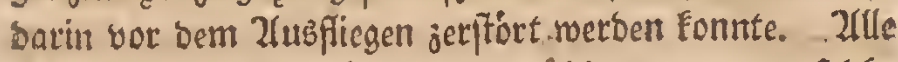
Zfrbeiter waren hinlánglict) befónaftigt, um ıur fold)e Drte nod) ju fäubern, in weldsen bic troctenen Bán me nodf fo jiemlid) einzelln ftanoen, rooburd) benn auds bamals. noct verfdjiebene Begenden in ben Blanfentrurs

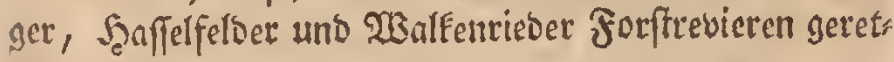
tet wurben.

Gim Saf̧r 1782 warte bie Noth nod) inmes

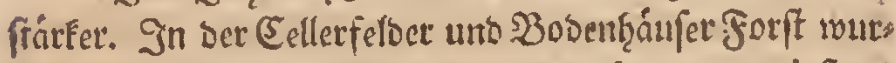
Den bennate 4000 Morgen, worauf man wenigftens 350,000 Stámine redjncte, mutrmtrodfen; und int Eom:

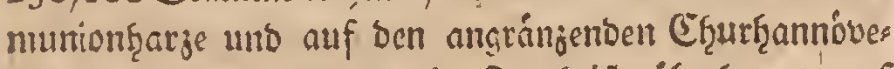
rifchen 3ergen wurbe bie Trocknis úberţaupt auf 600,000 Etámme angefdlagen.

\section{\$. $2 \mathrm{~T}$.}

Jitbeffen wurbe bod) nod) inumer bef̧auptet, bet

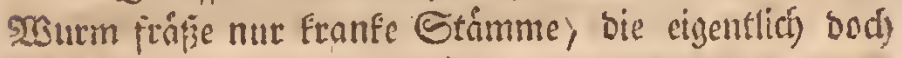

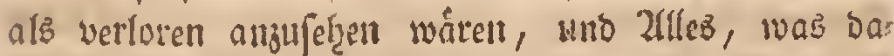
mals ebenfalls in grop̈er \$enge über diefe Eadje ge?

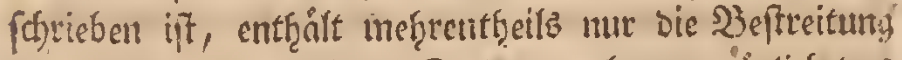

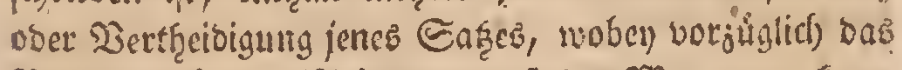

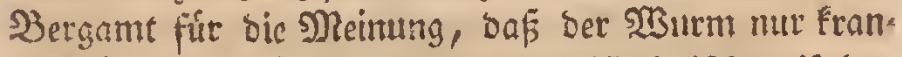
Fe Bahume anfråpe, mit aller minifterialifigen llebers

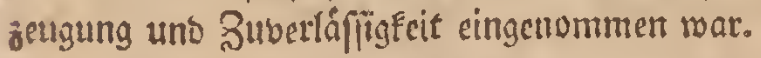

Noth uno Furtigt bejdaftigte intoffer ben biefem Hebel jeben Şargberwohnner, unb Iflles rourbe aufgebos

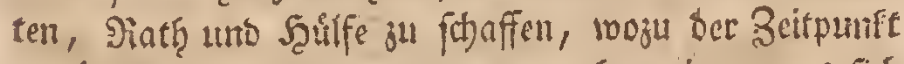
verfânut war. Shun fam benn auch), vie man es fith

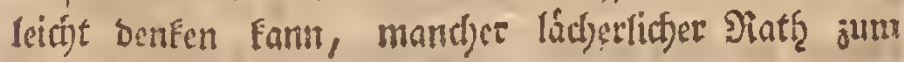
Dorjifjeir. 


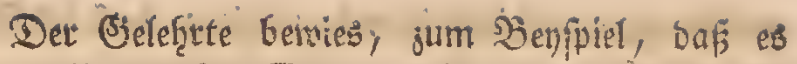
ber waf̧re Dermeftes Typographus fir), mo betect)s nete aus ber Injaf̨l ber (Ever, weldhe Der Rififer nads bem limnee legen follte, die Sảaerfomilien fur bie fols genbea Sabte, uno rieth, Genjeiten mit Dem Sobtma hien ber: Sífer angufangen.

Det Theulog verglid) biefes llebel mit ben Egys

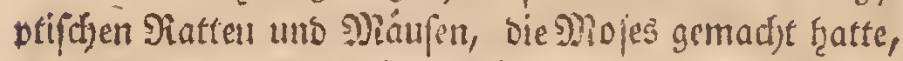

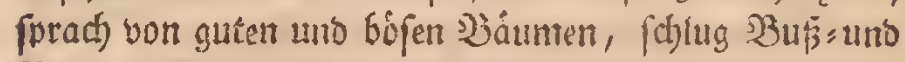
Settage vor, rieth, fromm ju fevti, unb verfprach beffere Beiten, bie benn auch wirtlid) nad) cinigen Jaf̨: teit erfolgf fint.

Einige rieţ̨en, man follte bie B̉âme ele Etrifitent, wornad) bie Safer in forectlid)en Conbuifionen fretben tvatrben. So wollte Der Jyrofeffor Sioffig mit Eirtem

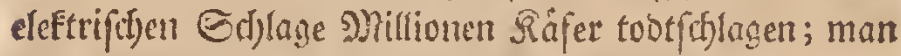

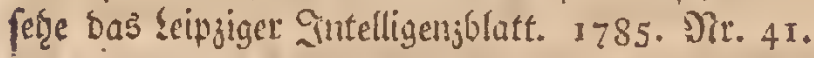

Ein gerwiffer ?potfetfer mollte bem Säfer ein

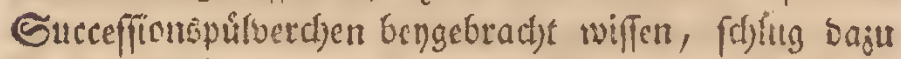
Bumntiguttå bor, wollte baburd) eite anfertenbe

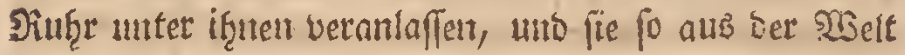
fif)affen.

Znbepe woliten bie Råfer austäudyetn, ungead): tet fith ber :

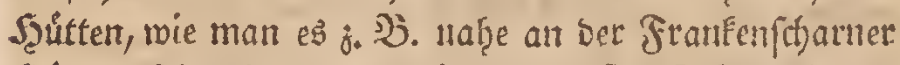
Şưtte gefeten hat, mitten in ben biffiten 6 d)wefels unt Zrfenif: Sampfen ganj wobl befinden fam.

Znbere, welche nidyt begreifon fonnten, baé man

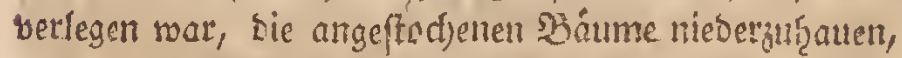

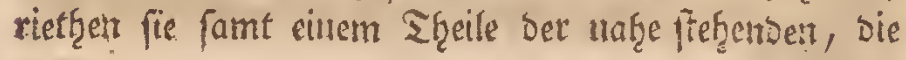
Doch 
bocb) in ben folgenten Saķren trokfen werben wirrben, abjubrennen.

Diod) anbere wollten bie angeblid) franfen YBált:

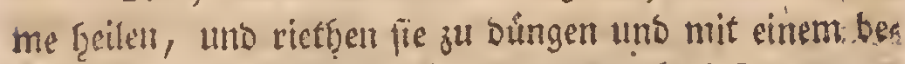
fonbers baju gefudyten Düngewaffer zu begiefen.

(Finige (Eaum follte man es glauben) riethen, ant Den crft angefrodjenen Báumen bie Siaferlóner aufjus

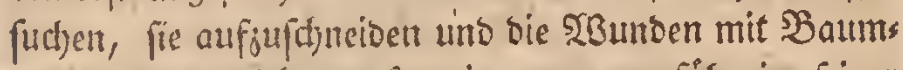
fuad) jll bertleven, fo wie man ungefâhre in jeiner

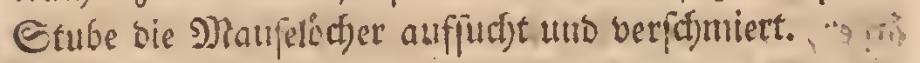

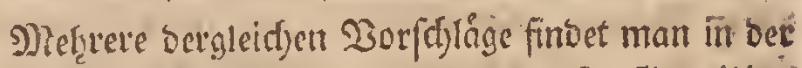

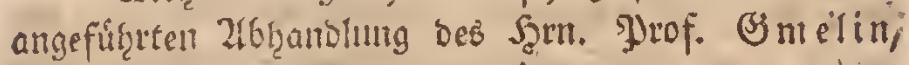
mit unverbientem Sleiß̧e aufgefíf̨rt.

Einige bicfer ládyertid)en Derfdylige wurben vers.

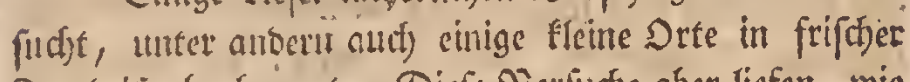
Srodfnis abgebrannt. Diefe כerfindse aber riefen, wie

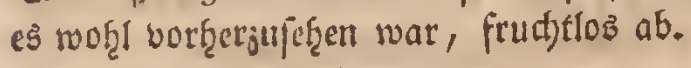

\section{§. 22 .}

Zllez, was hingegen fûr bie gute Bemukcung beš trocknen \$2oljbeftanbes angewenoct werben Eonnte, wutrs be mit befferem Erfolge vorgenonmen. Es wurbe,

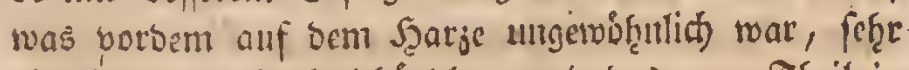

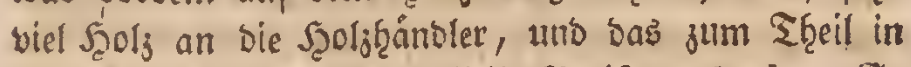
ganzen Dertern, fur wohlfeile Dreife verfautit. E⿺ surbe cine grofie IRenge verfohilt, unb bie Siohlenvor:

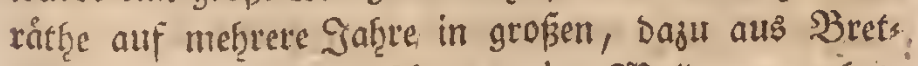

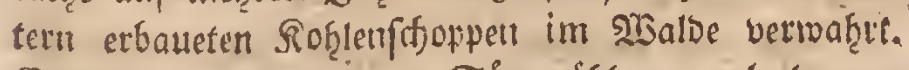
Es wurbell mef̨rere neute Sågemuthilen angelegt, um

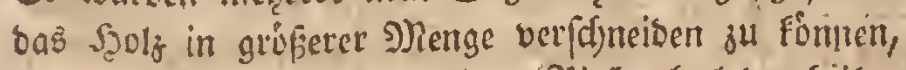

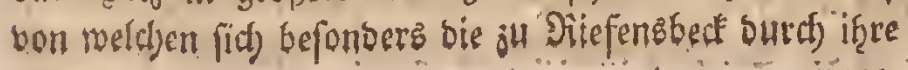




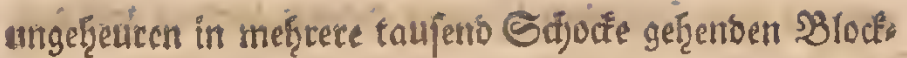
vorrâtţe auzzeicfneten. Lleberţaupt sourse bie Sgolgs

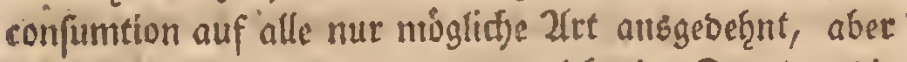
benrallen ungendjtet, wat man nid)t im Etanbe, bie foimtlifje Şoljatroctenif aufjuråumen, von ber man noch iefet auf bem Scarze grofe verfaulte Diefte antrift.

\section{23.}

Im Jaf̨re r783 wurbe bas llebel noch immę ăraer, befonber' nậm es im Şarjburger ano Celler: felbet Sieviere, am ftárfften aber im Ef̧urf̧anniveris fojen Şarze 3u. Es mogen in Sem Gaf̧re allein, am

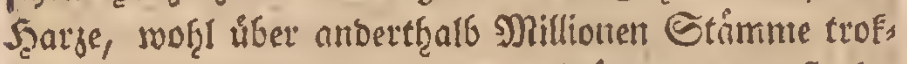
fen gevorsen fenn; ittoem in ber Nláfe ber angeftodjes nen Sigenben fein junger, auf ben ftárfften Surwacts ftef̧enber Tanmenort, feloft bie nidjt, bie ntan Picts: taumen ju nemen pflegt, vom গSGume beriçont blieb. Die vormals fhonften forftgegenten franien auf Etuns ben weit trocfen. Tam fijlimmiften fah ber Odhwarjens berg úber Slaustrgal aus, woran inan fratt ber yormas ligent fojomen grúnen Tanmenwanb die tranrigften 2fıs:

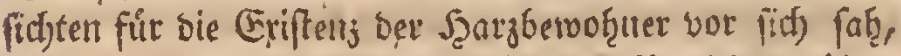

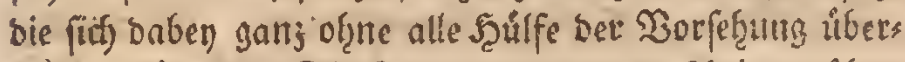

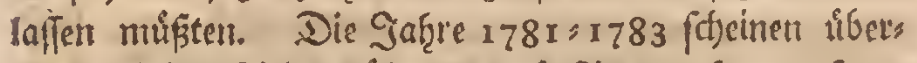

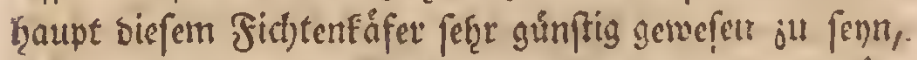

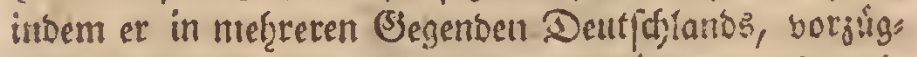

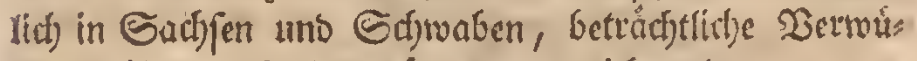
ftungen) in ben fichtenwálbern augeriot)tet frat.

In bem folgenten, 1784ften Gahre war bie SBitterung zut Zeit, bo ber Râfer fiegt, anţalteno riaj und falt, woourct) berfelbe feçr vernitioert wurbe, wno bie Trobnis nterflid) abnaţm." Jutefien fiel boch 


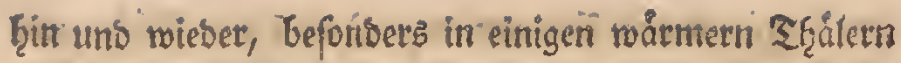

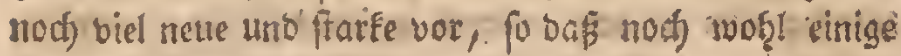
ந̨underttaufeno Etámme barauf gingén.

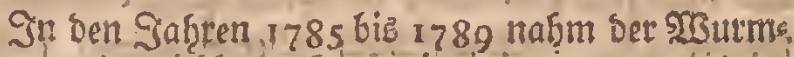

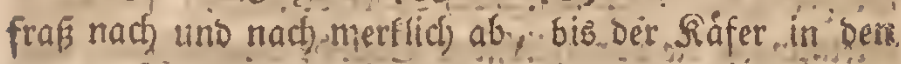

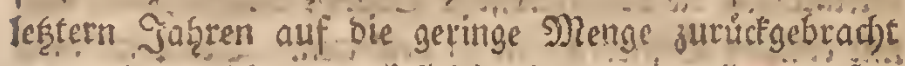
war, in woldjer er pielleidts immer in allen grosen Sidjtenwaibern sleiben wirs.

Sm vergangenen 1793ften Gaḩe aber hat ber

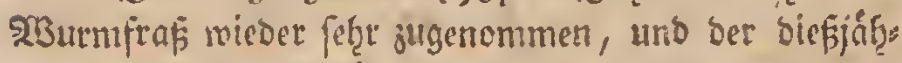

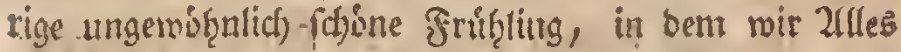

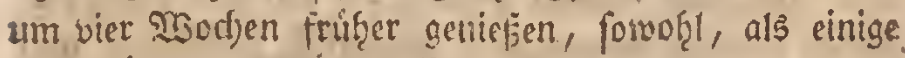
Dem ßåfer fouft günftige Ereignilfe, noozu bie ungę̧euer

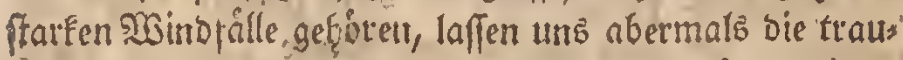
rigften Folgen fúr bie tvenigen guten Sannenórter fúrtef).

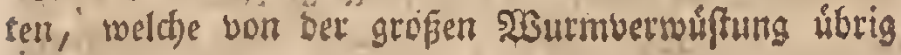
geblieben finto.

\section{S. 24:}

Da nun ber ůberḩanonef̧mente Såferfrá, wie

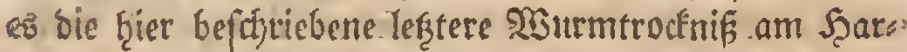

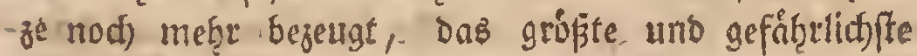
Hebet ift, was in cinem grofen fidbterimaloe borfome: men faun; fo ifts fürr ben forfturann auserft widjtig, diefes llebel, und bie bagegen anjumentertben smittel

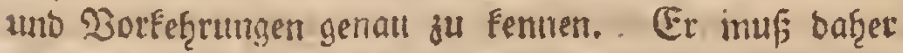
Die Urfact)en Deffeleen ju erforfiten fudjen, uno barf Destwegent ben Der Entfäseioung Der ofen bemerften bes

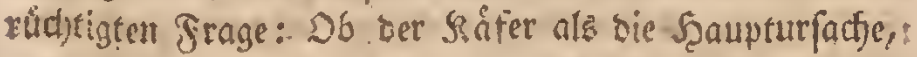

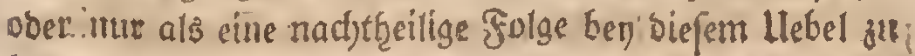
betradjten fen, nicht gleidygultig bleiben:

Trit 
Súr bevbe Nieinungen; a) baf Der Såfer nue

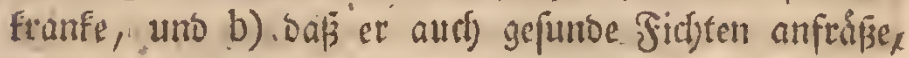
gab es bamals Dettheibiger uno Woiberfpred)er genug; und noch jef̧t hiort man fie oft leb̧aft beftreiten uno Jerţeibigen. Jdj will mid) baf̧er bemúf̨en, für berbe

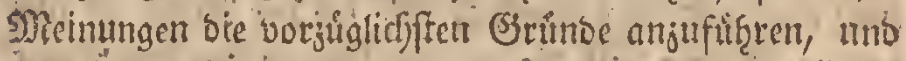
mit einigen Biemetfungen gu begleiten. Der befer inas bant felbft uttheifen, in wie weit iff in Der baruber ges faf̧ten Meinung Nied)t ḩabe ober nidjt.

\section{§. 25.}

Es muf freylith jebem, ber fich mit entomolo:

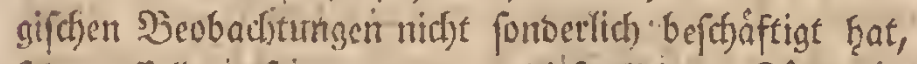
fectr auffallenb ferin, wenu cr biefe flemen Răfer gas fimblifgeinente und im bollen Eafte fragende farfe Sannenbåme angreifen fiefet, bie in Furjer Setf, in

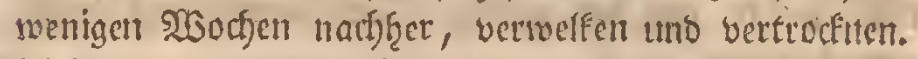
seidft fam baher ber Jebanfe ben if̨m auffeigen, baj̄. biefe Båume fdgon bother Franf gswe fen fenn módbten, bejonbers da man meţr Safer im verborbenen, als im grumenoen Syolge anjutreffen plligt. Da bie Sarje unb Garzartiget Dele oen J̄nfeften-ưberf̧aupt sacfs

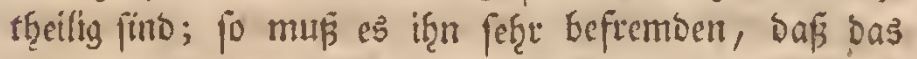
frifide harbige :sefen einer im froben ftef̧enben faftuollen Sanne biefen Siafer nicht tooten follte, ba er fogar Den Theil ber Tanne anfidyt unto Geworint, in weld)em baz meb̨rfte Şar befinolich ift.

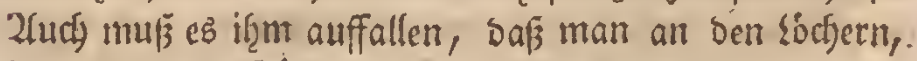
in rold)en bie $\Re$ áfer fich eingefreffen haben, wertig uno nur felten Eleine Şarjtropfen finbet, Da boch fomft aus jeder Soutenbefdjábigung der grủnen Tannen vicles Sarj zu fiefen pfiegt. Sff es Daher bey diefen yotaus: 


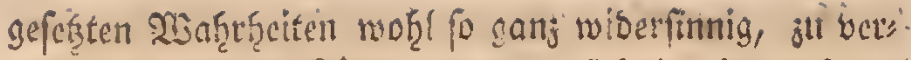
mutţen, baf ber Sifier, toenn or fich in cine gefunde Sanne cingefreften b̧âte, Durd) Dent juftromentent Gaft getiostet werben múlite, weldjes man hicr nidjt

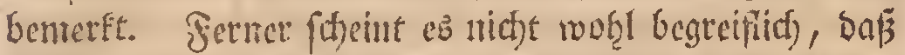
eine fo geringe Befchabingm, wic biefes Elcine \$nfeft

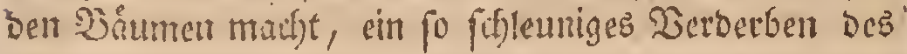

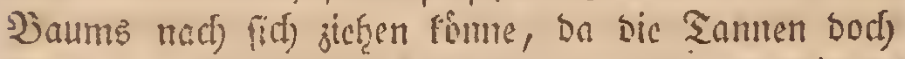

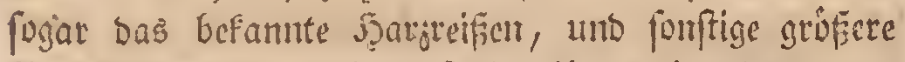
Şcrwunbungen, mef̧rete Sinf̧re finter cinanber cttra gen finnen; babingegen in einer von biefen Siffer ans geftod)enten Tanne alle Drgetation fogleid) nuffufioren

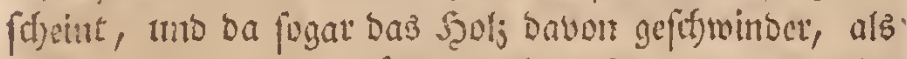

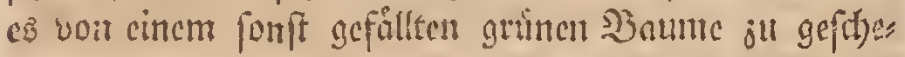

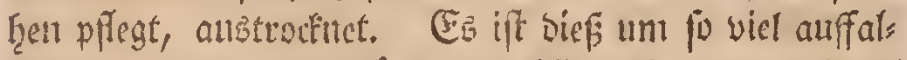
lenber, ba man oft $3 a$ aume, folbff fordse von geringes

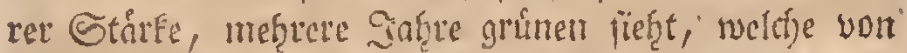

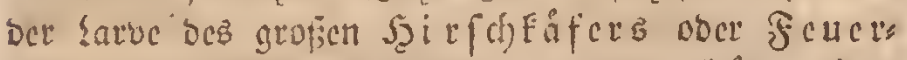
wurms (Lucinus Ceruus), Deffen Şånge ủbcr euren hatben Soll breit fints, unb tief ins Scols gefent;

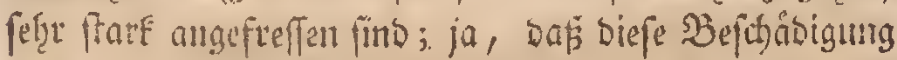
oft inieber julvádjft.

\section{§. 26.}

2̧enn ntan aber bagegen in Erwågung zicht,

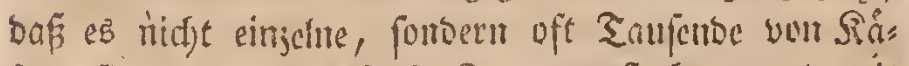

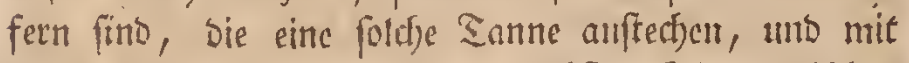
if̧rev' Şrut gerabe ben empfindfichften Sheil zwifitjen

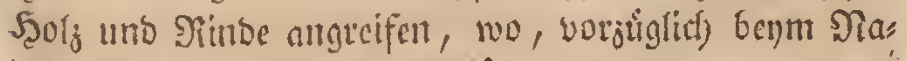
odf̧olje, bie mef̧uften Gaftrof̧ren liegen, unb worant

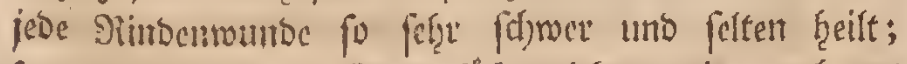
ferner, buf biefe Saftoffópie nicht, wie ç henm

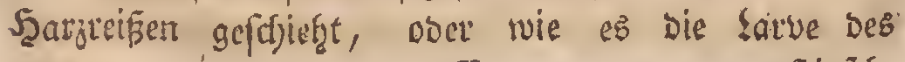

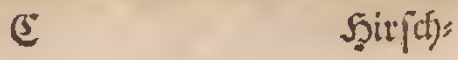




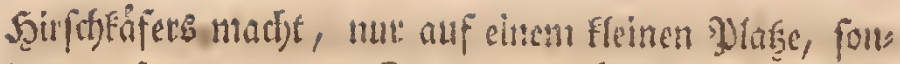
Derit auf Dem ganjen Gtamm!e ujáfiligema! bon ben Sifern ber Duere nach burtjifhnitten uno ganj aufzes jef̧rt twerben, fo with man es leidjt cinfegen, weldje

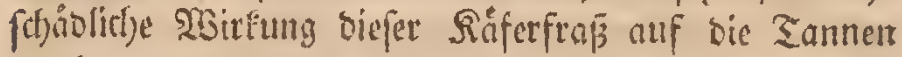

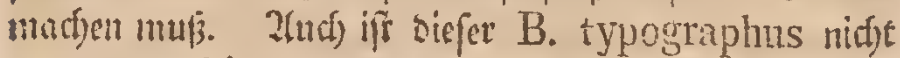

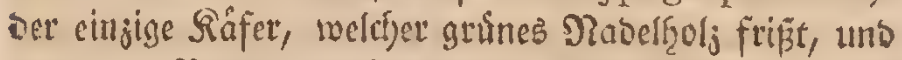
anter ser borfe beffelben lebt. Man braudyt mut bie

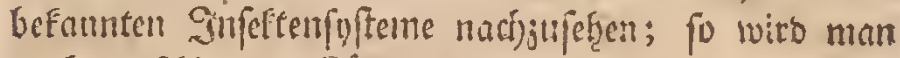
noch veriffiebente Siffer finten, die auf grinnendem

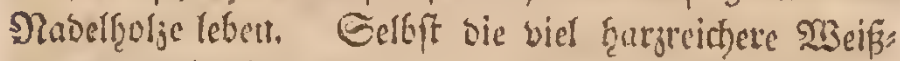

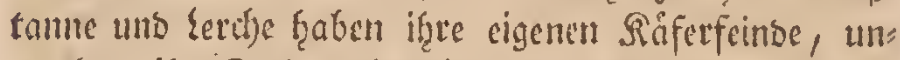

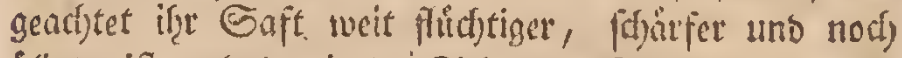
Dligter iff, alsె ber un ben Sidjten. So cutbesfte j. $\mathfrak{B}$.

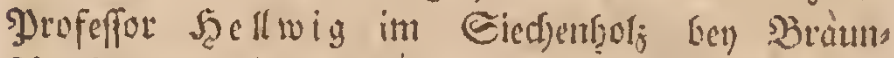
(đ)weig an ber \{etdjentanute (P. Larix) einen bis ba: fin mod) unbefannten Boftrichus, bem B. typogra'phus fehre åf̧ullid), aber um ein Drittel Hleiner, ben er B. Laricis nannte, und der bon fabricits unter biefem Nanten iut fir Guftem aufigenommen nurbe.

Diefe Saferatten find an ben Gaft unb bas

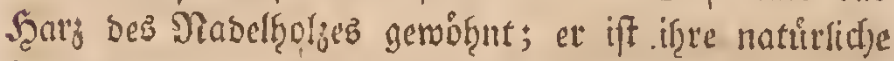
Dafzrung, unb fie leben barin, wie andere Sfiere int

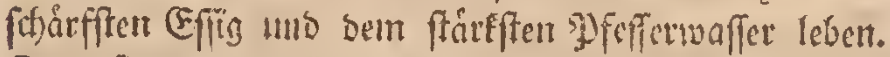
Det Saft bes Dabelfzoljes ift aucf) im grumenten Baume bey weitem nicftet fo haraig, als er ez an Det Suft wirb, in weld)er er, nad) Serbunftung ber wåks rigen feuthtigfeit, oufammentinnt, wie man foldjes an frifotgeborftem Wabelholje (cid)t bemerfen fann.

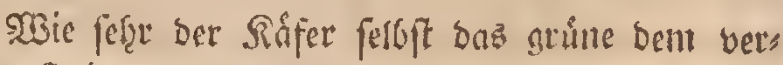
welften Sgolge vorjichet, faun man baraus folliejen,

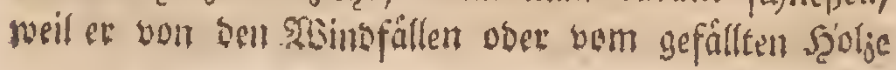




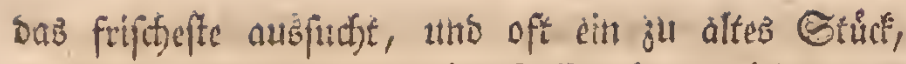
aud) wetm or fid fdjon cingefiefien fiat, wieber bet:

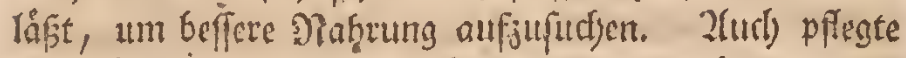
Der Siffer itt Der Scit am Eqduifigften jut jhtwarmen, und

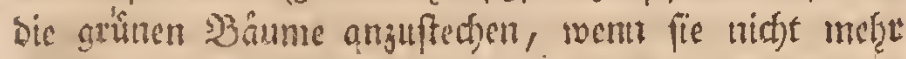
ganj in bollem Gafte fitefen, als im May umb Zutguif nad) bent erfen uth jroenten Sriebe, wann bie Borfe faum meţr geţt.

Dap fidl an ben angeftocfietcri Samnen vor ben

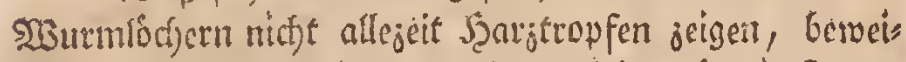
fet aus Der eben betrif̧ten litfacte nichte für bie Siranfs

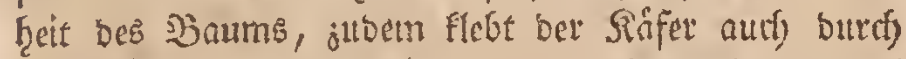

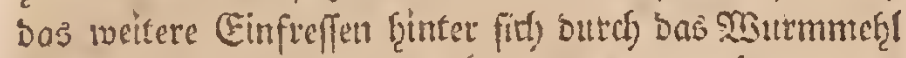
bas boct ju. Dft finbet man aber auth f̧álfige uns

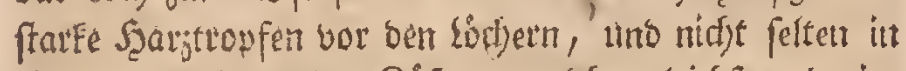
biefer verflebte tobte Riffer, welifje gleid)fam barit,

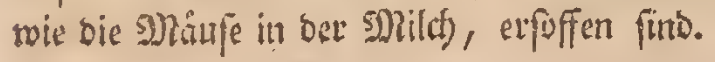

\section{5. $2 \%$}

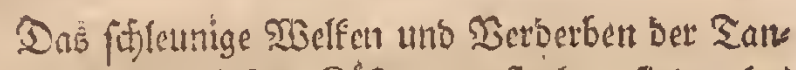
nen, welcje bun biefem Siafer angeftodyen fino, hrat freylid) vicl 2tuffallenbes, inbem falbft cin Baum, bem man um Einen Sus breit an Stamme bie Borke nimmt, nichte fo sechwrint, als jenc, vettrocfnet.

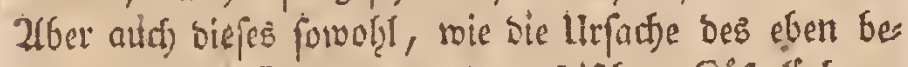

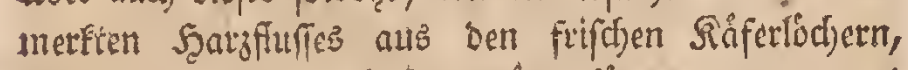
wurbe man viéleidyt Eeffer erfláten finnen, wenn uns alle bamit suitfenden limfinge genauer beEannt wåretr.

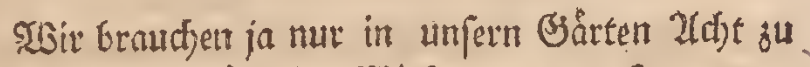

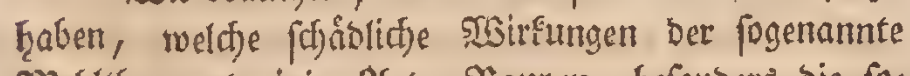

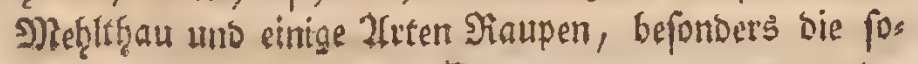


genanten SBlattwicler, auf ungere Frud)ebaume uno

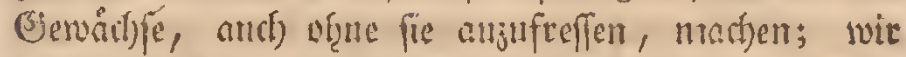
burten unr bemerfen, welde 23 efdádigungen in ben Foriften bie gropen 2!meifen vernffachan, ober wie bic

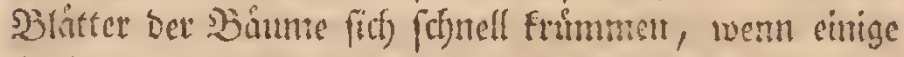
Snfeften nut ifere Ener saranf legen; imgleidyen, wel che fonberbare soirfung auf bie Siláter ber feire Etici) ocr Balfweppe (Cynips) ficrootbringt, aus bem,

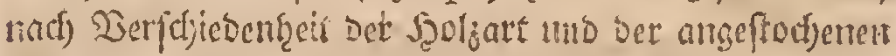

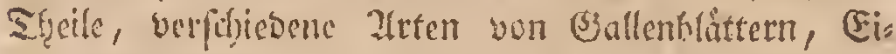

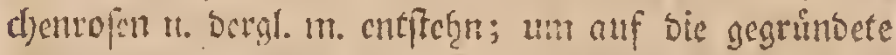

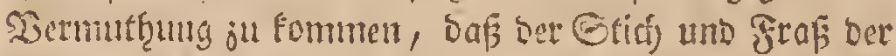
Sinferten anf tie Yllanjen uno 3Bonme eben fo giftig und reijent fond finne, als ber Gtit) ciniger andert Sinfreten auf bie Sfrere ift. So ift $j$. SB. Der Stids

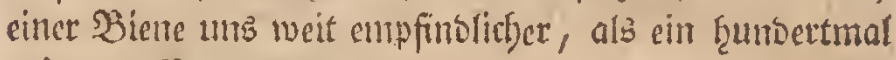
groficrer Mlefferfonutt.

\section{28.}

Es wutrbe and bie widftige Frage: Db ber Sä

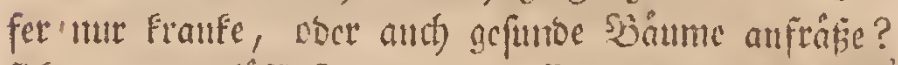

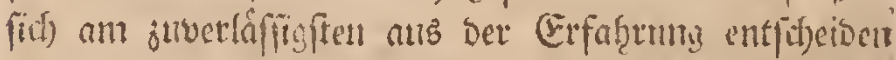

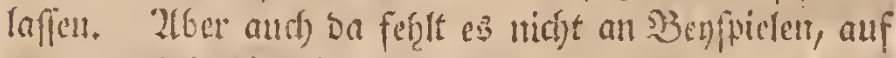

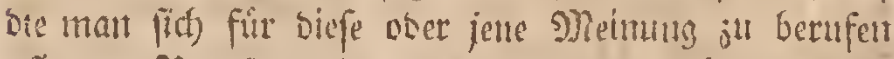

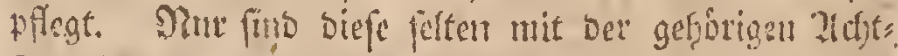

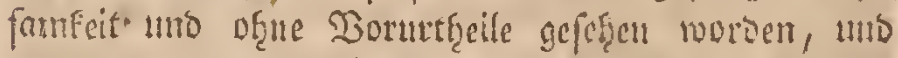

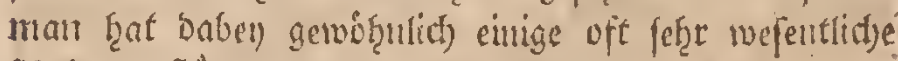

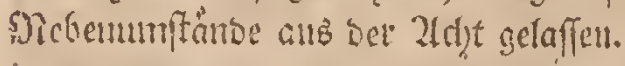

So zrigte man in einigen fruflitbaren Brünoen uno anf eitigen tiefer gelegenen Drten, befonters an ser Sinfter in ber Grumberforft, verfóficome Scourfite

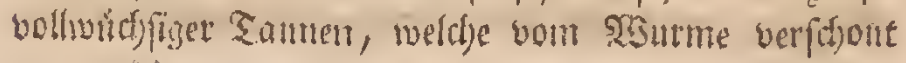


geblieben waren, ba bod alle unt biefe beer, nuf bent trocknen, weniger frudjtbaren Intróben geftandentent Sannen vetheett twaten. 2(nte), anf cinigen alten, trof: Fen geworbenen Dertetn wurben chinge gut erhaltente jüngete Tammen gejeigt, Imo Daran bie Solge gejogent, bafs bie im Zhale geftantonen unb die lefetern jungen Tamten mur gefunt, jene auf ben ?tnhibgen, unt bie úbrigen alten Sannen aber vom Ravine getrieben uno sont ju fratfent Dorren franf gewefen wáten.

abie viele Beypipicle liefsen ficly aber jeigen, wo bie in ben fruchtontifen Thaleur geftanbenen Tantren bom şurne verborben, unb bie auf ber nafen Intrig̨e verfifont geblieben maren. Itno fann nidyt gerabe ein ftarfer sibinsuly, ober ein auf jeaen Brumben ober tics forn Deten ant ber Sofrer gelegencr. Nebel, ber, in ben

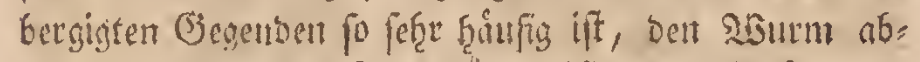
geţalten fraben, bic Taumen bafelteft aubufallen?

$$
\text { 6. } 29 .
$$

Dagegen erimtere id midy it ber Monnect)ęofer

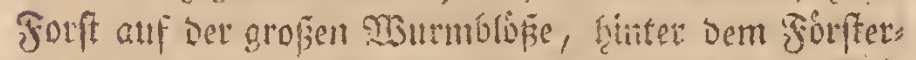

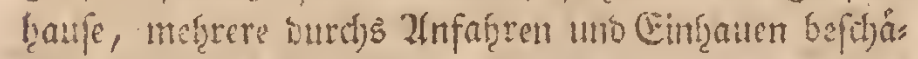
bigt gewejene ₹annen, uno ant Gdymorientorge fogat

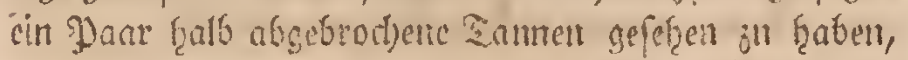

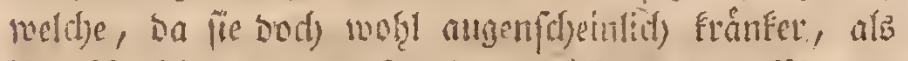

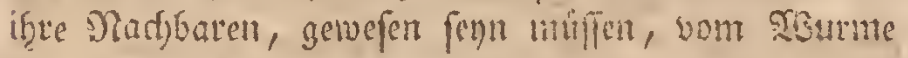
verfigont geblieben, unt fingegen alle übrigun umftes hemben Samuentaufetbucife trocfen geworben waren.

So fand "Der Socuforfter Siseiuf fyenf, int

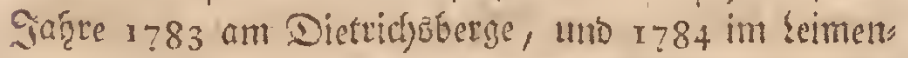
thale mitten juifdyen Taufenben mumtedener Samuen, mbly 
mef̨iete - verfljont gebliebene grume Santen, troyon baß

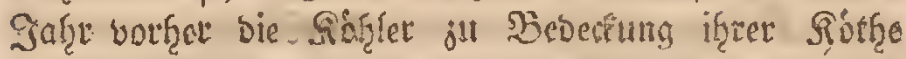
Borfe genommen hatten, weldje alfu gewif frant was ren, als bet Sáfet-ifere gefumbern g?adjfazn anfiel.

Gelbft ver alte Santrenot am Sirdberge Saus tenberger forft, welder netremals jum Sarze geladj:

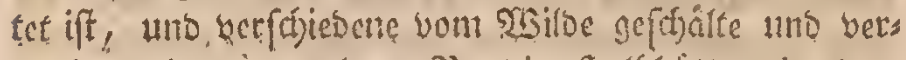
borbene Datter, als of 3 . Dia Syalbịtitten in sem

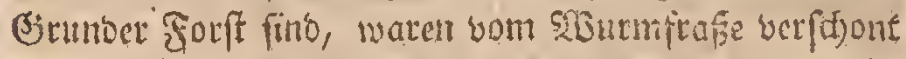
gcblieben. 2fuch roob in tem vergangenten und in bies

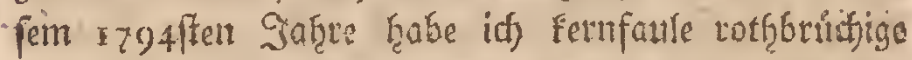
Tannen gefesch, weldfe neben ganj sefund fbeinetioen

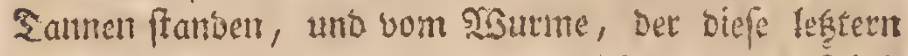
angeftorben f̧aite, body nidye angegriffert waren. Bicfe Erjofjeinung wat mir befonbers auffallent, yeil bee Reffer bodj folche SBáme, dic nidye gatiz in vollem

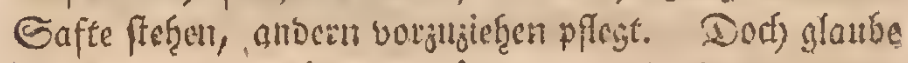
idf) fie bamit crefliten jul Fonnen, Dafis bic fermfaulen

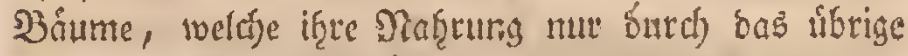

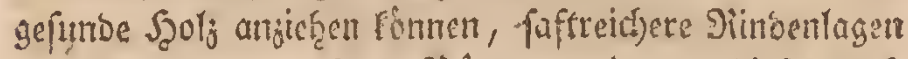

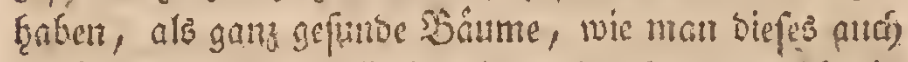

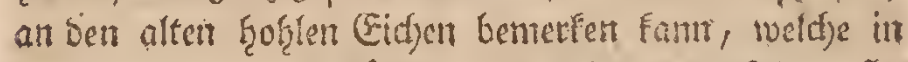

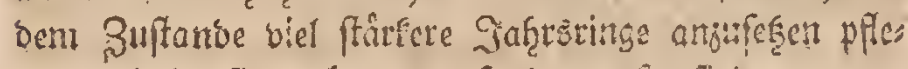
gen, als sa fie nod galio gefumb gewefen fitto.

Serbft cinige sactiuche, weiche man in bett bo: fêt Râferiahèen mit einiger Zannen aniftelte, bie

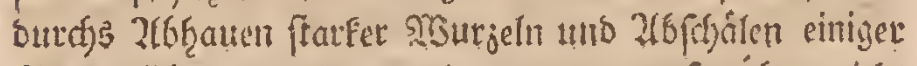
Botfenfticke frante gemorlyt waren, entpradiden nicht immer ber Ermartung, unb viele bavon bifcben vont

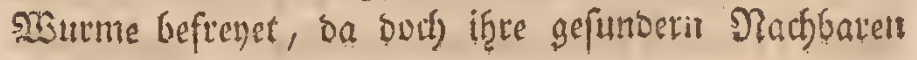
verborben wurten. 
Sunt ftaffiten Bomeife, baf bet Siafer auch acs funbe Tannen angreife, mogat bem bodf wobt bie

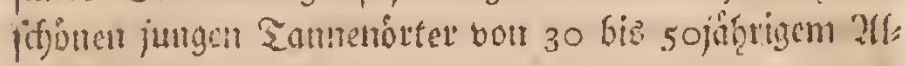
te: sienen, iveldye in ben Tafquen 1782 แtwo 1783 wurm: trocken geworben fint, uno auf tveldyn man an ben

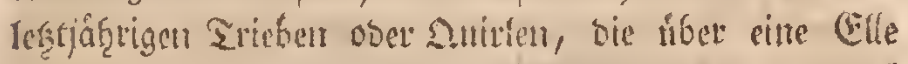
lang waren, fich solffommen ưbergersen founte, ba

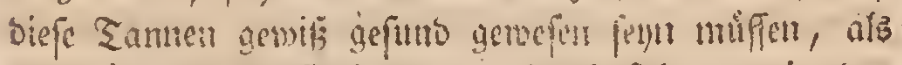

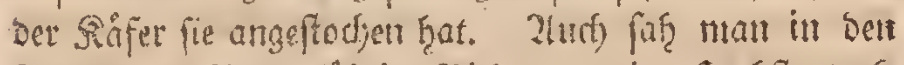

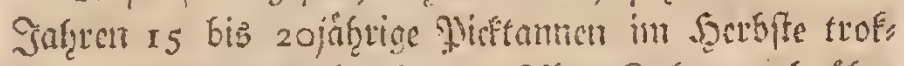

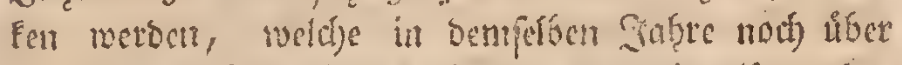

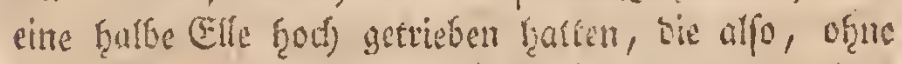

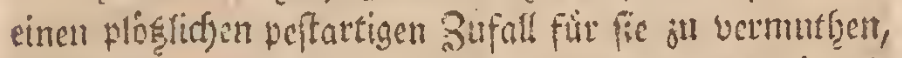

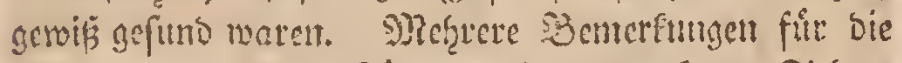

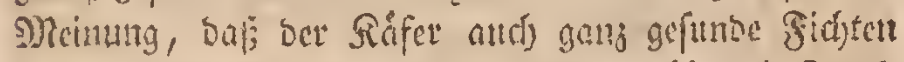

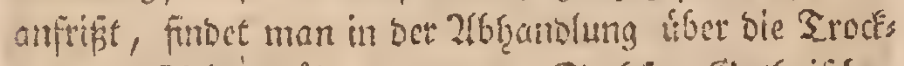

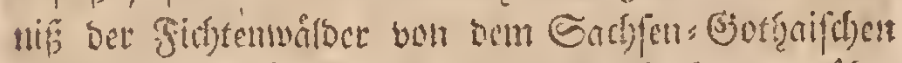
sibilomeiftet gager, uns in ben Protad)tungen libet:

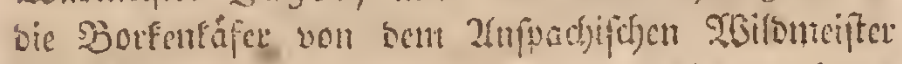
von $5 a$ as. Liabrigen sicnem bie anf bem Scarje Dantals po oft wiebetḩolt gamad)tent Erfahrungen jum

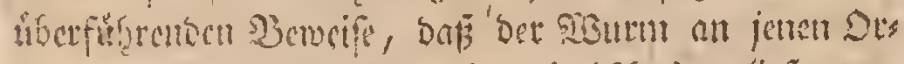

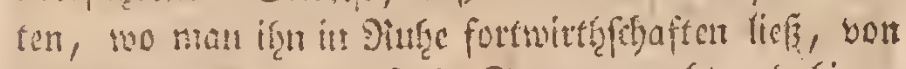

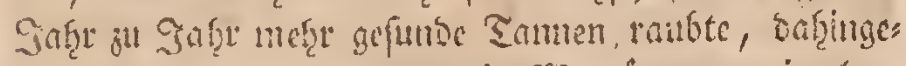

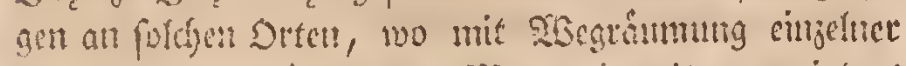
angeftodjenter Bäune bor 5 Gum bongriten geminocrt

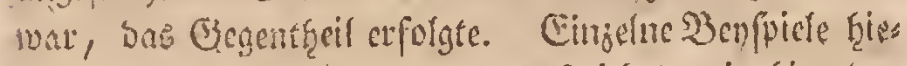

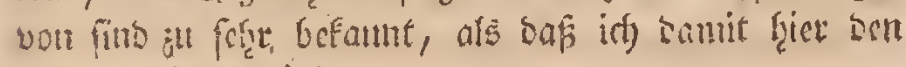
sefer comủsen módjte.

$$
\text { S. } 30 .
$$

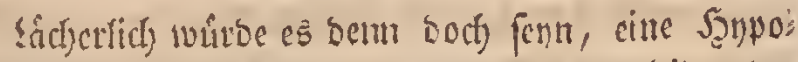
thece fo writ vertseibigen ju wollen, als es leiber bas

$$
\text { ए } 4 \text { mals }
$$


mals mit fo vieler Seeftigleit gefdoab, thib twie aus ben

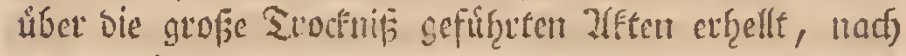
weld)er úbertzaupt alle Santet an ga!njen $S_{e}$ arje, feloft bie jûtugften, in vollem Sriebe geftattoenen Jidftamten, eine bzeimlid)e Siranff̧cit gcţabt habent follen, wovon

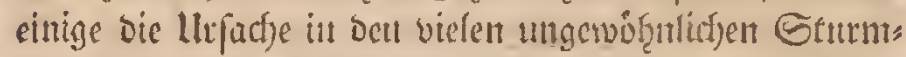
minban, in ber Durre unt Stif̧e; andere in ben vielen Bemittern, in Den Conftellationen, und molę gar it bem lef̧etn Someten, gefuttoen ju haben glaubten,

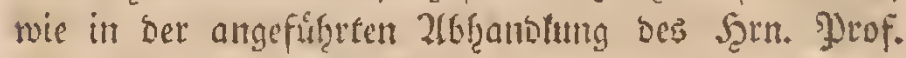
(S) me lin ju refen ift.

Daben aber vaumten boch bie 2tuf̨anger biefe:

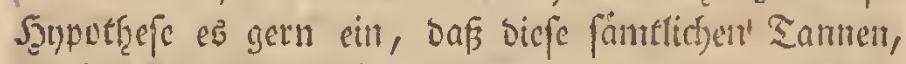

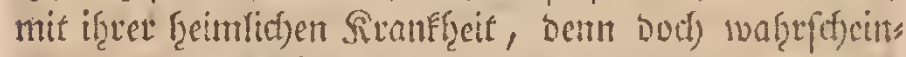

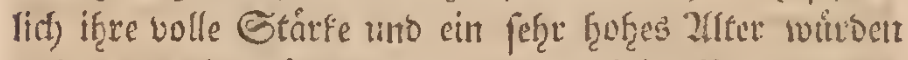
fraben etreichen fontren, menn bet reisige şum fic in

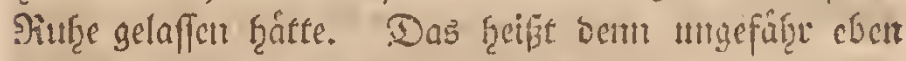
fo vicl, als went matr cinetr gefuttoen juntgen Micts fot)en, Den man mit Gerwalt iberfithute, daj cr citte fecimliche Eolif báte, won ber er frwar bis in fein achts

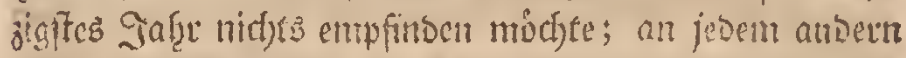

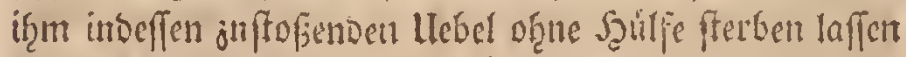
wollte.

\section{§. ' $3 \mathrm{r}$.}

Diefer bomals voroutglich beridytigte Gtreit ift úbrigens fưr ben praftifchen fouftmantr tmo für bas

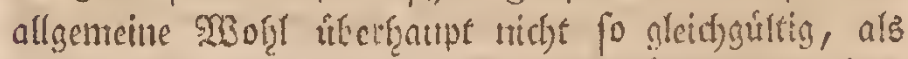

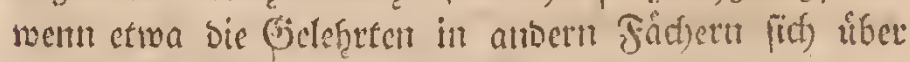
Dinge zanfen, Deren Entfiteidung fur meerc Ecelens

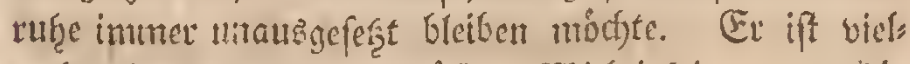
meḩr alsbant von ber grofften soidjtigfeit, twenn bie notritge 


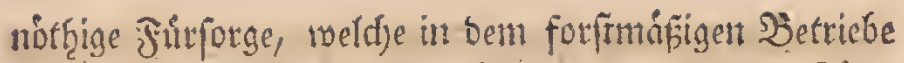

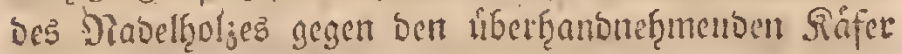

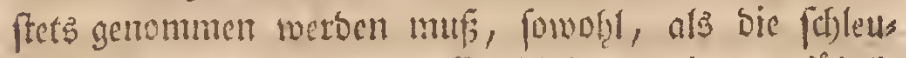

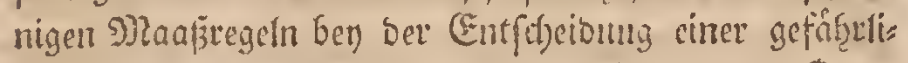
d)en 25 mmetroctinis felbft, bavon abhangen. - Dem!

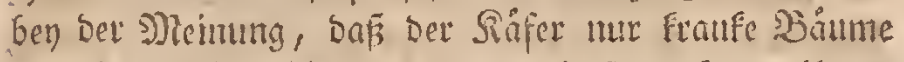
angreifen follte, blcibt unb, ba wir fic borf vont if̧rent beimliden llebel nicht befreyen founen, cigentlid) gegen

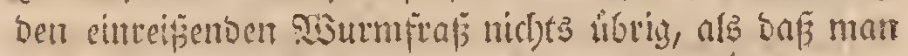

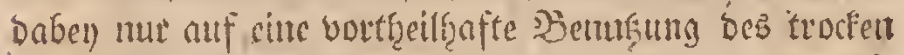

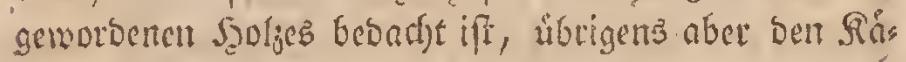
fer, bis cr ans Mlangel franfer Santen verf̧ungert,

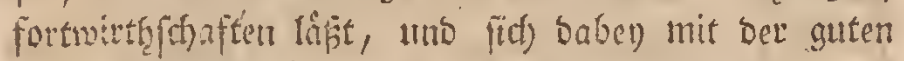
Syoffung cinjolifert, baß, wenn cholid) Die franE

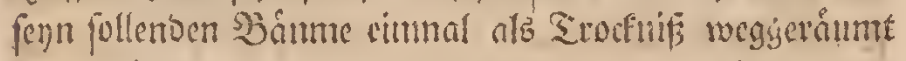
feju wirben, ulewe Radformmen bet britten ober. vierten Bicneration Dem becl) redyt sefunbe Saunen fres

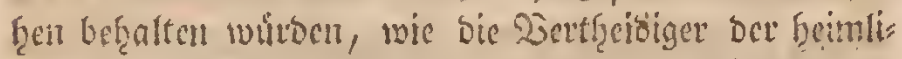

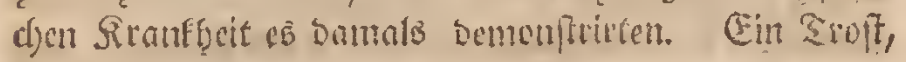
Der inir gerase fo. vorfonmt, wie jetter eines altert

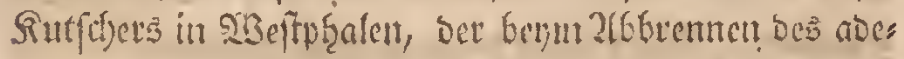
lichen Soufes bie Siatten pfeifen haorte, utto gelaffen feis nen guábigen Scerrn bamit troffete, baf, wem es̉ noch Eimmal fo fonmen modste, fic boch woht enolich bie bofen Siatten los werden whitren. Der geneigte sefer nag unir biefis Ssifforthen vargaifent, ment er etwa bie

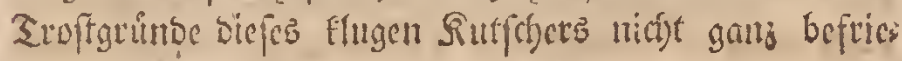
bigens finben follte.

$$
\text { §. } 32 .
$$

Sien ser entgegengefefeten Meinung aber, oafs

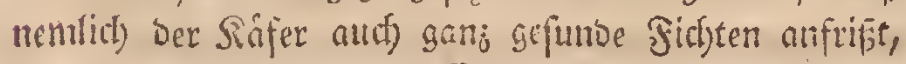


Gleiben bod) now ehige Mittel ubring, bie mant fum

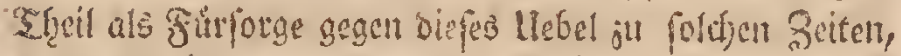
mem mant es famm an eingelnen Etanmen maburninmt,

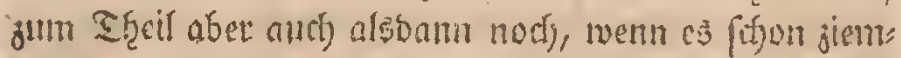
Vid) fart eingeriffen ift, juberlofing onventosn fonn.

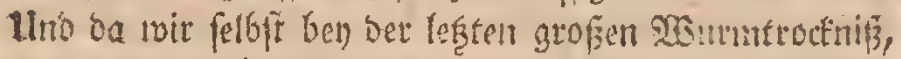

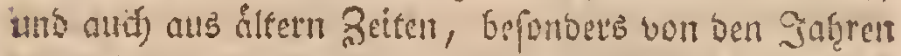
I 745 bis r 752 Benfpiefs geming haben, unb ans ber

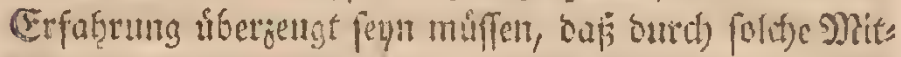
tel nicht allein eimilne fleine Drte, fortom ganje grofe Sorffer gerettet, uns antore fingegen, in welchen man,

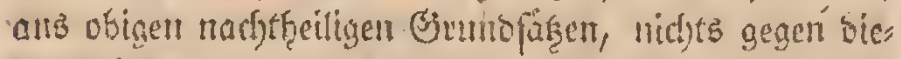
fes Hebel urgenommett featte, berloren geganget finto; wie man es aud) an einjelnen wntrmtroctuen $B$ Baumen

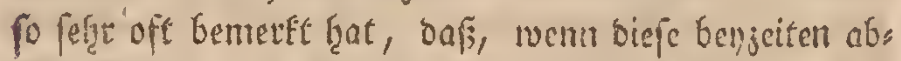

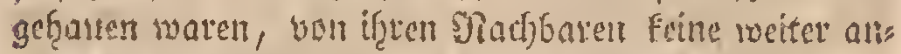
geffocfen wutoun; - po geigt bieje Erfafeuth fojon allcin, welifer bon berbent פleinungen wit wenigftens amtêpflithtig zugetfan feyn folfen, wenn wir aud fonft mod) einigen STang zum sibiberfuredien basen funben

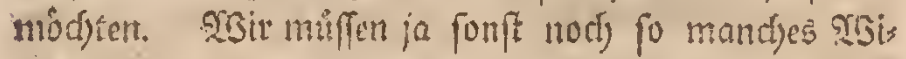
Deryinuige (d)lechtweg glanben, von bein oft unz feloft

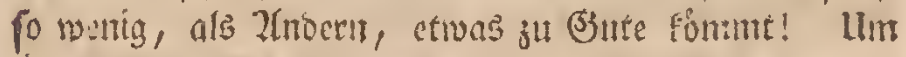

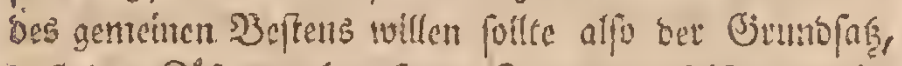
Dof bet Sififet aud) grfunte Saunent anfitst, menigs

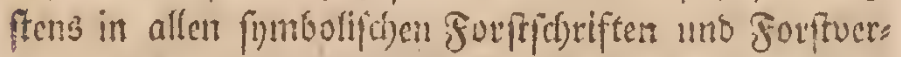
oromungen als ansgemad)t unto unbegmeifelt angenon= nent werber. lint furt biefen will-idh benn and ans

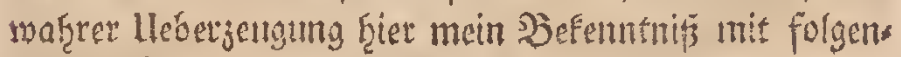
ben Sulfigen ablegen.

\$. 33. 


\section{33.}

Meiner MReinumg nad), glante ich úber biefen

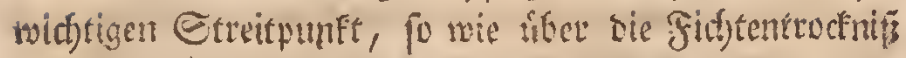

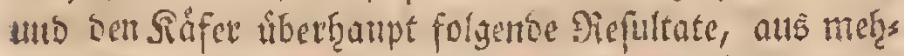

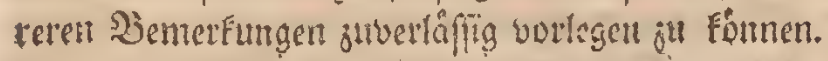

a) Eह ift blefor Boftrichus Typographns, a!s ein

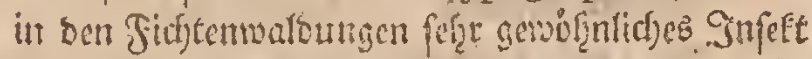

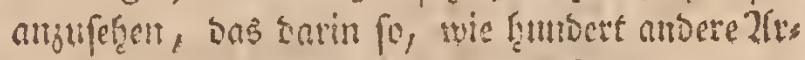

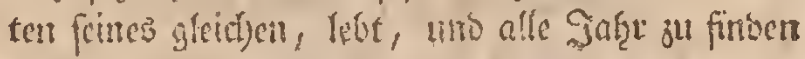

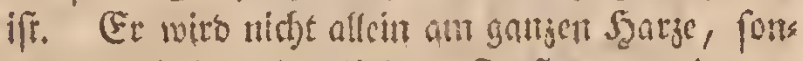

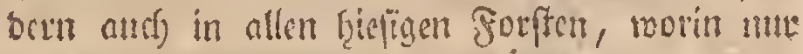

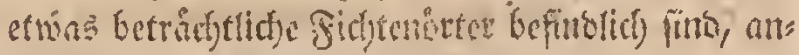

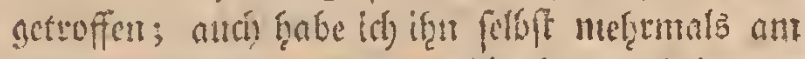

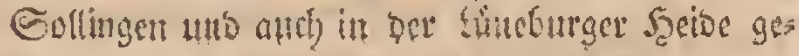
funber.

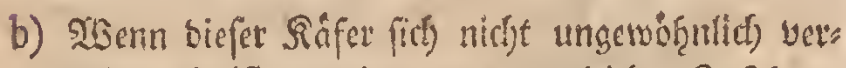
merget; fo if er, wie antbere bergleidjent Strfeften,

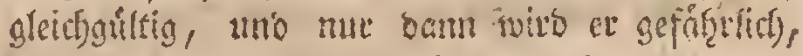

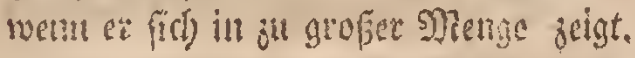

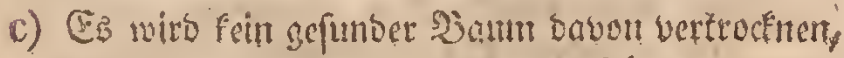

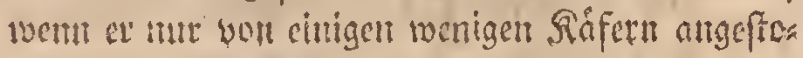

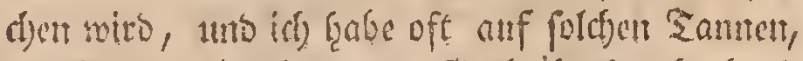
wethe jum Estroime ber Jierberborfe abgebouft waren, seutlitge Epuren von vormaligen şourn: fritfen bes B. Typographus gefunden, weldfe

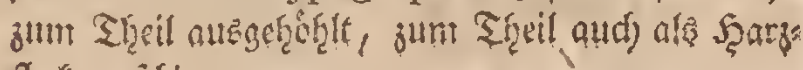
flecfe eridictrent.

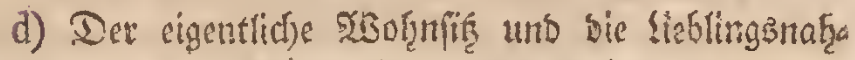

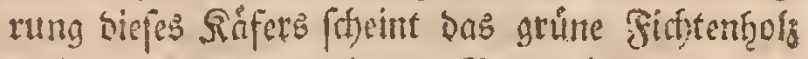
m fenn, weld)es, mit ber Sorfe bebesfit, nidut

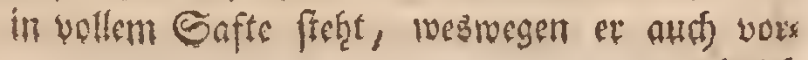




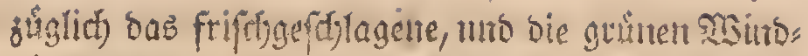
falle auffudgt, weld)e oft in wenigen Sagen nadh ber fóltung, autif in foldfen Oegenber, worir man auf Stutiben weit Feine befonbere Mentge Siffer wahrgettummen hat, vont Sifferil angefillt fino. Diefe gewis auffallento Erfochenung wiro

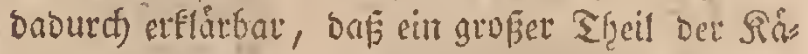

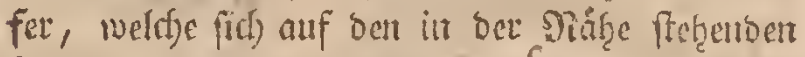
Tamen einjeln aufgebalten ḩaben, bieje verlap

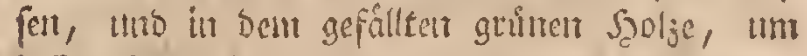
beffere Mafrring ju findeil, jufammentemmen.

e) Dafi, biefer unb mef̧reten Erfaf̧ungen gufolge, ber Sáfer inmer licber aud) foldje Bäune anfte: d)en wiro, bie nidat in vollem Gofte ftef̧u, als junge faftuolle fratfuadjente Samen. Er twirb

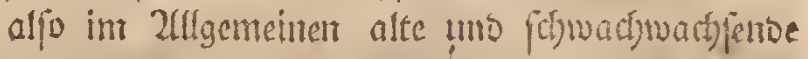
jetten worjitef̧et.

f) So weit; als bas in einem Samuenorte befind:

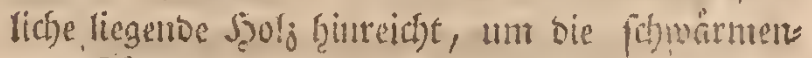

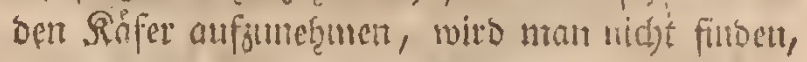
Daf et gefunoe Snumen anficht. Gins aber jene nidft fiulanglich; p fäll er auf oic vom şinse gelefruten, ober allf irgento cine foldhe ?lit in

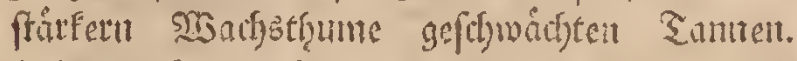

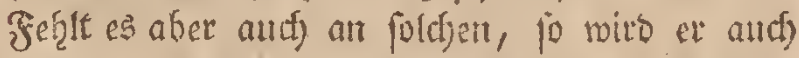
ganj gefuntoe, in bollent sisadjothume frebende S3innte angreifen, in weld)em falle befonders

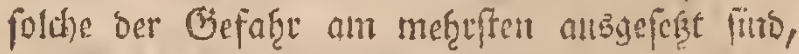
weldse vor ben gefdjloffenen Drten an ber Gous nenfeite, ober aut) in biejer ?age auf bet in jenen

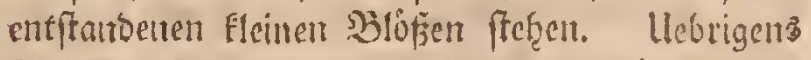
fdjeint ex fogar unter ben frefertoen ß3aumen oft ebea 
eben fo gern bie gefunben z̆l wåh̨len, als Frantle cle Gtanme, wie bie im \$. 29. angefihterten Sbes: mertungen begeugen.

g) Dap alfo ber Ráfer voer vielmebr bie therf̨ands genonnene angcheure Menge beffelben, als' bie

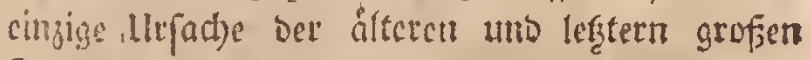
Iroctuiffe anjulferen jey.

h) So ivie cs in Einem Saf̧re oft mef̧r ober wenis ger Juffeten bon biefer ober jener 2let, ja oft

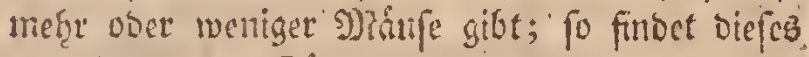

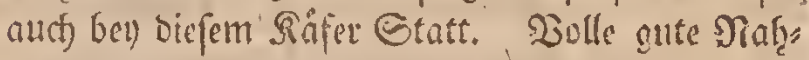

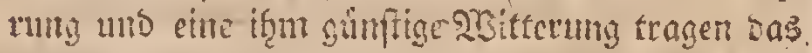
Meifte ju feinet Dermetcung ber, fo wie ber S)angel ber erfern, ntto cin if̨m nad)treiliges mindigns, naffes ober Faltes Stsctter sicfen bofen (Siaft am beften vevtilgt utto auf feine gevób̨uliobe

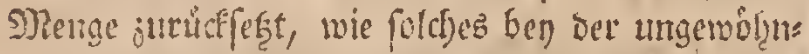
liclen Sormebrung anberer Sulefter, unt ferbft bey beir felomåuen, weld)e bey einem falten Morbruinbe oft in wanigen Tagen aju verjd win Den fidecinen, ebenfalls sefolieg̨t.

\section{34 .}

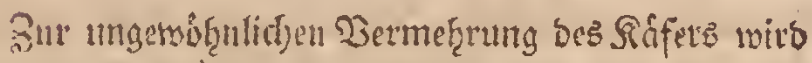

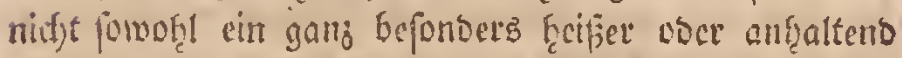
troctner Eommer erfordort; cs ift viclmefer jur Bes

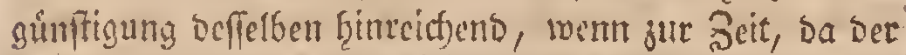
Safer ansfiegt oder fdwwámt, unt went er bie ßerán

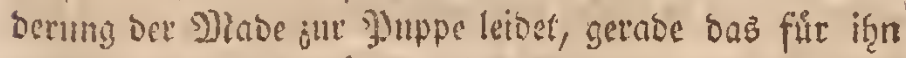
pafferioe ssetter cinfallt. So fahe man in sem legets veryungenen Scerbfte, des f chonen Tsetters megen, foft

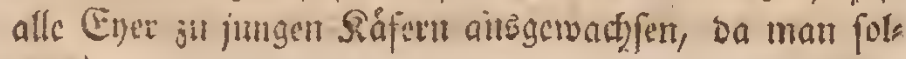


d)es th ansarn Sab̨ren nut bon elmen geturgèn Sheile" benerft hat. Es mus baher das futoone Wetter in bies fem frithlinge unfere Beforgniş vermesten, weil es ger rabe in sie Seit gefallen ift, two bar Rafer jaymátnte.

\section{S. 35.}

Die \{age ber J̈jebirge Faum efenfarts futre vicles

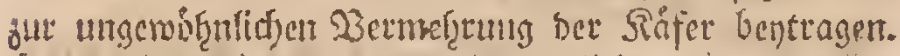

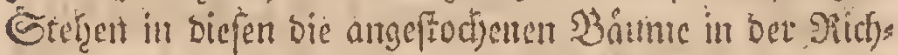
tunt, ba bie braus flegenden Siffer mit ben wárs

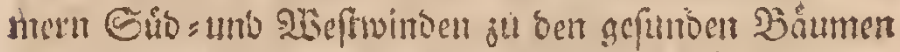
unto fteşenten Dertern getrieben werben; fo viti ba:

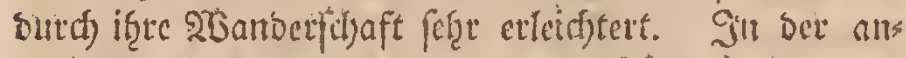

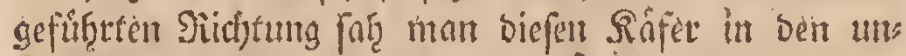

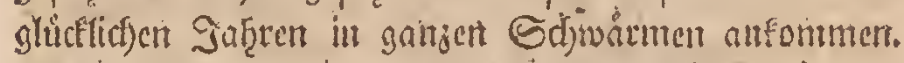

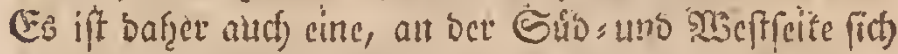
zeigente Stucknif gefäfrlid)er, als an ben entgegenges fegten Eeiten ber Bjebirge. Dieper llmifan, wortiber unten hoch Stefirctes gefagt werben wito, mus bec forf̧rmam bcjonbers metfett.

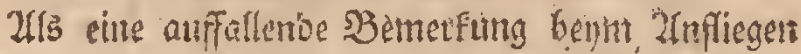
Der Rafer verbient nud) folgenbes angefiff̨rt ju werben.

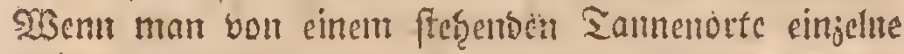

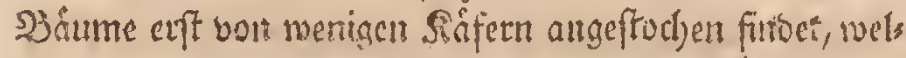
d)es man aus ben unt wenigen frifthen Sifferlodyern foflesen. Eann; fo wirt man oft nad) wenigen Stumben

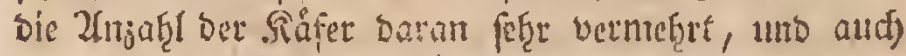
siefe in irgem fluge nuf biejelbe Tanne fallen fergen, ins Deffer bie neben biefen ffeţenten S3åme ganj baven bes frenct bleiben, ungeachtet man jwija) an biejen unt jenen,

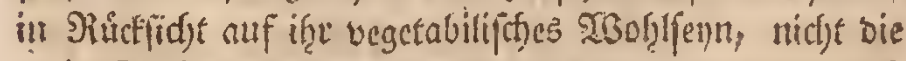
geringfte Derjebiedentieit entbecken fann. Gelbft burd) 
bas Ulmhaten foldyer SBăme habe id) Die Utrache nițt ausmittch foumen, warum biepe vor jenen bon bem Siffer beifojont geblieben waren.

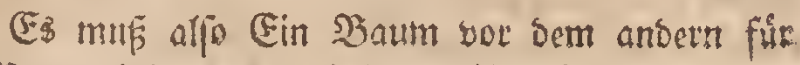
ben 2rurm einige unb unbefannte Sorzughe, und bis"

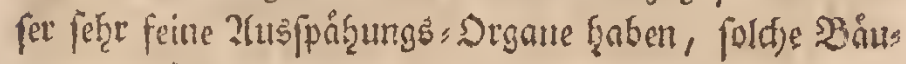
me ausjufinoen.

Diefe Bemerfung bient aud) Sem forftmann jut Beruhisung, bafi, wenn er aud énige bom sourme

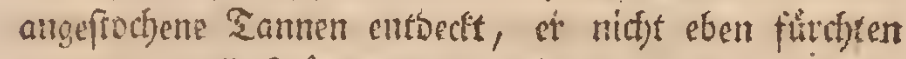
Sarf, baf alte Száume in ber Biegent fiton won bem

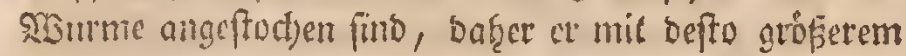
Fleipe bie angefrocjenen cinjcluen Taunen auffucten, umb Den barin mofinenten Siafer bernitgten fanm.

\section{S. 36 .}

Die slittel, welche nach obigen Brturnen tho 23enterfungen gegen bie TSurmtrocknis in ben grojen

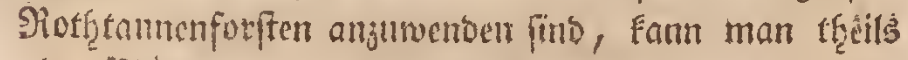
als Dititel ber firlorge, theilis dis Dets tungsmittel anfergen. Die erftern finto bie juver

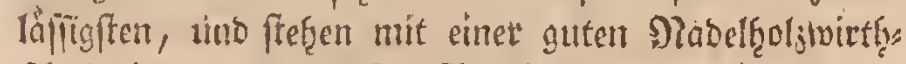
fhapt in ber genaueften Sorbinumg. Die lešteren

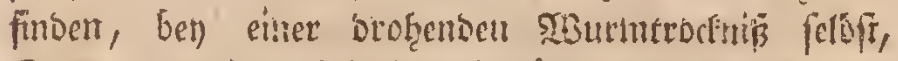

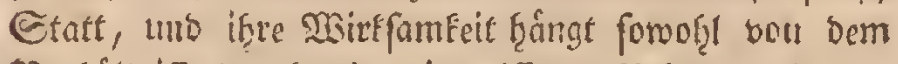
Serf̧âttniffe bes bereits eingeriffentr llebels, als von bem Eifer uno vot ber Şråtigfeit ab, mit ber fie an' getwentet inerben. 


\section{§. 37.}

Duri) die Mittel ber Shirforge miffer bem sisurme alle (jelegenfreiten benommen werbent, fitt) gut

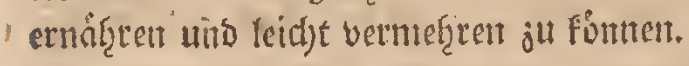

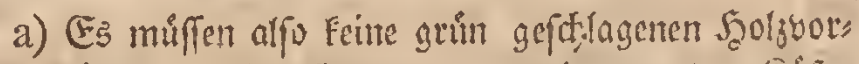
râtfe in foldsen Segenoen, worit man ben Sififer in Menge benterft, fo lange Bcit liegen Gleiben,

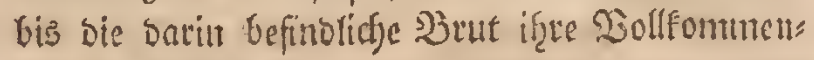
Feit etreicht f̧at.

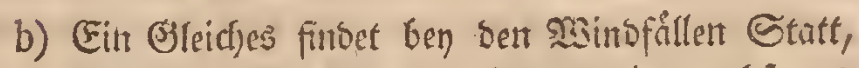
auf bie ber forftmann immer cin wadjfames

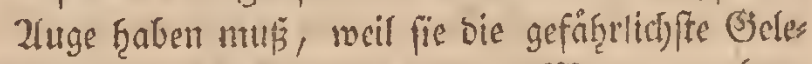
genflect zur ßicrnteḩrung bes ఇourms geben. siegen unut foldis ooer auth bie oben benterften soljuorratte in cince fortent lage, bas bic war"

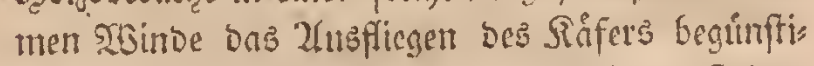

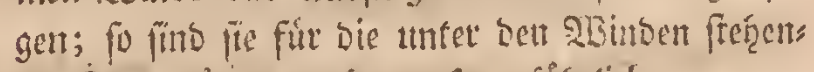
ben Sannenorter nod) um fo gefób̨rlid)er.

c) Es múfen alfo pidje vom sisume angeftodyes

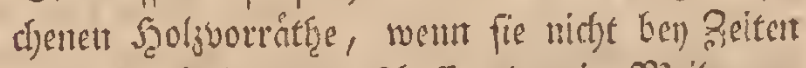
aus betm Scolje ivesacflyafft ober in Meifer ge:

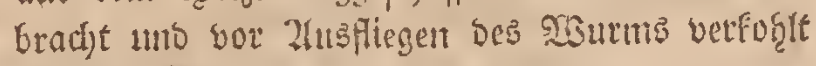
werben foutuen, abgeborft werben.

d) 2uch múfen bie fontfichen, int Sratue liegents oen Sluscholjsorritţe, weun fic nicht ben Beiten abgefoficent werben fonnen, wenigftens it fo weit anfgearbeitut werben, baf bie Riferbrut barit jerfifort wirs.

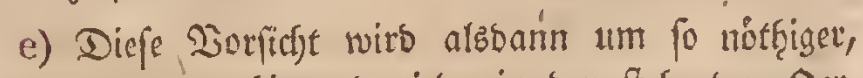
wenn mant fin utto wieber in ben frefeenden Dev: 
tern, einige gelfgemorbene Tamnen maf̨rnimmt, wie man foldfes befonders in bergigten froiften bon einem 2tbf̧ange bes Berges jum andern leidjt bemerfen fann. Soldje gelbgeworbene. Båume betratten fdjon ben Sífer it einem uttgewobn lichen Llebermanje, unb miffen freisig allfges fucdt, niebergefiauen unb abgeborft rerben. In biefem falle fontuen Flcine Gtrafen für ßers

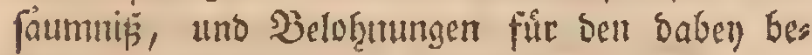
jeigten Dienfteifer yon guter griufung fern.

f) Da fid nun ber Såfer vorjuglid, an ber Con nenfeite ber Bjebirge jeigt, uno ba aud ben Forftbebienten in einem Sicviere foldje Derter fofon befaunt zu fern pfegen, too bergleichen eins jelne Sisurmtannen vorfallen; fo múfen folche Gegenben mit vorguglidiem fleipe nadjgefeben werben.

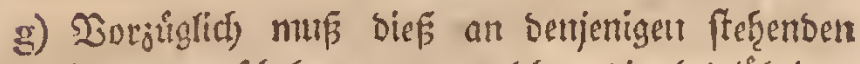

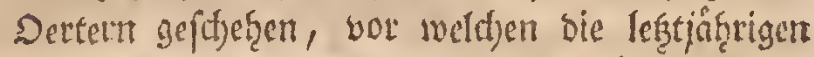
Seaunngen ooce fonffigen Sabljuorráthe gelegen Gaben, weil es baben nicht inmter fo setran abs jugetzen pflegt, bafi nidft eit Sḩeil ber bafelbft ausgefommenen Botut auf sie umftergenben grus nen Tautren fallen follte.

1) ZIแn nteiften muß man bie zu leid)t autgegę̧aues nen, obar bie burch ätere Trocfnif ober burch

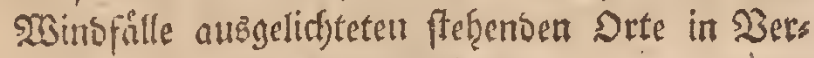
bacht habett unb oft nad) ferien.

i) Hebrigens iff als cin fef̧r angemeffenes jtoedmâf figcs smittel fús fold)e Drte ju empfę̧len, roorin 


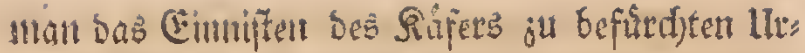
facte bat, wemr neble ben etwa umgehouenen angeftoct)enen 3iumen cinige grutite Sånme mit 1umgeţauen weroen, 1min ben in ber Gegento

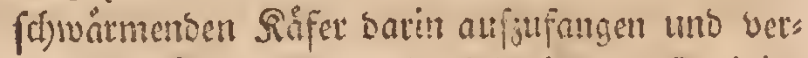
tilgen ju fonnen, in welcter 2 toficht man fie cinige Beit unabgebortet liegen laffen mus. 2tuf biefe Tht fonn man eimen foult mistigen Sufall, als

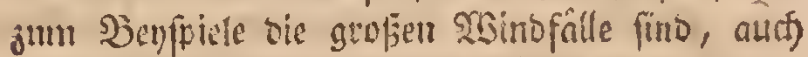
zun guten SMittel gegen Den Siffer Genufen.

\section{38.}

Son beh Siettungsmitteln find, went

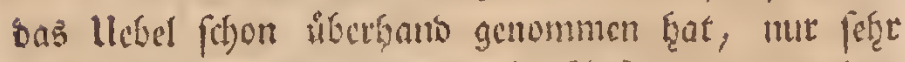
senige anwentoba:, Daferer fie im Infange ber brohens ben Biefafer mit befto groferem Eifer anjuraticen fint. Sie beftehent allein batin, daf man bie frühe Stocinis

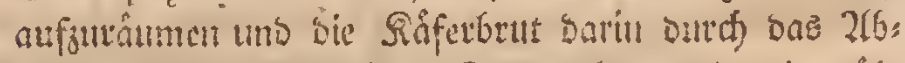
borfen jul vertilgen futft. Da es aber, wie mir mings

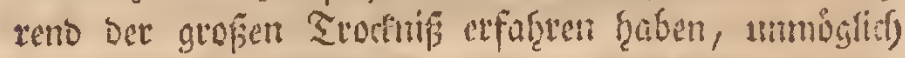
meroen faum, bem llebal entgegen ju arbeiten, fo mü man alsoant mu biepes Mlittel anf fold)e Biegenoen

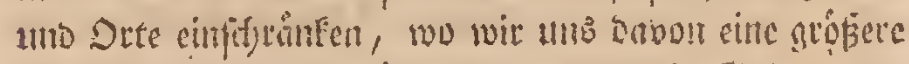

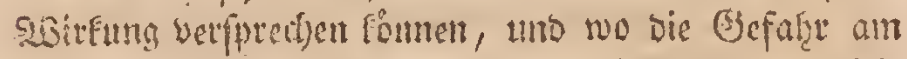

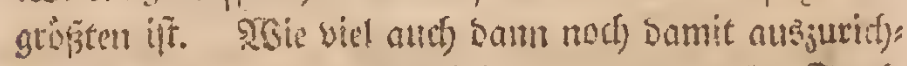
ten iff, bagu bienen uns einige aus ber grofien Truefs

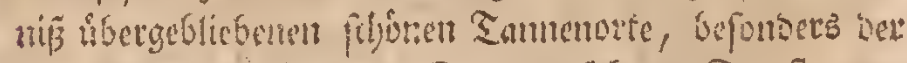
am Brefert in ber Seepalthen Forft jum

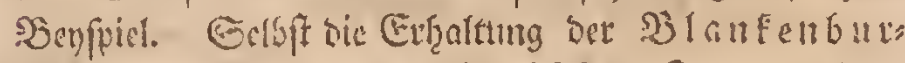

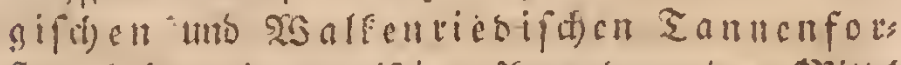

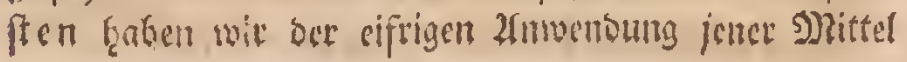


ju bcrbanfen, mit weldjen man aud am Şarje felbjt

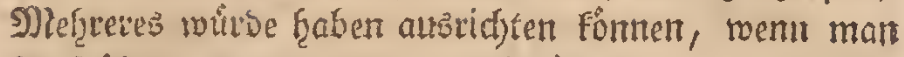

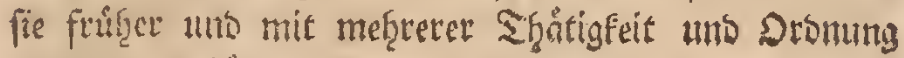
angeventibet Geitte.

\section{§. 39.}

5jei) Dem Zl6boufen bet anteftoclyenent Tammen

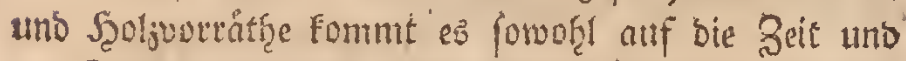
Den Suftanto bet barin befublichen Saferbut, als auf

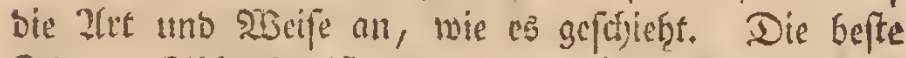
Seit atm ?b6orfen ift, wen bie Sifferbrut barit als vollyetwadjfue Lurbell, Doer als Juppen liegen; weil fie alsoann an fitferften gefobtet werben, utno weil

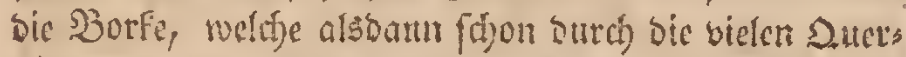
gange ber SBrut serfecfen iff, fick leidit von Solge abs

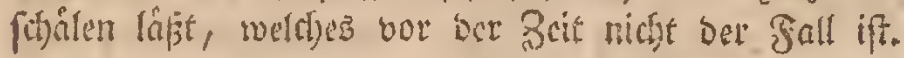

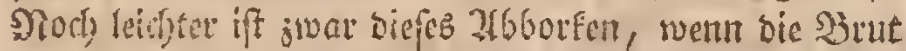
batin zu jungen Riffern ausigewat)jen iff. Es pflegt

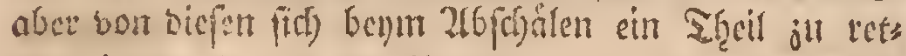
tell, inoem fir aus ber Jerfe fallen, und firs in bie auf Dem Sosen liegensen shaseln vetfriethen, bofors - .

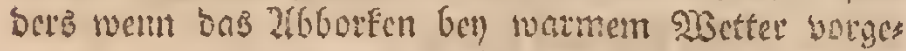
nomment wirb. Bè ber Sifte im Sisinter frat ç $\mathrm{Das}$ bey Eeine Befarst, weil bie Sifer alsonah, wie erfart?

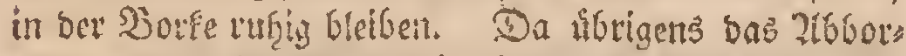
fen bas Dertichten ber Siffubrut jum Enojwecte fiat;

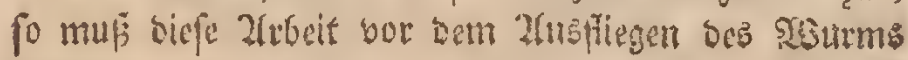
beenbigt fintt.

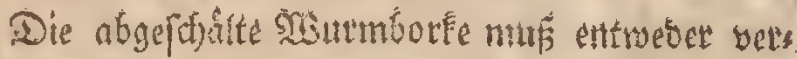
brannt, ober: tief cingegreban werbut. Erffetcs ift

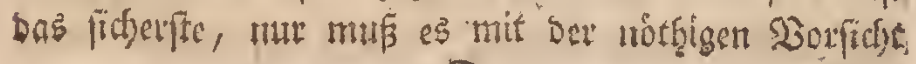


gef chefen, insem fonịt baraus, wic wif leiber traurige

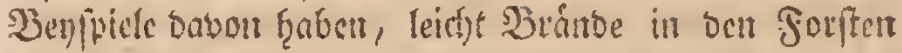

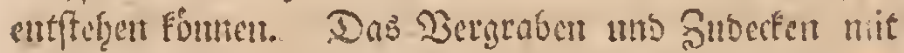

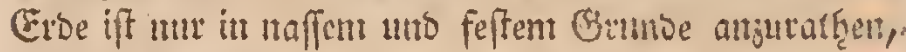
inbem bie Rafer a!n ben Sorfenbaufen, weld)e mit

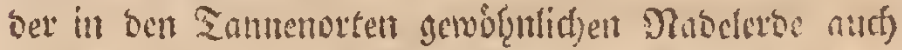
auf Einen ful bृod) bcoedt fimb, ausfricchen founcm, wie id) mef̨rnals bemertet f̨abe.

\section{40.}

Diefes arborten verridjen sie genónglichen

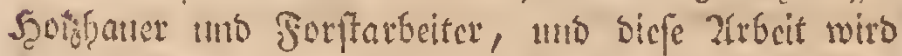
if̧nch cutweber frammeije, ober, wenn das Syolg foron gef̧anen ift, mattrucife verbungen, woben fids

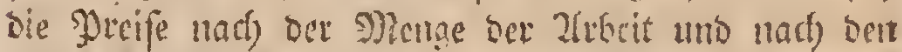

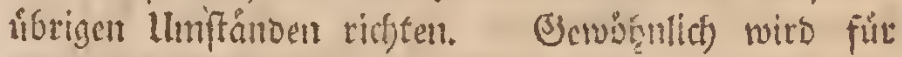
jeocn Stamin I Ggr., and wol I6 ff., unb für ein Malter bon 80 \%ur boppelt fo bicl gigebut. Do bic

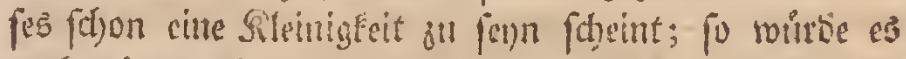
bod), went bie in sen Gobren 1783 unb 1784 geftant: bene Trochnis batte geburft watsen múfen, übet

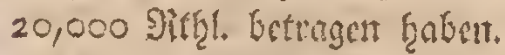

\section{§. 41 .}

Da Horigcus fierben and oft bie frage vors

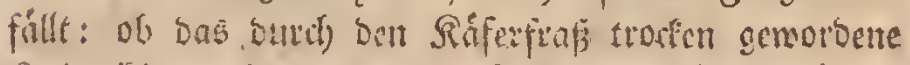

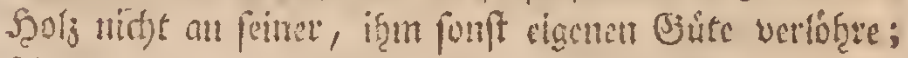

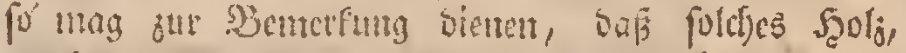
wetches Gald nach bem Stodfentuerben gefillt ift, mol nicht biel baran serficren mod)te. Zlite ₹rucfnis aber,

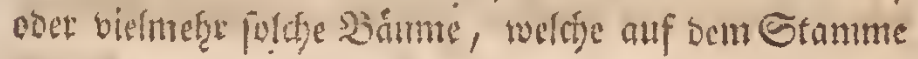




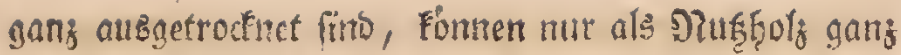

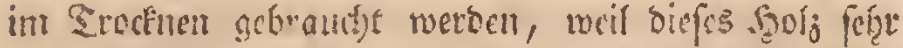

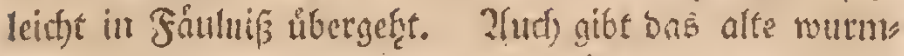

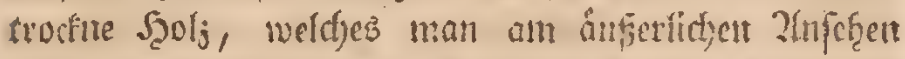

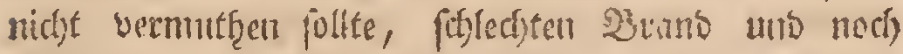

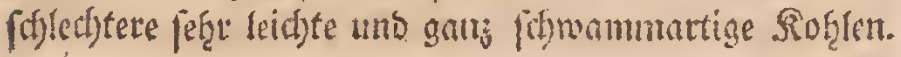

\section{42 .}

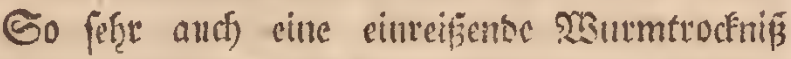

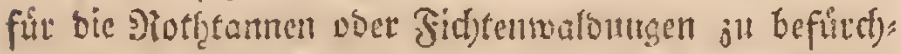
ten ift; fo nuf fie uns benn bod) feincsiveges abfat: ten, bicfe vortrefflidye Soclant mit allem móghithent Eifer anjubanen. (ád)ertid) wirbe se vichtuefer fom,

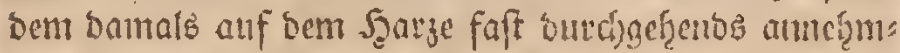

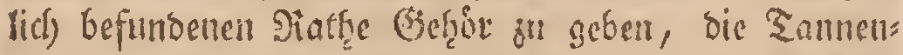

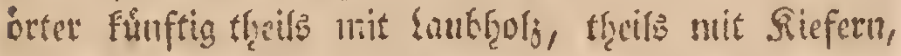

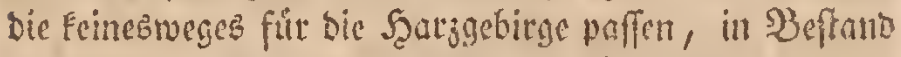

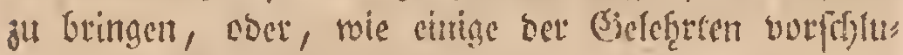

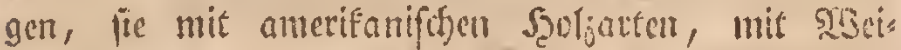

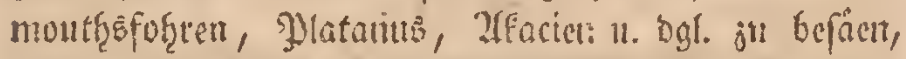
wovon man fogar einige verunglidete 2ierfuclye finder.

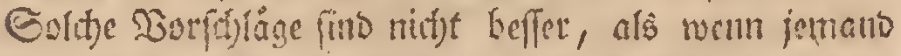

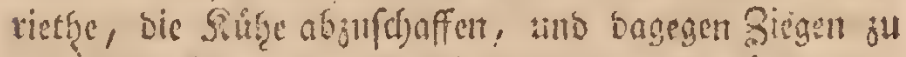
Ezalten, weil jene an ber SBichferche fretben formen.

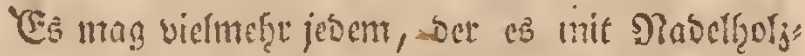

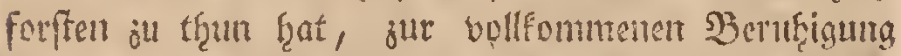

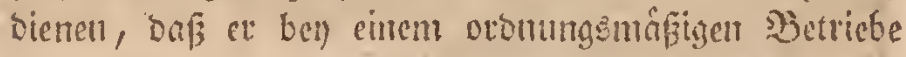

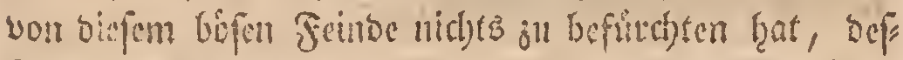
fen ßerwiftungen nur immer, als sine Folge ublet

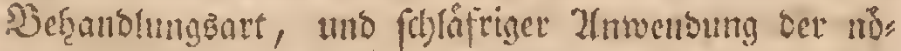

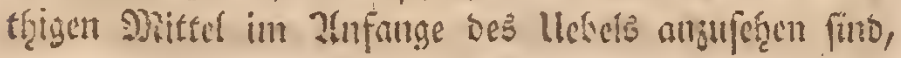


inbem alsbann bie Eadje mit bet fo gewiffnlidien lles berjougung, baf es nidjts ju fagen hrabe,

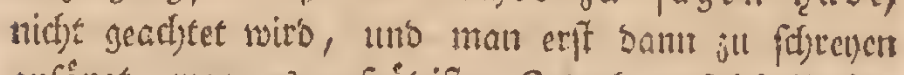

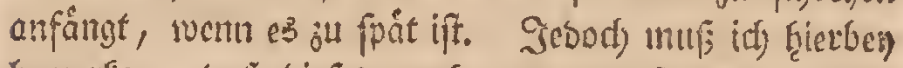
bcintetfen, baj bicfes and nur von foldyen forftent uns Sannenorten ju verffehen fen, in welefen ein ge:

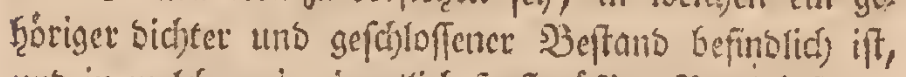
uns in welchen cin cigentlid forfmáfiger 2 etrieb Giats

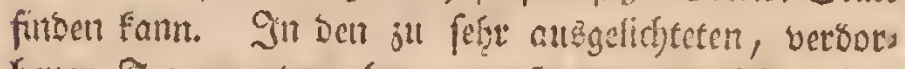

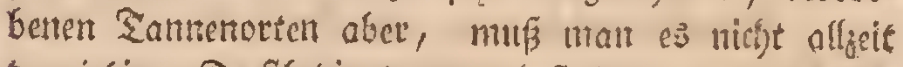
Den jeşigen Forffbébienten jut !aft Tegen, wetn barin

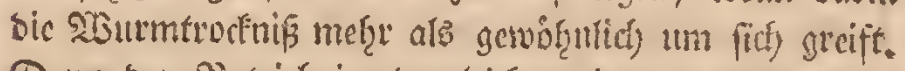

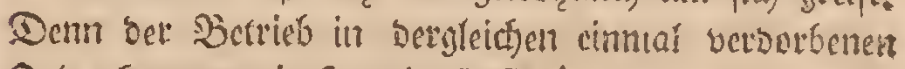
Drten fann mur in fo weit forftmápig gefüfert werben,

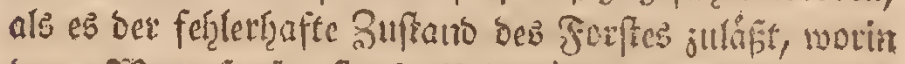

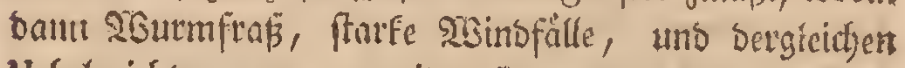
lleber nicht ganj ju vermeiten fins, unts cins alls bem anderit ju cutfefęen pifegt.

\section{§. 43.}

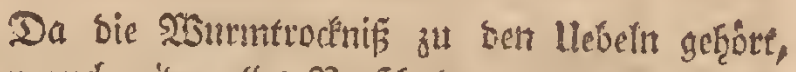
bie man aud wiber alies Derffouloen aus bent aligrents àenben Scoljungen cthalten Eamt; fo follen billig fiers

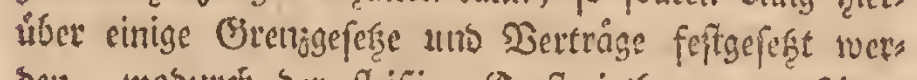
ber, wobuteí) ber fleifige forftritth, gegen feinen nadflaffigen, ober gegen Den für bie oben bemerfte cuts

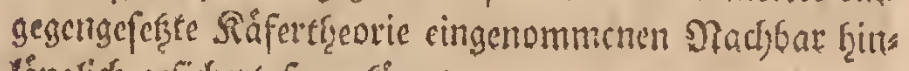
langlid) gefidfert fentr founte.

Thenigftens ift biefer Punft fur bic Şefifer grof:

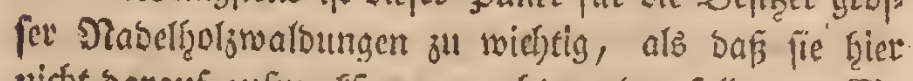
nidht barnuf anfmerffam gemadgt werben follten. Ein 


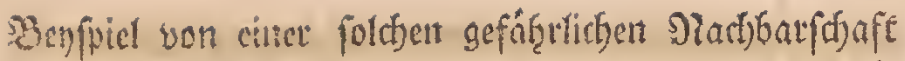

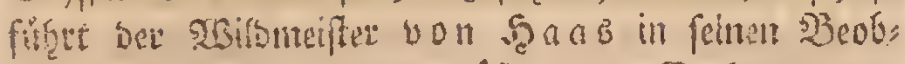
atfungen fiber ben Botfenfafer an. Er hratte nem:

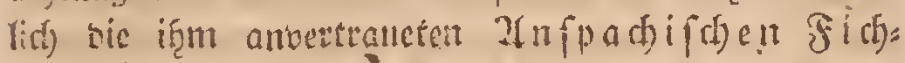

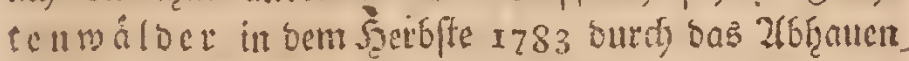
sel: angefrodjentr Etonme gereinigt. SBeil aber in

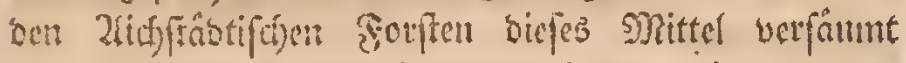
wal; fo wurben in bisfen barnuf gonge Drte wurms

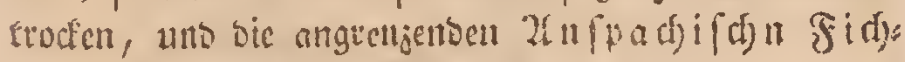
ecu folgungen wou neuem angeftodfer.

\section{44 .}

Zliz Dbigem cthecllet, baj bie bey einet großjen

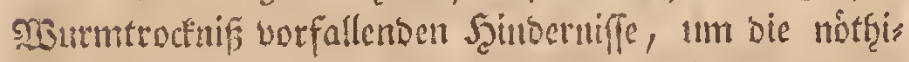

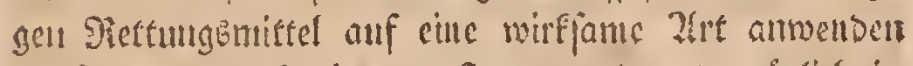
ou fintuen, welche in ben faarjgegenton vorjuglich) in

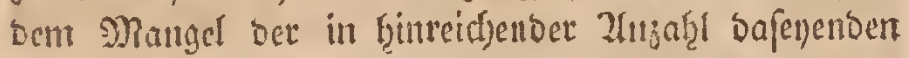
Sceljhaner beftencen, cigentlitif nur in fo weit, alo ente

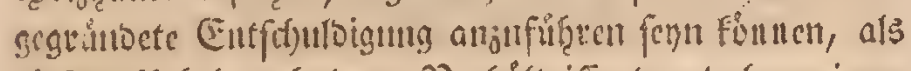

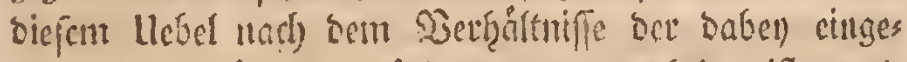
tretenca limifainoe, geţorig entgegengearbeitet ift, uns on es fid it ben metheten forllen bey cince richtigen Uluterfutjung ergeben modjte, ba man bas llebel im 2rnfange, als ç nod) unbebcutentio ju fent fesien, vet: faumt bet; fo fint anth barnads bie jwar nachlece ridys tigen Entfdulbignngen ju beurtheilen. So fonnen

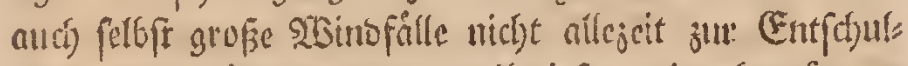
bigung angefïhtet weroen, weil bicje, wie oben $\$ .37$. bemerft ift, oft fogar als segenmittel fefte gut ju bes

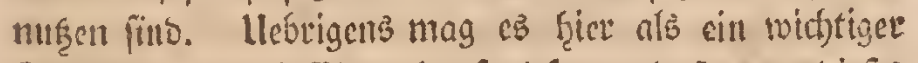
Forftefirraf nod) Eimmal gefagt fenn, baj man biefes

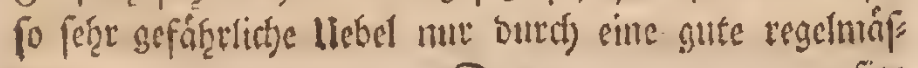




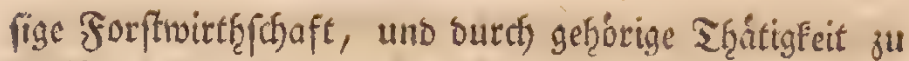
verhintuern im Gtande fen, unb baf man bahcer auch

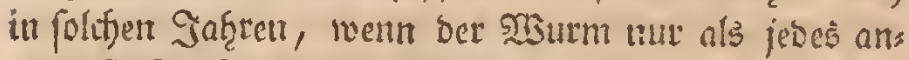
bere Smfoft in geringer s) Jenge da iff, Gernt Forffoes

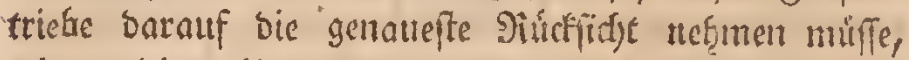
woic es leiber bis jeţt am Şarje nod) tiidjt allgemeit gefiefenen ift!

\section{§. 45 .}

2fufer bem eben befuricbenet Boftrichus Typographus gibt $\mathfrak{e}$ nod) einige anbere alten Sootfen: faffer, weld)e zwar ben weitem nidje fo gefáfictlidy, als jener, finto, bie aber body itmmer beswegen nod cinige

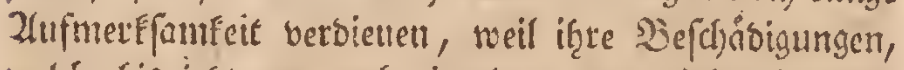
melcje bis jef̧t nut not) cinzelne, ober einige berfarm,

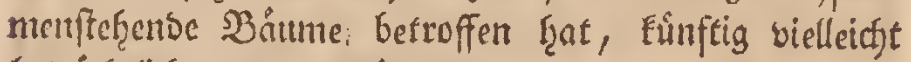
betrádjtlicher werben fónntert.

Shierfeer gef̧uout ein weit fleinerer Sáfer, ober vidmeţr einige 2Irten beffelben, bie man auf Dem Şarje unter bem Namen ber If fif áfer fent, weil fie ges woblentich nut bie obern Spif̧en uno bie 2lefte bes ges fáltetu Scorjes anjugreifan pflegen.

\section{46.}

Einer biefer fleinen Zffte̊fer, ben man noch am b̧áufigften antrifft, ift Der Boftrichus chalcographus. Er unterfdeioet fich vom Typographus in ber Brofie, meil er faum ein Drittel fo grop ift, als jenter, uns

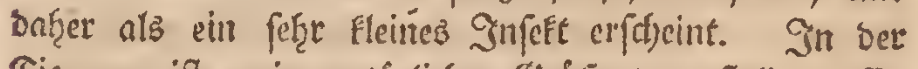

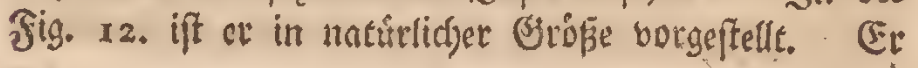


Frat an ben hintern Steilen ber Flúgdbecten nicht ben

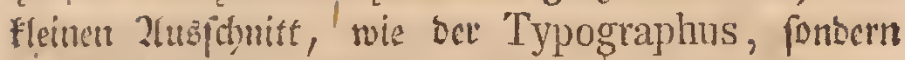
fie fitio ganj abgerumbet. Lebrigctis ift fain Sibrpens baul mit bicfern fetre gleid), nur feine Farbe, weldhe am Sopfe uno SBruffticke fetre butfler ift, als auf ton Flügelbecten, f̧at cinen gröjern Blanj.

Ecine Lcbençatt ums fein Fortpflanjungsuwefen hat aud) mit ber bes Typographus sielce nemcin,

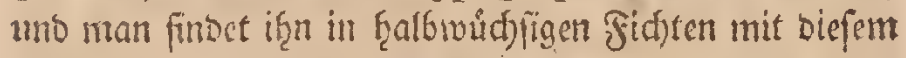

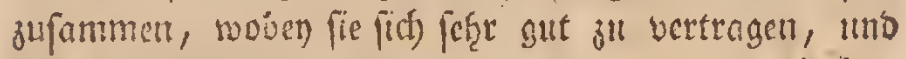

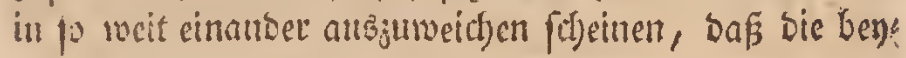
berjeitige 23 nut baburd) nicft letoet.

\section{S. $47^{\circ}$}

Diefar B. chalcographus, utro nact) if̧m feinte Brut als tarve uns Siafer freffen fich ebenfalls ifgre Gảnge in ben faftodlen Rimbenlagen ber grinen Tan nenborfe, nur fint biefe Bange viel feimer, unto ber Scauptsang ber alten Siafer nid) in geraber śnie, wie

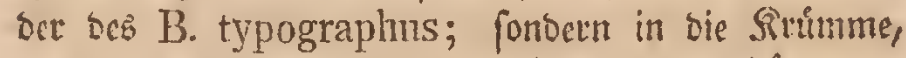

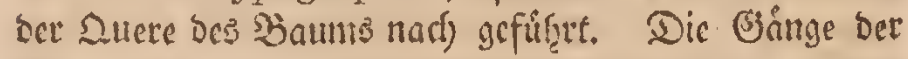

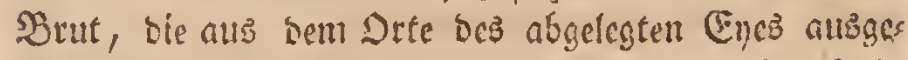

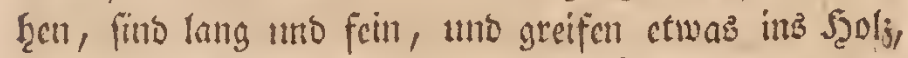

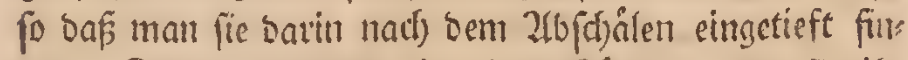
bet. Sumveilen freffen bie alten Säfer, wemn fie igh Fortpflangungsgeftioft bectibigt haben, oft allf I bis 2 Boll tief ine fefte sols, wo man fie bann geivofintich toot antrifft. 


\section{§. 48.}

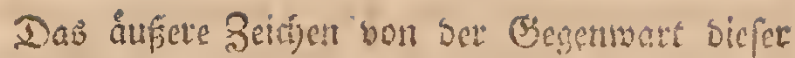

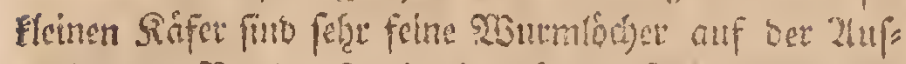

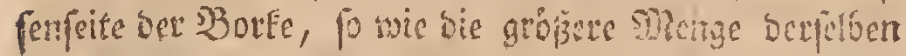

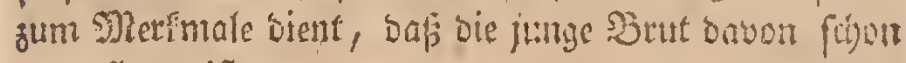
ausigefogen ift.

Dicfer Chalcographus aber for eint nod meit fructsbarer als ber Typographus ju fenn, oa idf bes fortoers in Scerbfte yon 1793 bon enemt eingigen jaare Safer tiber 80 bis go tarvett uno junge Siffer gejum sen rabc.

Die rite Figur ftellt cin yon biefem . Safer an

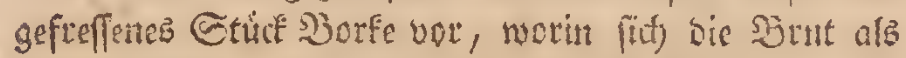
Sarve befinbet, weldyez id) genou nach ber Natur abs gejeiçnet f̧abe.

\section{S. 49.}

Diefer utb bie übrigat fleuten 2ffféfer fallen,

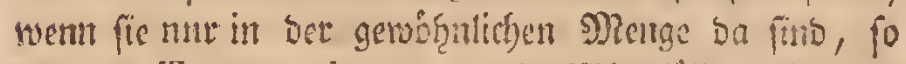
wie Der Typographus mur sic æroindofille, Ecinces britdie uno gefôlten frifoten Tannen an. TSent fie (ith) aber, wie es cbenfalls in ben bojen Sifferjaf̨ren

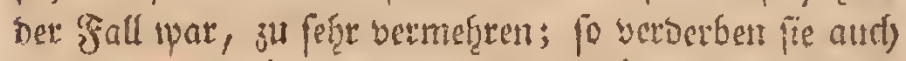

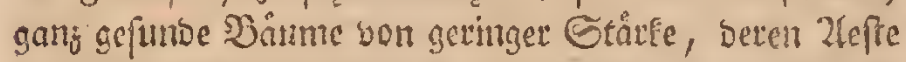
uno obern Gtammpifen fie angreifent. Sit ben Saf̧̌

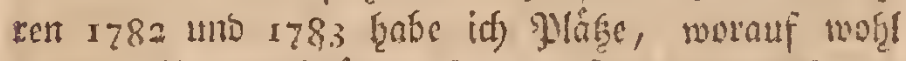

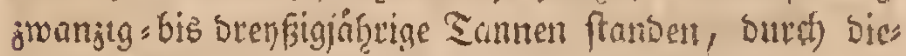

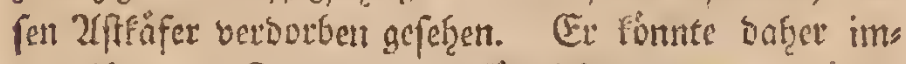

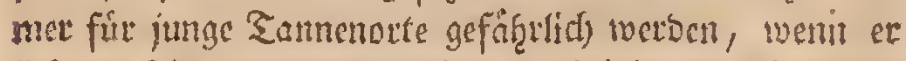

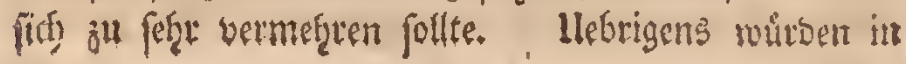


bem falle aud) bie Mtittel gegen biefn Sáfer grwectmaj: fig anjumention fenn, wie man bis joft mur gegen'sen B. Typographus wortufercen pflegt.

\section{\$. 50.}

Metrrere Irten von siefen Fleinen Sorfenfaferm fino unter ben Ramen vou 13. micrographus, polygraphus 4. F. w. bofantt, unt in sent Entomologits

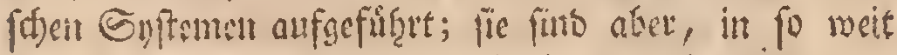
(id) ber Sorftutam Dartum jul befuntmern beaucist, vou

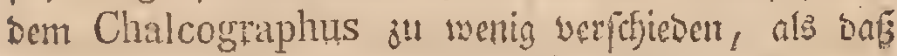
ses nothig fenn follte, fie fier meitläufger ju befdreibent.

\section{5. $5 \mathrm{~T}$.}

Ein anoeret Borfenfafer, ber (idi) wegen feute

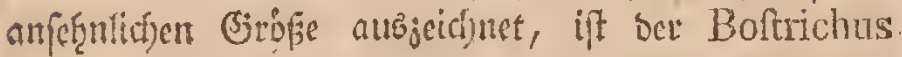

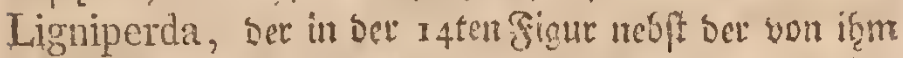

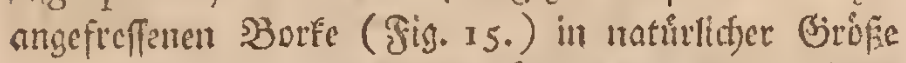

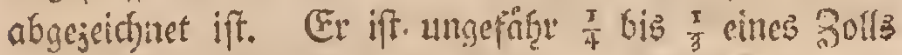

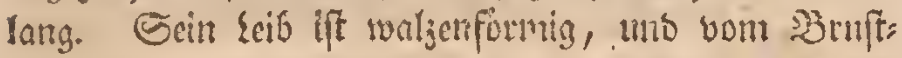
frucle, bas fict) nach) worll jll itwas verengt, mit einet watttiefen Simne abgefcęt. Das Buffftid uno ber Unterleib finto mit Furjen, feinen, borftentartigen saares

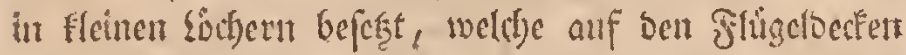

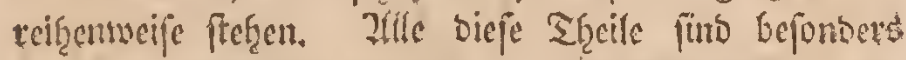

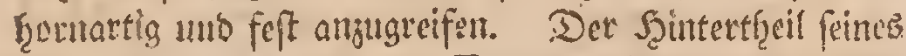

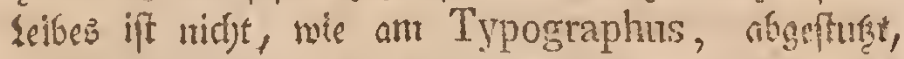
fonoern jusefpifet,

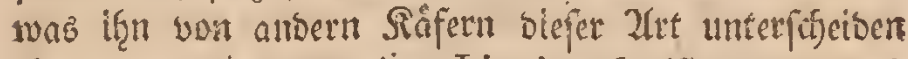
fonnte. Die Farbe eines Ligniperda ift ganz bunfers fotwarjbraun, eines jungen unaubgerwadjenten abef lichtoraun. 


\section{S. 52 .}

Ticjer Ligniperda lcbt cbenfalla, wic ber $B$. typographus, unter ber 33otée our fidjen, worin cr

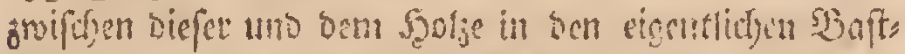

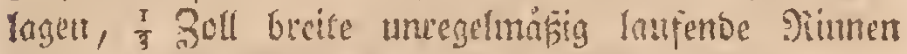
fript, in bie er nicht, mie sev Typographus, bie Ence cingeln, fortocu zufommen auf Eure Etelle abs legt, unto mit sisurmuchę verfebt, worauf tom bie aus biefen Enetn ansfrichentoen Larben mo jumgen

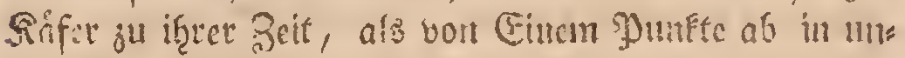
regermáßig lanfenocn (S)itgen fíl) sociter freffon uno auspliegen.

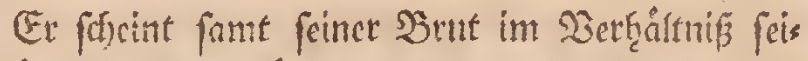
nce Gribe uidgt fo gefráfig ju fonn, wie bie obai bes foricbetren \$oftridyen, uno man fubct aud an ten

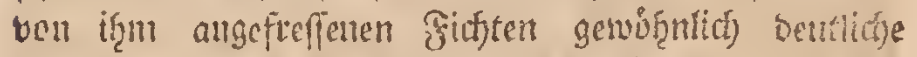
Epuren, baf barin fojon meţece Ginerationen bies fes Siffers gutet Gaben.

Diefer Râfer if bis jest nux felten jul futben, uno fein Einfue auf bic Sbefdobigungen in ben Sidy tenforffen ber Eicfigen Giegento galls, unbebentento ges wefen.

\section{53.}

Die Rentnit; Det ibrigen Sinfeften, welde in unfern Tantenwalbungen loben, ift fü ben Forftrmann

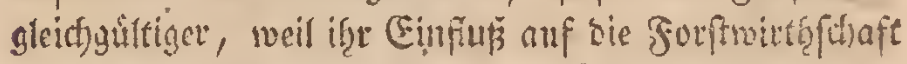
von geringer Erbeblidgfeit iff. Dect) verbienent fies now folgentide sabon bemerft zu werben.

- In Fräflidien, uno yoriơ obet äwey Jofgren verpfiantern fleinen Tanten finoet 
fich ẹin fleiner 23orfenfifer, etwas groferer als ber B. chalcographus. Dicjer: Siafer, weldjer in ber Brißje, in ber mefercten ober minbern fófwåglicf)en Farbe, smb

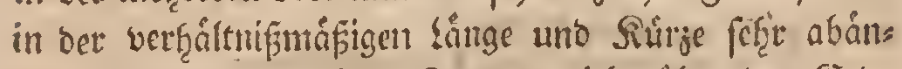

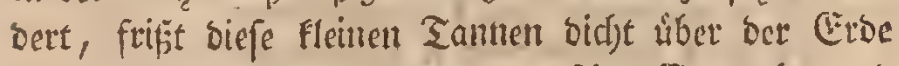
auf einten Boll breit an, legt ba feine Ener ab, 1 mis

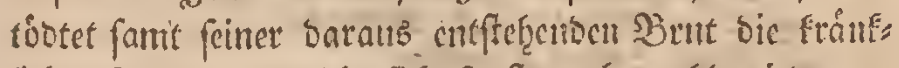
(id)en Sannen, weldje fid fonft nod) wobl wieber ers

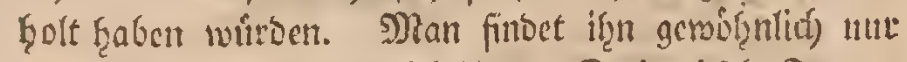
ferge cingeln, bod) habe ich in ber Gtiegifd)= Sta

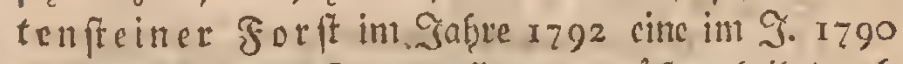

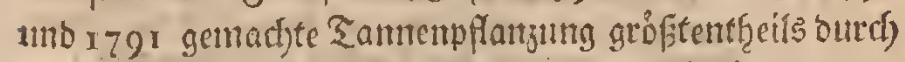
bicfen Safer verborben gefefin, wovon bie übrigen gut geblicbenen Tantren einen gans guten 20 ad)istfrum wet: frrarben. 2(ud) fetbft von bersen, weld)e von biefem Siafer angeftowen unt vertrocfinct waren, fanto maur Dentlicye Epuren, daf fie of̧utc bicfen Sulfall gut gcblies

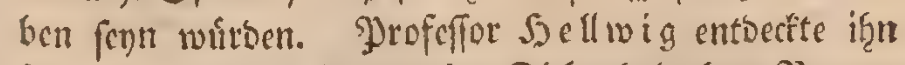

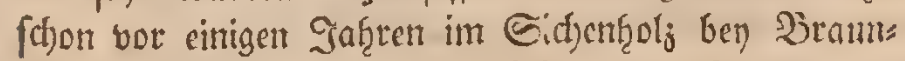
(d)weig, unto nannte if̧n Boftrichus angultatus. 


\section{3ruăfeblex}

Cuite ro. 3. 24. Innent, ft. ifm

19. 3. 28. himbubringen, ft. bingugubringen

25. 3. 8. Converfationen, fit. Eonfervationen

3. 9. von nitien, fert, ft. ferst

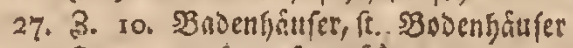

30. 3. 22. musten, ft. máEten

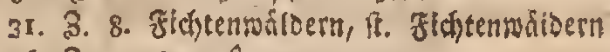

46. 3. 22. vor, ff. ton

49. 3. 25 . licht, it. leicht

50. 3. I6. frifote, fit frilie

(irifche Trocinis, bebeutet fo viel, alb neuc oder

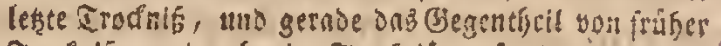

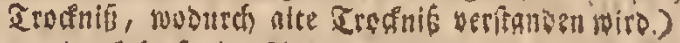

57. ลิ. 5. QumEel, ft. QunEler. 
23en) Dem Merleger if aud) eridtinen:

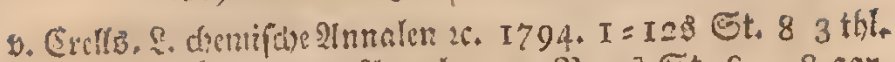

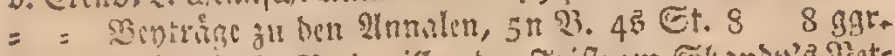

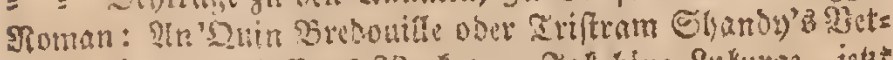

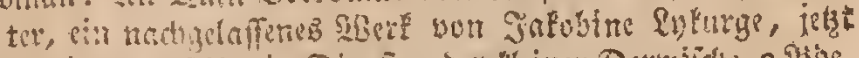

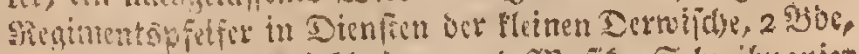

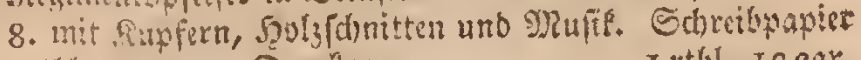
I thi. 20 şตr. Sututray. I ththl. I 239 \% de Roff, P. Fauna etrufca fiftens inferta. quae in prouinciis Florentina et Pilinia prafertim collegit, edit. IT. cur. I. C. Hellwig, T. I. fafe. I. S mai. cum I I fig. coior.

2 th). 10998.

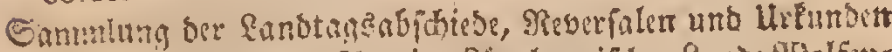

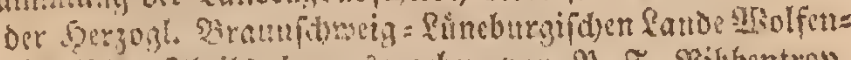

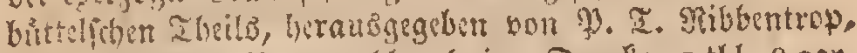

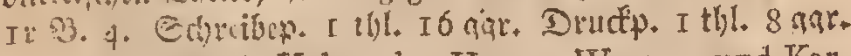
v. Veltheim, A. F. Ueber der Herren Werner und Karfren Refurmen in der Mineralogie, nebft Anmerkungen über die ältere und netere Benennung einiger Steinarten. gr. 8

$6 \mathrm{ggr}$.

- - - Etwas über Memnons Bildfänle, Nero's Smaragd, Toreutik, unc die Kunft der Alten in Stein und Glas zu fchneiden, als Zufätze der vorftehenden Ablandlung, gr. 8

4 ggr. 



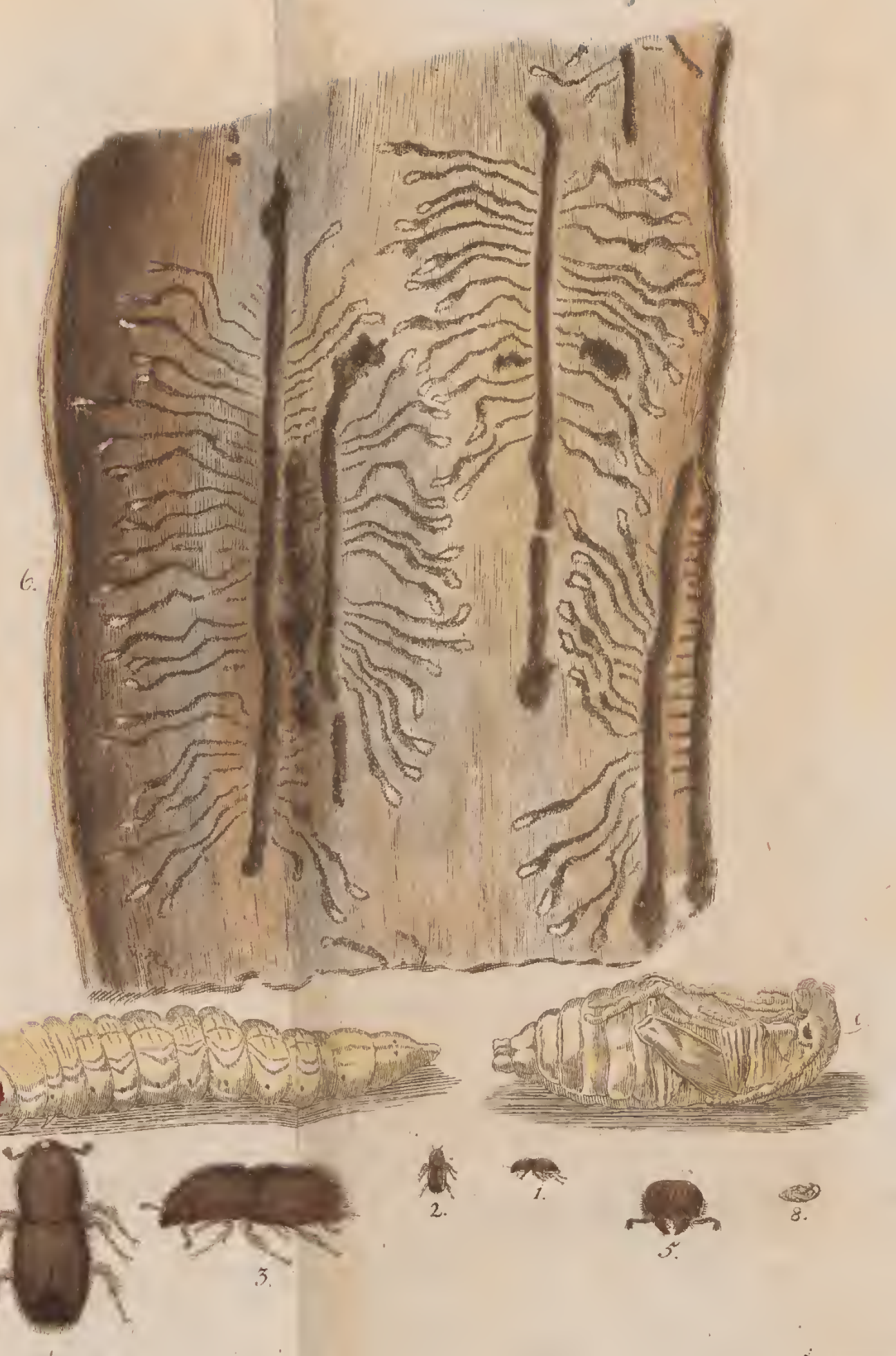




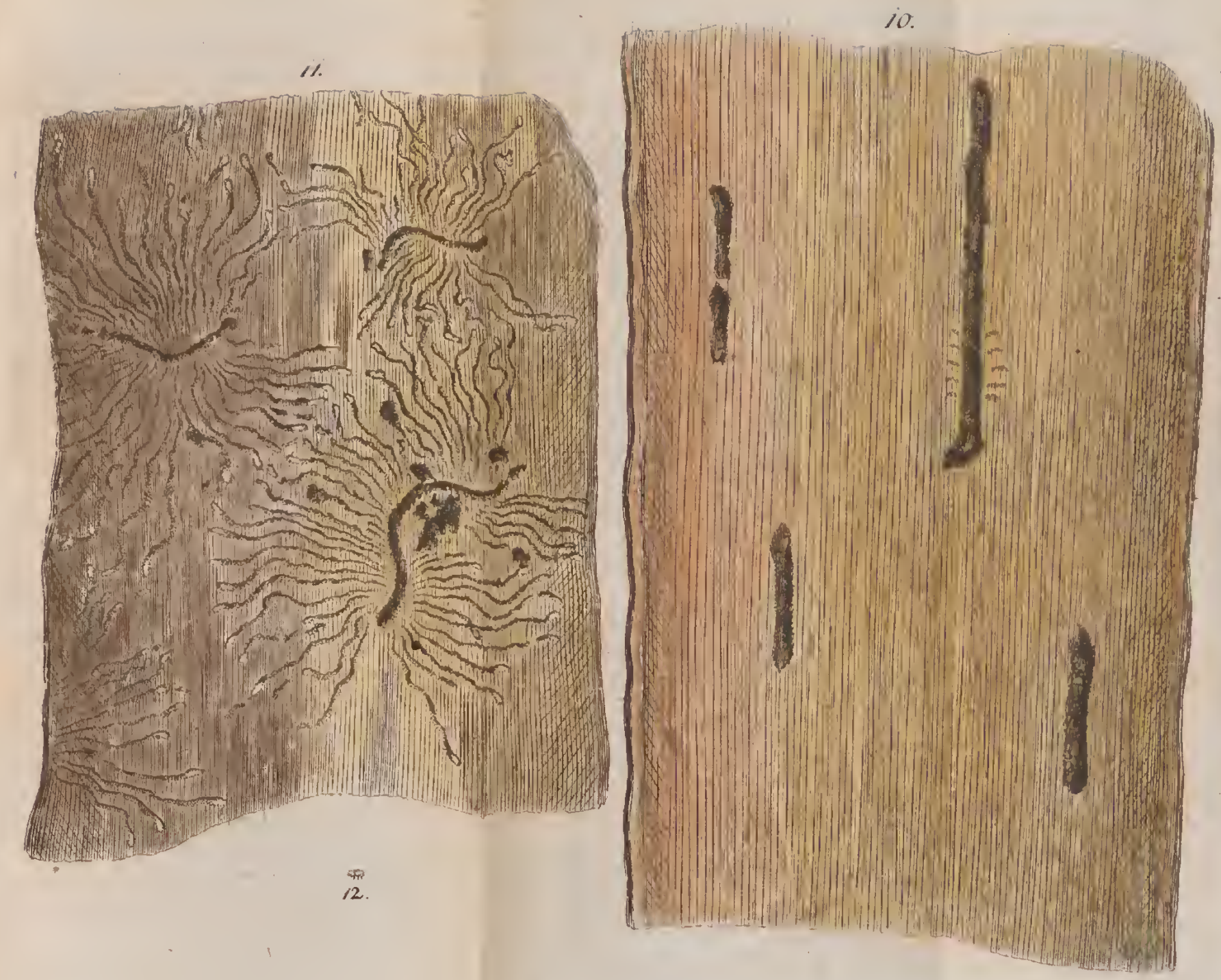


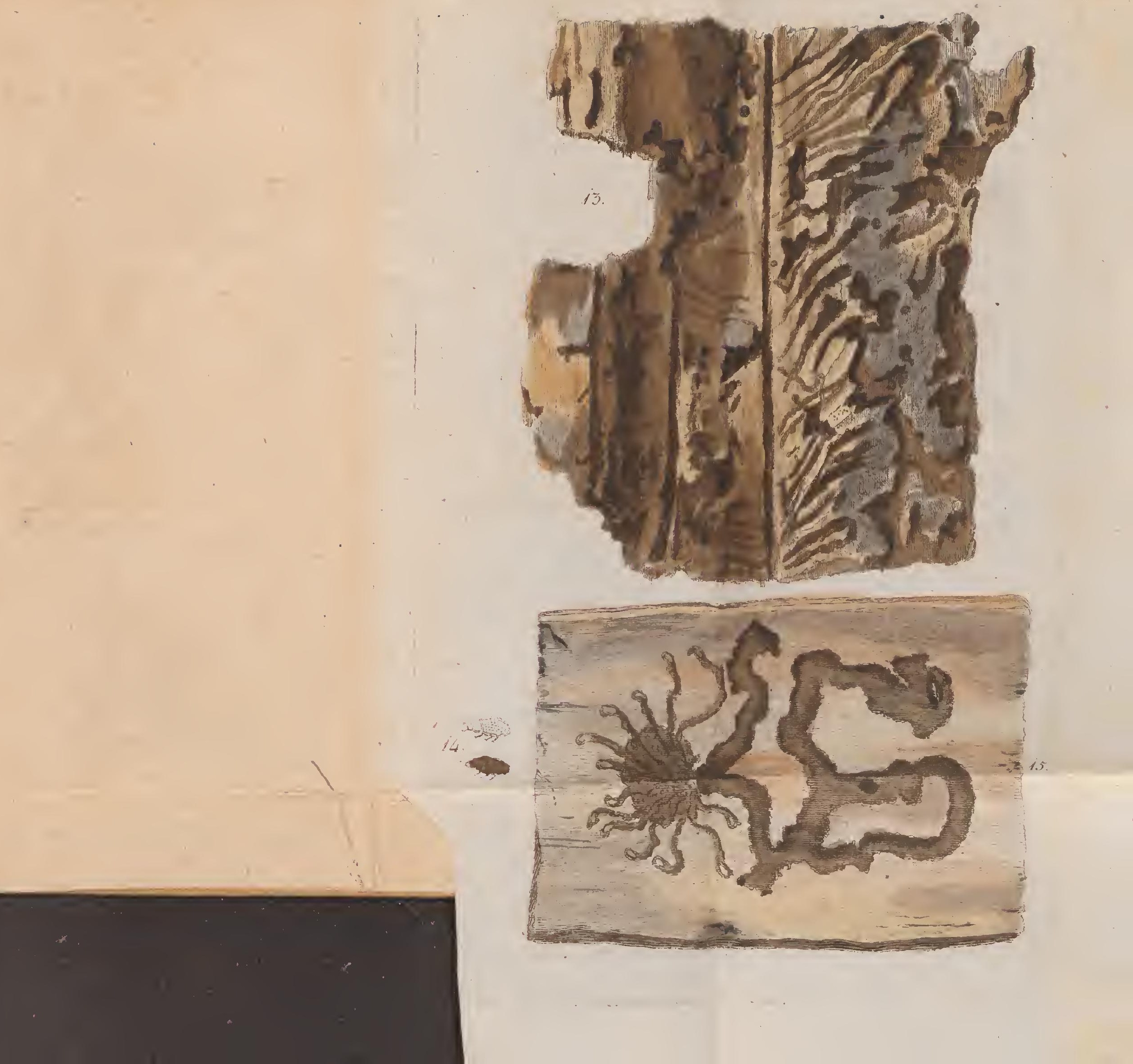







6023 
